\title{
A MULTIPLE CASE STUDY OF FEMALE STUDENTS' ACADEMIC SELF-EFFICACY WHILE PARTICIPATING IN A MIDDLE SCHOOL ROBOTICS PROGRAM
}

\author{
A Dissertation \\ presented to \\ the Faculty of the Graduate School \\ At the University of Missouri-Columbia
}

In Partial Fulfillment

of the Requirements of the Degree

Doctor of Education

by

CAREY DAVIS

Dr. Barbara N. Martin, Dissertation Supervisor

DECEMBER 2020 
(C) Copyright by Carey Davis 2020

All Rights Reserved 
The undersigned, appointed by the dean of the Graduate School, have examined the

dissertation entitled

\section{A MULTIPLE CASE STUDY OF FEMALE STUDENTS' ACADEMIC SELF-EFFICACY WHILE PARTICIPATING IN A MIDDLE SCHOOL ROBOTICS PROGRAM}

Presented by Carey Davis a candidate for the degree of doctor of education

moreover, hereby certify that, in their opinion, is worthy of acceptance.

Dr. Barbara N. Martin

Dr. Sandy Hutchinson

Dr. Jason Morton

Dr. Hayet Woods 


\section{ACKNOWLEDGEMENTS}

This dissertation was made possible by the generous sacrifice of time on behalf of my loving family, who has always encouraged me, believed in me, and pushed me to fly to further heights. To my husband Noah and my children Parker and Marlo, you have all provided such strong support and love and I hope to one-day return the favor as you chase your dreams. To my mother, Carole, and sisters Jacey, Brenna, and Lauren, thank you for raising me, and showing me what strong women can accomplish through sheer determination and willpower. I also want to thank every other family member or friend who encouraged me with kindness, love, and support.

I would also like to thank Dr. Martin and my amazing cohort at the University of Central Missouri-Lee's Summit. You have all inspired me and believed in my abilities from the beginning, and I cannot express how much that means to me.

Finally, thank you to all the robotics coaches and volunteers out there making these programs possible for our children. It is truly "the hardest fun you'll ever have!" 


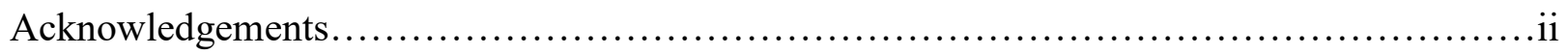

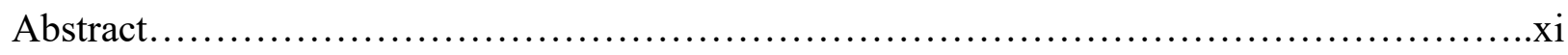

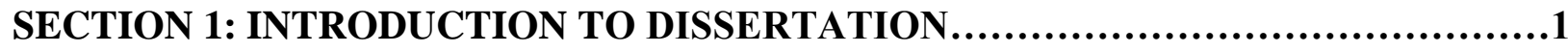

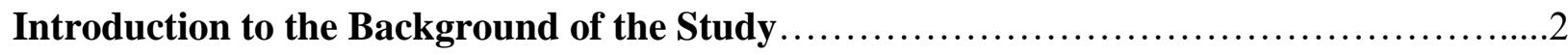

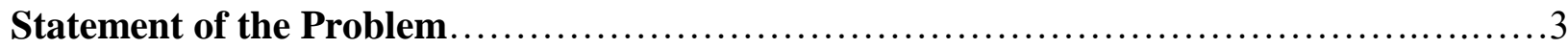

Problem of Practice.........................................................

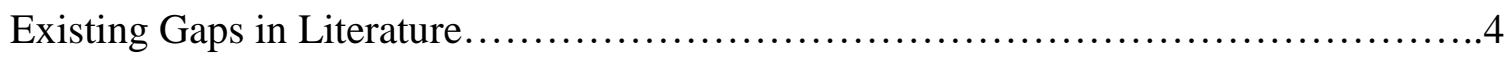

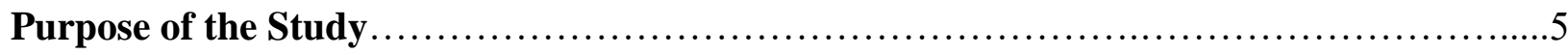

Research Questions..........................................................6

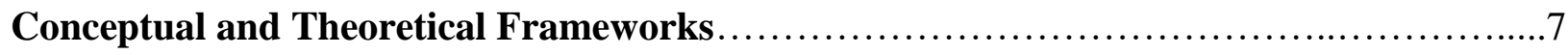

Discarded Theories.......................................................

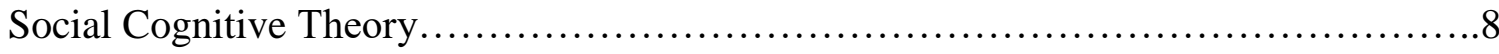

Self-Efficacy Theory of Education.........................................

Gender Schema Theory..................................................11

Robotics Programs and Females in STEM....................................12

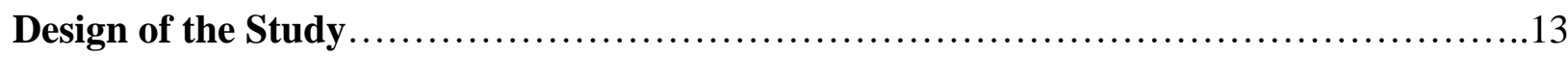

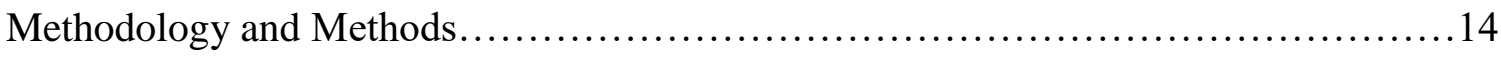

Study Setting.......................................................... 16

Participants..............................................................

Data Collection Tools.................................................... 17

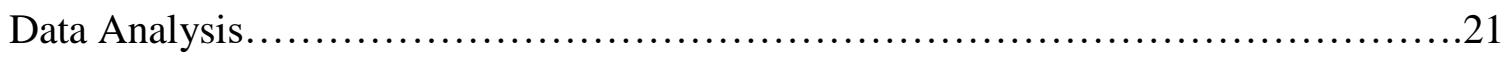

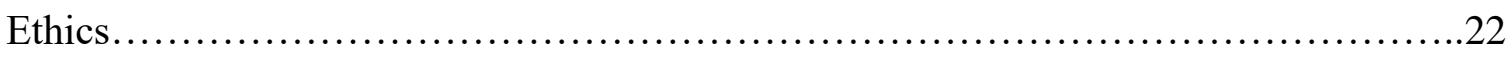

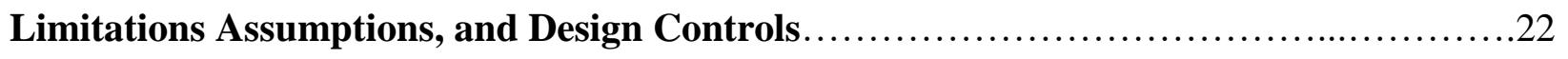




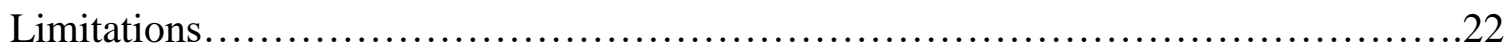

Assumptions............................................................23

Design Controls............................................................ 24

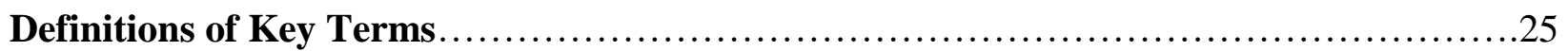

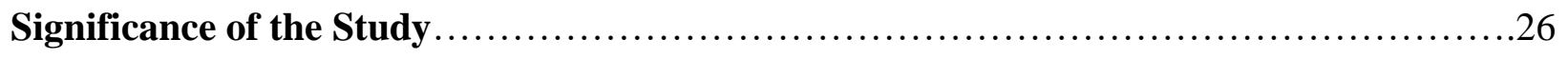

Scholarship..........................................................27

Practice..............................................................27

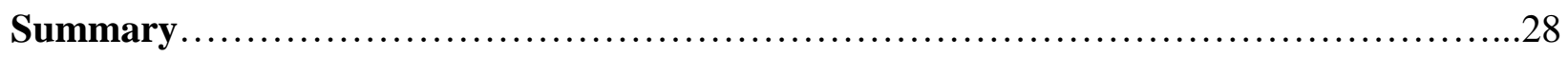

SECTION 2: PRACTITIONER SETTING FOR THE STUDY...........................29

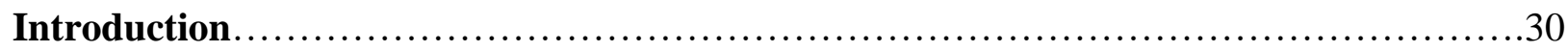

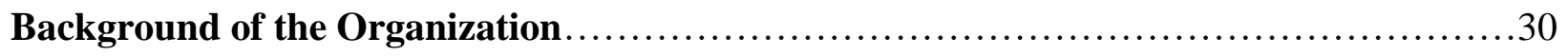

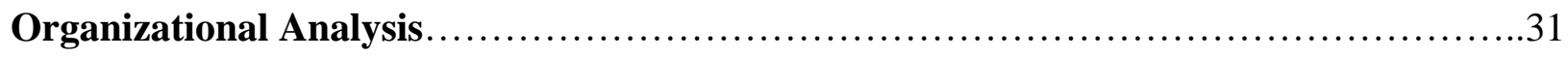

Structural Frame........................................................... 31

Human Resource Frame................................................... 32

Political Frame.............................................................. 34

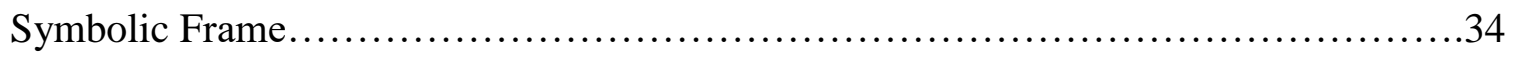

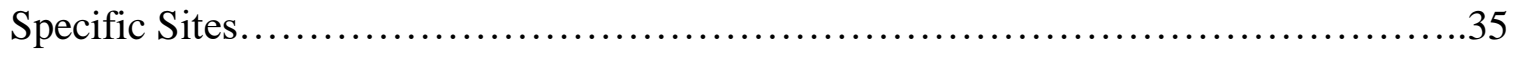

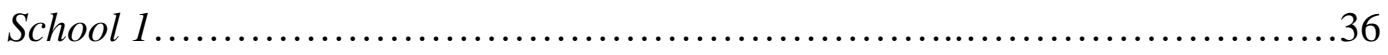

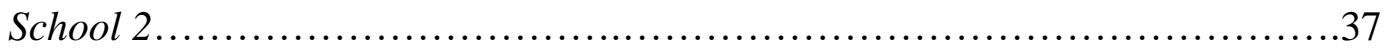

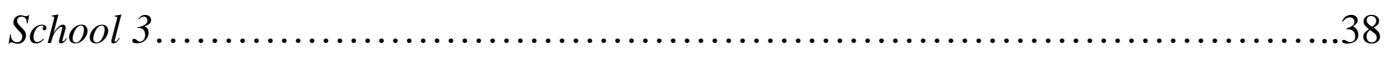

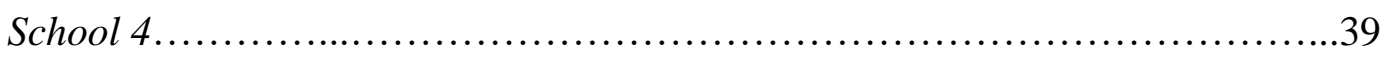

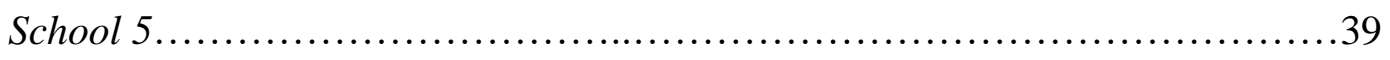

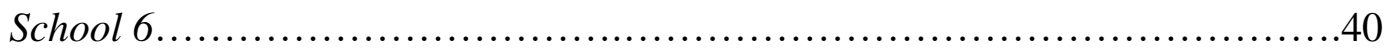

Leadership Analysis........................................................ 41 


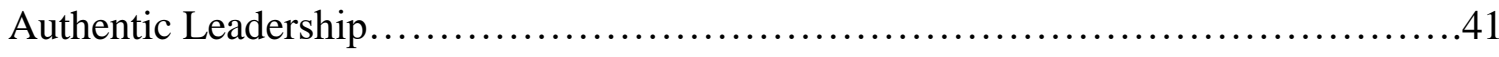

Adaptive Leadership ..........................................................44

Implications for Research in the Practitioner Setting .....................................46

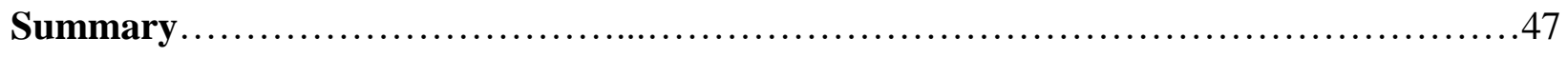

SECTION 3: SCHOLARLY REVIEW FOR THE STUDY ..............................49

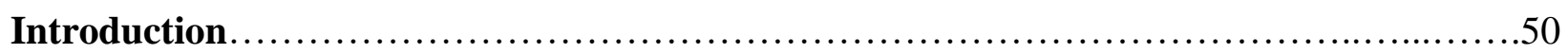

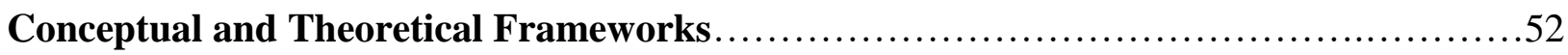

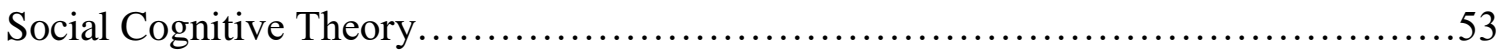

Self-Efficacy Theory of Education................................................56

Gender Schema Theory .............................................................

Robotics Programs and Females in STEM.......................................67

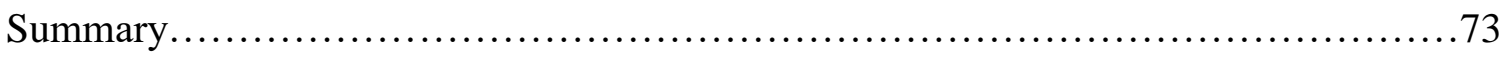

SECTION 4: CONTRIBUTION TO PRACTICE.....................................75

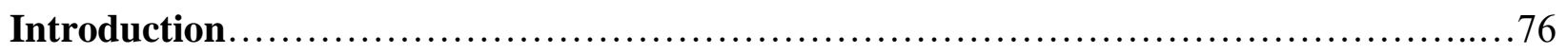

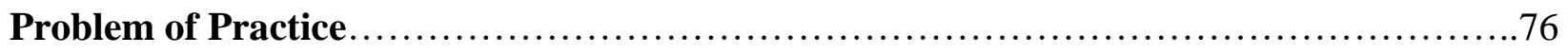

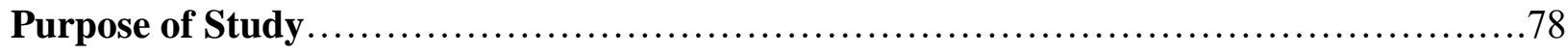

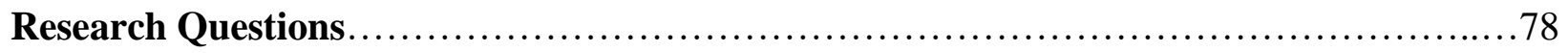

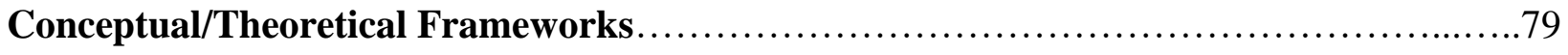

Social Cognitive Theory ......................................................... 79

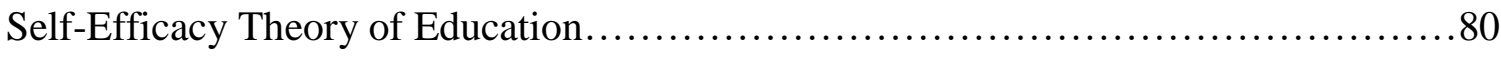

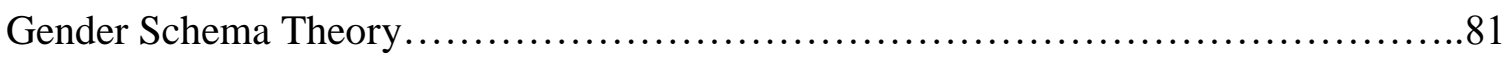

Robotics Programs and Females in STEM......................................8 82

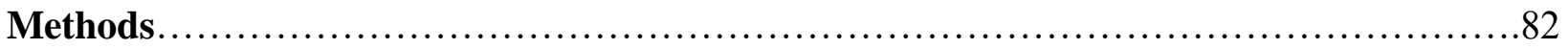




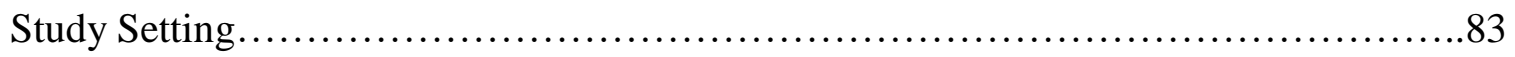

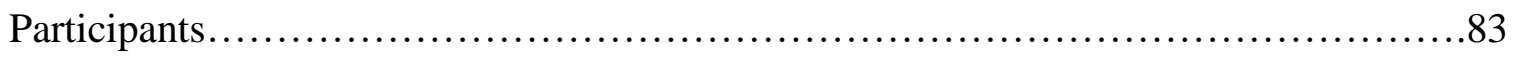

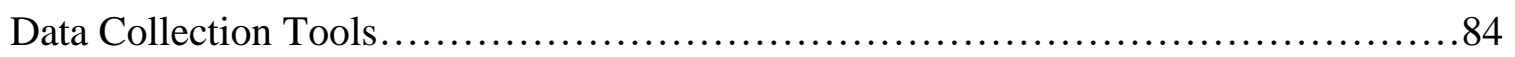

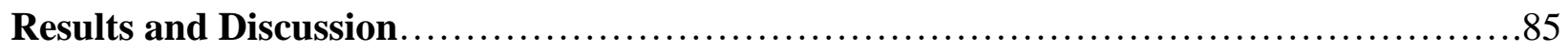

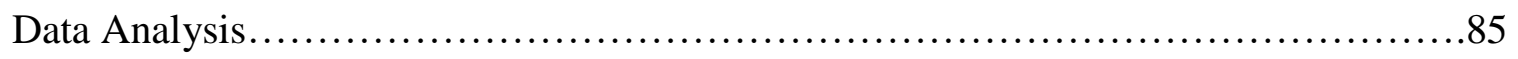

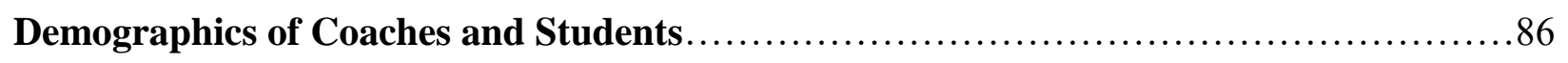

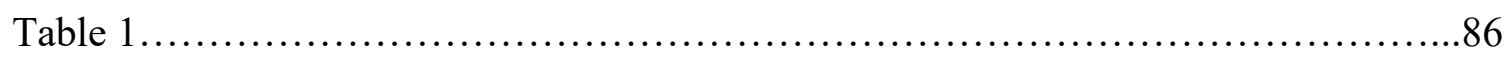

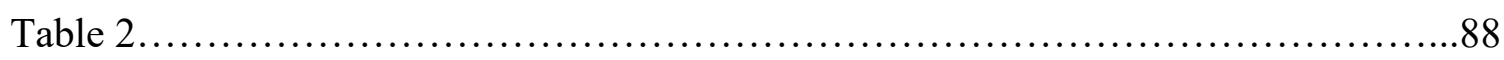

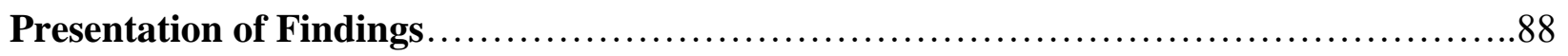

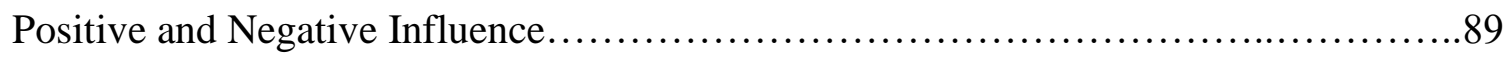

Coaching: Strategies and Recruitment....................................99

Impact: Skills, Long Term, Careers, and Post-Secondary.......................91

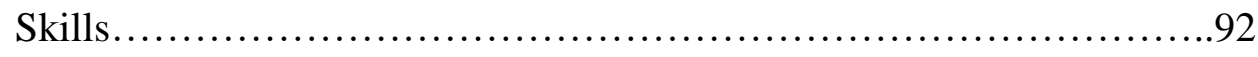

Long Term............................................................93

Careers............................................................94

Post-Secondary......................................................95

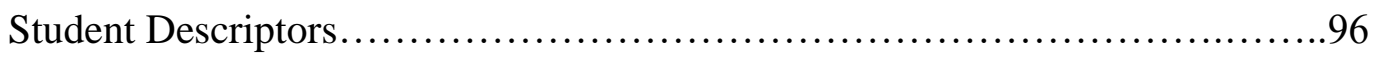

General............................................................. 96

Male .............................................................. 97

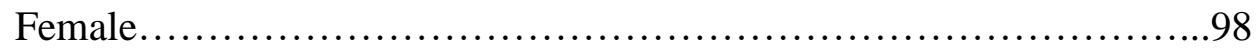

Male-Female Percentage............................................99

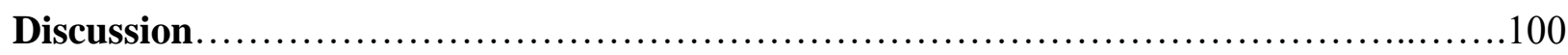

Social Cognitive Theory....................................................... 100

Self-Efficacy Theory of Education.............................................102

Gender Schema Theory ...................................................... 104 
Robotics Programs and Females in STEM..................................106

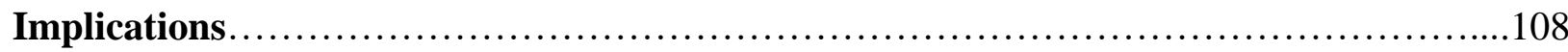

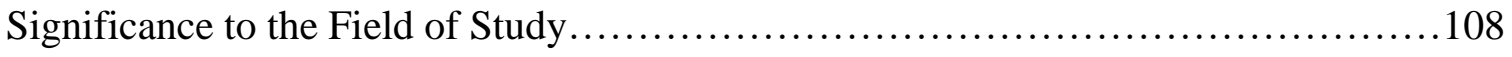

Recommendations for Schools ................................................. 109

Support Robotics Programs in Schools.........................................109

Focus on Mentorship .................................................110

Expand Opportunity and Eliminate Obstacles...............................110

Suggestions for Future Research............................................ 111

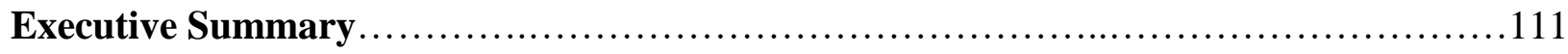

Conclusion................................................................... 116

SECTION 5: CONTRIBUTION TO SCHOLARSHIP................................117

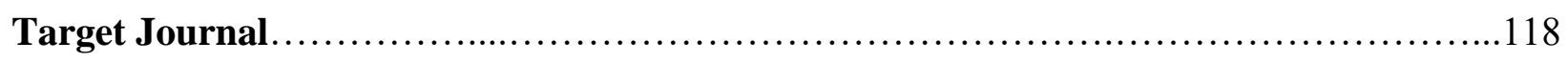

Rationale for this Target................................................ 118

Plan for Submission.....................................................119

Submission-Ready Article for the International Journal of STEM Education.............120

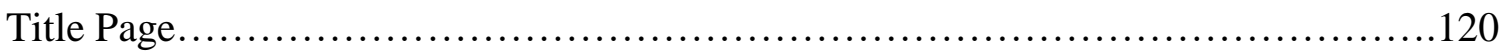

Abstract................................................................... 121

Keywords............................................................... 122

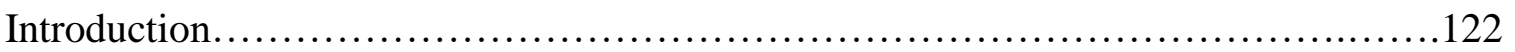

Summary of Existing Literature....................................123

Problem of Practice..................................................... 124

Purpose of the Study.............................................. 126

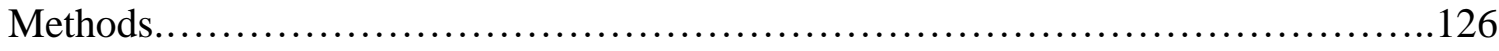

Study Setting ..................................................... 127 
Participants...................................................... 128

Data Collection Tools...............................................129

Results and Discussion................................................ 133

Data Analysis...................................................... 133

Results............................................................ 133

Experience............................................... 134

Influence................................................134

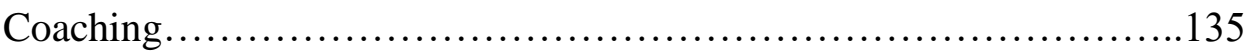

Impact...................................................137

Skills................................................137

Long Term...........................................138

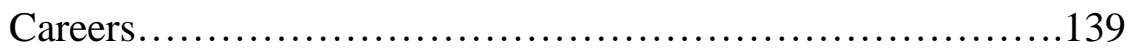

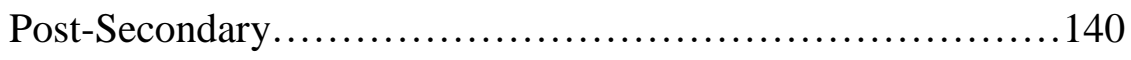

Student Descriptors........................................141

General............................................. 141

Male...............................................142

Female................................................143

Male-Female Percentage..................................144

Discussion......................................................... 145

Social Cognitive Theory....................................... 145

Self-Efficacy Theory of Education.............................. 147

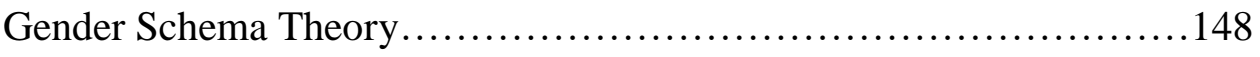

Robotics Programs and Females in STEM........................151

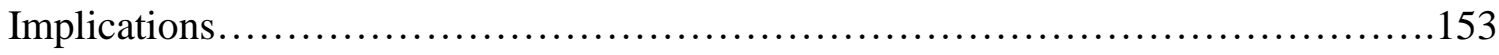

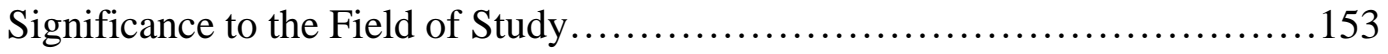


Recommendations for Schools........................................ 154

Support Robotics Programs in Schools..................................154

Focus on Mentorship............................................ 154

Expand Opportunity and Eliminate Obstacles........................155

Suggestions for Future Research............................................155

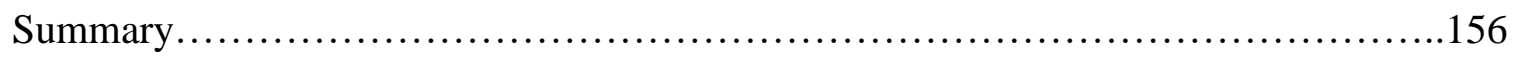

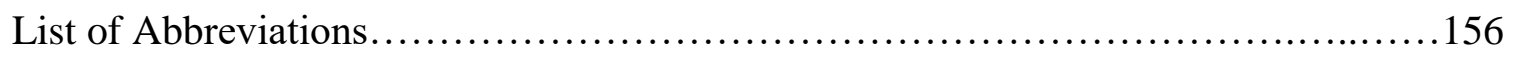

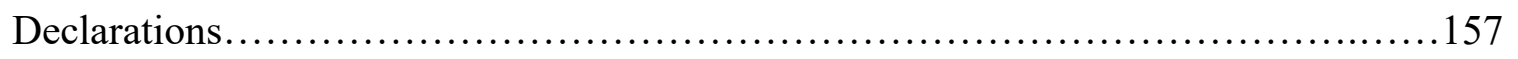

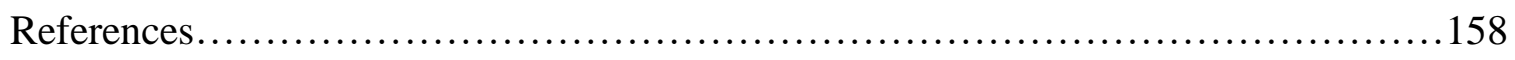

SECTION 6: SCHOLARLY PRACTITIONER REFLECTION..........................163

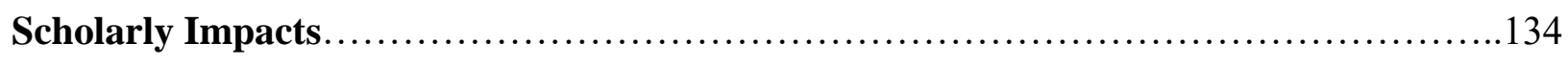

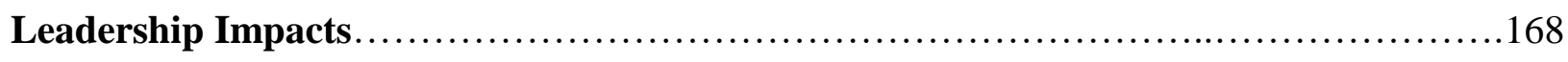

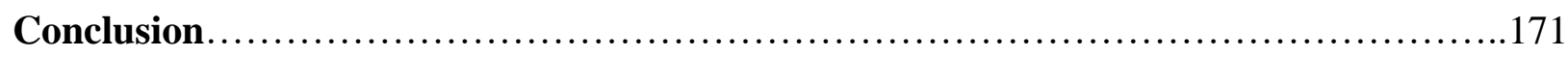

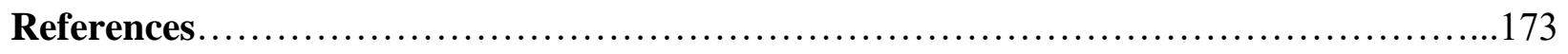

APPENDIX A: IRB Acceptance Letter.................................................... 190

APPENDIX B: Observation Form.................................................... 191

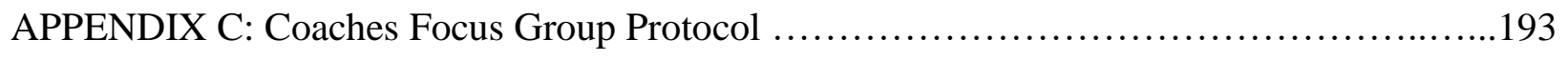

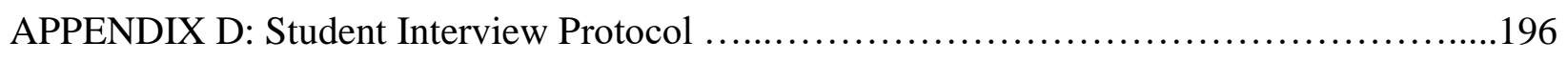

APPENDIX E: Child Assent Form ................................................... 198

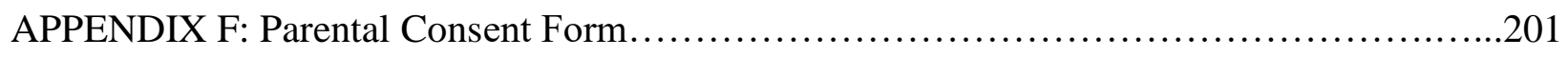

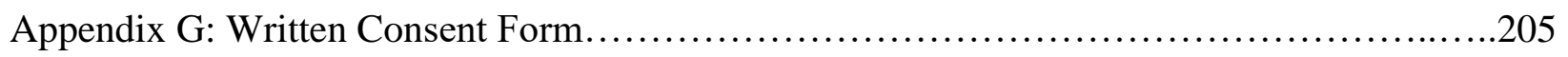

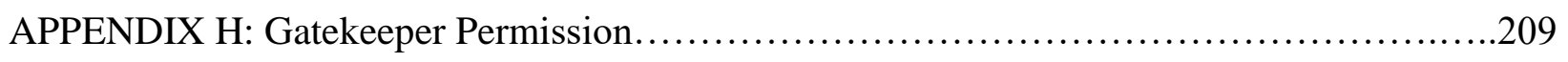


APPENDIX I: Social/Behavioral/Education Research Protocol............................211

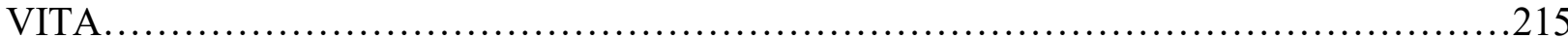




\begin{abstract}
An instructional focus on Science, Technology, Engineering, and Math (STEM) is a current popular educational due to the widespread need for skilled workers in these growing fields. Compounding this labor shortage is the fact that female students and workers are underrepresented in STEM subjects. The purpose of this study was to examine the experiences of female middle school students participating in school-based robotics programs to gain a deeper understanding of the relationship between gender beliefs and academic self-efficacy related to STEM subjects. The results of this study were organized into the theme of experience, influence, coaching, impact, and student descriptors. Contributing factors in the decision to either remain in robotics or leave the program were noted in the category of influence. For the most part, coaching strategies aligned with the idea of the coach as facilitator and schools varied in how they attracted new students. Impact was divided into the coded impact areas of skills, long term, careers, and post-secondary impacts. The theme of student descriptors applied any time coaches and students described students or themselves in specific characteristics, traits, or behaviors. The majority of observations regarding specific gender-related behavior fell into this theme.

The data gained in this study contributed information to the field of study in the areas of significance to the field of study, recommendations for schools, and suggestions for further research. The results indicated that individual gender schema is well-established by the middle school years, and it is a transformative moment in life when one must choose what to do with that knowledge. Based on the findings of this study, school districts should fully support robotics programs, focus on mentorship, and expand opportunity while eliminating obstacles for students. First, research should be conducted to determine where gender schema comes into play at the elementary level. Second, research should be conducted to determine what factors
\end{abstract}


students use choosing between robotics and other activities in middle school. Third, schools that are experiencing great success at producing students who enter STEM careers should be studied. 


\section{SECTION ONE}

\section{INTRODUCTION TO DISSERTATION}




\section{Introduction to the Background of the Study}

An instructional focus on Science, Technology, Engineering, and Math (STEM) is a current popular educational trend (Jung \& Won, 2018). This global educational push for STEM is due to the widespread need for skilled workers in these growing fields (Kandlhofer \&

Steinbauer, 2016). As a result, economists predict proficiency in STEM-based skills will be vital to future careers and industries (Kelley \& Knowles, 2016). However, the United States is experiencing a greater shortage of adults and students entering these career fields as compared to other countries, which is a concern to educators and those working in these fields and should be a concern to all citizens as the economic impact of this shortage is already being seen (Kandlhofer \& Steinbauer, 2016).

Compounding this labor shortage is the under-representation of female students and workers in STEM subjects and careers (Zeldin \& Pajares, 2000). An area where STEM and female students come together at an impactful age is the site of school-based robotics programs. Shown to provide effective and engaging exposure to STEM subjects at an early age (Ospennikova, Ershov, \& Iljin, 2015) are Robotics programs. While there are many studies extolling the benefits of robotics programs and their ability to increase students' academic ability in STEM fields (Eguchi, 2016), nevertheless, even with demonstrated benefits for students engaged in a robotics program, females are not experiencing these benefits to the same degree as males (Kucuk \& Sisman, 2017).

Given the purported importance of STEM subjects to future society and the unequal participation experienced by females working in these fields, this study attempted to advance qualitative data regarding the personal and societal factors affecting female students currently involved in school-based robotics programs. Outlined within this introduction to the dissertation 
in practice is the investigated problem, including existing gaps in the literature, the purpose of the study to be conducted, and the research questions to be answered. Also discussed will be the theoretical frameworks of social cognitive theory, self-efficacy theory of education, and gender schema theory that are used to further understand the study as well as those not chosen for use in the study. Then, the specific design of the study, including the methodology, setting, participants, data collection tools, and finally presented is the data analysis. Examined lastly are limitations and assumptions, definitions and key terms, and the study's significance.

\section{Statement of the Problem}

\section{Problem of Practice}

The problem in this study was the global underrepresentation of females in STEM subjects and careers. Both educators and researchers have identified an amalgamation of factors contributing to the shortage of both male and female adults and students entering STEM fields (Fluck, Webb, Cox, Angeli, Malyn-Smith, Voogt, \& Zagami, 2016). Since experts established STEM as an area of concentrated career need in the future (Lemons \& Parzinger, 2007), any evidence of a workforce need going unfulfilled by society or career opportunities lost by individuals is a problem worthy of attention.

Of particular concern is the fact that this shortage is pronounced among female students and workers than for males in the same areas (Heybach \& Pickup, 2017; Lemons \& Parzinger, 2007; Witherspoon, Schunn, Higashi, \& Baehr, 2016). While many female students take STEMbased classes in middle and high school, the number of female students entering these fields at the post-secondary and career levels is far below that of males (Grubbs, 2013; Zeldin \& Pajares, 2000). One can assume a large percentage of the population experiencing a significant drop in 
interest in STEM fields before adulthood is at least a contributing factor in the global shortage of individuals entering careers in these areas.

It is imperative for researchers and educators to gain a deeper understanding of the experiences of female students as they relate to STEM subjects in order to begin to comprehend the causes behind their underrepresentation in STEM fields. This lack of understanding results in the absence of meaningful action by educators, researchers, and organizations with the express purpose of eliminating the unequal ratio of males to females in these subjects and careers. Additionally, Heybach and Pickup (2017) pointed out this underrepresentation of females in STEM also, results in stagnation in the growth of knowledge in STEM areas as the voice of this part of the population is largely absent across these career fields. The question of what additional advances could be achieved with the input and participation of a significant portion of the population should be of concern to all educators, parents, and members of society.

\section{Existing Gaps in the Literature}

Not enough is understood about the reasons behind why females are not entering these areas as frequently as males or why they are choosing to leave these areas of study. In the literature review, few qualitative studies were found to analyze the phenomenology of female students participating in STEM subjects. Rather, as discussed by Heybach and Pickup (2017), there appears to be a broad deficit assumption across the literature that the lower numbers of females in STEM subjects are due to lack of access and confidence, approaching this issue as if one's femaleness is an obstacle to be overcome. Some studies even went so far as to blame females for their lack of participation in STEM subjects (Kucuk \& Sisman, 2017; Liu, 2010).

This is not to say that efforts should not be made to increase access to and confidence in STEM for female students, but rather, if these were the only contributing factors, this problem 
would not persist. One mixed methods study by Lemons and Parzinger (2007) found significant differences in the experiences of female workers in STEM careers, but did not examine female students younger than post-secondary. Females represent a large subgroup of the population whose participation could potentially go a long way in helping to solve or at least alleviate the global shortage of workers. Much of the existing literature acknowledged gender differences in academics and especially STEM, but did not address potential factors or causality behind these gender differences (Veltman, Davidson, \& Deyell, 2012).

Additionally, there was no qualitative data found analyzing the experiences of female students as expressed by the girls themselves in order to understand their reasons for continuing to be a part of STEM subjects or for leaving these subjects. Only quantitative data indicating evidence that such a difference exists was found (Morgan, Gelbgiser, Weeden, 2013). For these reasons, chosen was a multiple case study using qualitative methods of observations, interviews, and focus groups as the design of this study. The field of education needs to hear the voices of the female students who are standing at the precipice of both their secondary education and STEM fields in order to understand their experiences. Understandings that include the pressures, influences, and thought processes guiding their decisions to continue STEM studies or travel a different educational path into a career at this crucial period of time.

\section{Purpose of the Study}

The purpose of this study was to examine the experiences of female middle school students participating in school-based robotics programs in order to gain a deeper understanding of the relationship between their gender beliefs and academic self-efficacy as it relates to STEM subjects, ultimately leading to their decisions to remain in STEM fields or pursue other career paths. The researcher strived to gain insight into the personal and social factors influencing 
middle school females and limiting the number of females choosing to remain in STEM fields from early secondary education to career. The researcher did not intend to be able to attribute causality to any of these potential factors, but rather intended to gather data, identify patterns, and discern direction for further quantitative and qualitative study in this area so further interventions can be identified and implemented and more research can be conducted that will allow for potential solutions to this problem. The literature review made clear the fact that there is not currently enough qualitative data to guide future study, and any previous attempts at marketing STEM to females has resulted in superficially “painting STEM pink," (Heybach \& Pickup, 2017, p. 621), which is an ineffective attempt at solving the problem.

\section{Research Questions}

The study focused on a narrow scope of research questions, consisting of one primary research question and three secondary research questions. Addressing these research questions came through a variety of qualitative data collection methods including observations of robotics practices, focus groups with coaches of robotics teams, and interviews of female students who participated in a middle school robotics program for a significant length of time.

The primary research question guiding this study was:

How does participating in school-based robotics programs affect the learning and academic self-efficacy of female students?

The secondary research questions are:

Why do female students choose to participate in a robotics program?

How do female students' perceptions of STEM fields change over time after participating in a robotics program?

How does participation in a robotics program affect female students' career aspirations? 


\section{Conceptual and Theoretical Frameworks}

To understand the phenomena of low numbers of females choosing to participate in STEM subjects from education to career, considered were several theoretical frameworks. Some of these theories included situated cognition theory, social cognitive theory, feminist theory, and gender schema theory. In narrowing the scope of the theoretical frameworks for the purposes of this study, the researcher discarded theories that failed to encompass the myriad complex factors affecting females in STEM subjects. These discarded theories include situated cognition theory and feminist theory.

\section{Discarded Theories}

Since the chosen sites included school-based robotics programs and the unique phenomenology experienced by participants, learning theories were appropriate theoretical frameworks to guide the study. The first learning theory considered was situated cognition theory. Within a robotics program, there are learning conditions identified in few other educational environments. The situational learning exclusive to particular conditions in which learning and doing occur simultaneously is the cornerstone of situated cognition theory (Brown, Collins, \& Duguid, 1989). However, the researcher felt this theory did not adequately develop the societal influences discussed by Cobb and Bowers (1999) on student behavior nor discussed potential causal factors behind specific experiences for female students. As a result, instead chosen was social cognitive theory as the learning theory to guide this inquiry as it more clearly addressed these issues and the impact both personal and social factors have on behavior (Bandura, 2001).

Due to the study's focus on the experiences of specifically female students, considered also was feminist theory as a viable theoretical framework. However, after conducting a 
literature review of feminist theory and theories developed using this perspective, a focus on feminist theory was too narrow consideration for this study. Feminist theory carries with it a perceived dichotomy of male success in opposition to female struggle as it exhibits a binary approach to gender studies (Ringrose, 2007). Feminist theory does not acknowledge inherent differences in gender roles, but approaches the female experience through a critical lens suggesting an intentional othering of females (Karlsson, 2015). While feminist ideas are present when researching the experiences of females in comparison to males (Colaner \& Rittenour, 2015), the literature was unclear if the cause of fewer females in STEM subjects is attributable to an othering phenomenon. Since there was no evidence of intentional othering at the secondary education levels, feminist theory was not an appropriate choice as a theoretical lens for this study as it implied causation without evidence. Instead, selected was gender schema theory, a related feminist theory that posits gender socialization as an influential factor in the development of an individual's gender schema as a conceptual framework as it more aptly fit the acknowledged differences seen between male and female students without implying intentional othering as causation.

\section{Social Cognitive Theory}

Bandura's (1977) book, Social Learning Theory, discussed his theory of human behavior. In addition, highlighted what was then a unique perspective that both internal personal factors and external societal factors affect the behavior of individuals. With a later name change to social cognitive theory, it acknowledges the complex cognitive processes contributing to human behavior (Bandura, 1979; Bandura, 2001; Olsen, 1979). Based on the interconnected network of socioeconomic, familial, and relationships and their effect on human social functioning was this theory (Bandura, Barbaranelli, Caprara, \& Pastorelli, 1996). The literature review made clear the 
impact both personal self-efficacy beliefs and social influences can potentially have on the behavior of female students, therefore, social cognitive theory was chosen as a theoretical framework to guide this study.

The work of Bandura and others developing social cognitive theory suggested that human behavior is the output of a complex system of thought and action within individuals (Bandura, 2002; Caprara, Fida, Vecchione, Del Bove, Vecchi, Barbaranelli, \& Bandura, 2008). This work continues to be relevant today due to the human desire to seek a deeper understanding of self and the intensely complicated processes behind individual decision-making (Abdullah, 2019).

Through this work, two paths of understanding emerged. The first focused on the individual and self-directed thoughts leading to a chosen action. The second path suggested focused on society and its effects on the individual (Bandura, 2001).

These two paths identifying both individual and social effects encompass the ideas that both one's self-beliefs and the beliefs of others in an individual's capabilities strongly contribute to human behavior and decision-making (Bandura, 2002). Cobb and Bowers (1999) concluded that these two paths be studied concurrently, as their influential and complex overlap cannot be avoided when studying human behavior. Therefore, a dual research approach including both personal and social factors is appropriate when seeking to understand individuals' decisionmaking processes. Suggested from Bandura's work and the two research paths it identified, the chosen conceptual frameworks for self-efficacy theory of education and gender schema theory guided this study.

\section{Self-Efficacy Theory of Education}

Many studies identified the personal effects of self-efficacy on human behavior (Bandura, 2002; Caprara et al., 2008), with several specifically identifying the unique impact of self- 
efficacy in educational settings as related to student behavior (Bandura et al, 1996; Mills, Pajares, \& Herron, 2006; Pajares, 1996). Bandura's later research expressed his identification and belief that his research provided evidence that self-efficacy is the most powerful factor influencing an individual's personal achievement (Bandura 2001; Bandura et al., 1996). Because of this analysis, chosen was self-efficacy theory of education as the first conceptual framework through which to understand this study.

Several other researchers observed the powerful impact of one's self-efficacy on an individual student's academic performance. Usher and Pajares (2008) suggested that selfefficacy is a more reliable predictor of student academic success than results on objective assessments. Caprara et al. (2008) found a similar predictive relationship in a study. This study also established a negative predictive relationship between self-efficacy and student dropout rates. Yet another study conducted by Hattie (2008) found student self-efficacy had an effect size of .92. Each of these studies supported Bandura's assertion that self-efficacy is a significant factor contributing to student success.

In relation to females in STEM subjects and careers, Bandura, Barbaranelli, Caprara, and Pastorelli (2001) found self-efficacy also played a significant role in the career choices of individuals, regardless of gender. Higher self-efficacy in educational tasks translates into greater perseverance, interest, and academic achievement (Schunk \& DiBenedetto, 2016). The observed effects of self-efficacy on academic performance carry into STEM subjects as well (Leonard, Mitchell, Barnes-Johnson, Unertl, Outka-Hill, Robinson, \& Hester-Croff, 2018). Significant gender differences in self-efficacy beliefs were also noted in a 1999 study by Bussey and Bandura, who further suggested society confers judgment on those whose behavior is deemed socially unacceptable and enforces social punishments. These social punishments develop into 
self-sanctions, or a policing of one's personal behavior, which are seen more strongly in girls than in boys (Bussey \& Bandura, 1999). Usher and Pajares (2008) confirmed this and later developed the second conceptual framework, gender schema theory, used in this inquiry.

\section{Gender Schema Theory}

The societal influences suggested by Bandura's (1986) social cognitive theory as they apply to female students can be understood through the conceptual framework of Bem's (1981a) gender schema theory. This theory helps explain some of the impact gender socialization has on the behavior of individuals in a gender dichotomous society without implying intentional othering or ostracization. Gender schema theory proposed society instructs children on what behaviors are considered socially acceptable for their gender, thereby gendering them and causing them to become what Bem (1981b) called sex-typed. This sex typing occurs through repeated exposure to socially acceptable gender behavior by family, friends, communities, and media throughout the impressionable formative years of development (Bem, 1981a).

Gender schema theory suggests children develop a gender identity at an early age and place themselves into a dichotomous sex-type (Bem, 1983). These gender identities, or schemas, are developed as young as six years old (Master, Cheryan, Moscatelli, \& Meltzoff, 2017), and this evidence of gendering is seen in cognitive processes throughout the children's lifetimes through adulthood (Starr \& Zurbriggen, 2016). Additionally, Bem (1983) suggested gender identities provide a filter through which individuals understand situations and constructs, however, individuals have the ability to choose whether to accept or reject a gender schema and allow it to dictate their behavior. The participants of Lemons and Parzinger's (2007) study of women in informational technology (IT) careers demonstrated evidence this phenomenon. The 
women in this study exhibited a significantly higher level of non-traditional gender schemas than women who were not in IT (Lemons \& Parzinger, 2007).

More recent gender studies in STEM subjects supported these results. Found to affect female students' ability to adapt to certain academic subjects better than others was gender conformity pressure (Vantigham \& Van Houtte, 2018). Additionally, a longitudinal study by Sullivan and Bers (2012) found kindergarten girls and boys exhibited no significant difference in programming ability while participating in a school robotics program, but by second grade, these same students had developed a concept of which robotics tools were gender-appropriate, and behaved accordingly. Female students' interest in computer programming was lower than that of male students in a study by Witherspoon, Schunn, Higash, and Baehr (2006).

Other recent studies also utilized gender schema theory when analyzing the experiences of women and men in different careers. These studies suggest women are often considered less qualified by their male counterparts based solely on their femaleness (Lavallee \& Pelletier, 1992; Woodington, 2010). Others found compelling evidence suggested significant correlations between occupational decisions and what they termed the educational pipeline leading females into their chosen professions (Morgan, Gelbgiser, \& Weeden, 2013). Gender schema theory helps understand some of these results and the impact gender schema can have on female behavior throughout development.

\section{Robotics Programs and Females in STEM}

In addition to self-efficacy theory of education and gender schema theory, identified as an additional conceptual framework was the chosen site of middle school robotics programs for the purposes of this study. Due to the study's focus on social influences as a contributing factor in human behavior, it was imperative to develop an understanding of the social structure within the 
setting. Middle school robotics programs have the unique perspective of bringing STEM subjects and females together into one social phenomenon, making it an ideal locus for this study (Benitti, 2012; Sniderman, 2014). Papert (1987) explained that no educational tool can be divorced from the social structures of which it is a part. Robotics programs have the potential to provide substantial benefits beyond building and programming robots (Benitti, 2012; Grubbs, 2013; Spoloar \& Benitti, 2017).

There is still much to understand about the overall shortage of individuals in STEM fields, and especially the experiences of females and their experiences in these areas. The theoretical framework of social cognitive theory and the conceptual frameworks of self-efficacy theory, gender schema theory, and robotics programs and females in STEM provided a comprehensive understanding through which to analyze this study by filtering human behavior through a lens that sheds light on the internal and external socio-cognitive processes that shape individual choices. These choices and the personal development that occurs over time through these experiences are unique when looking specifically at females in STEM.

\section{Design of the Study}

In considering research paradigms with which to approach this study of the self-efficacy of female students participating in middle school robotics programs, used was the social constructivist paradigm. Creswell (2014) defined social constructivists as those who "believe that individuals seek understanding of the world in which they live and work," (p. 8). Since the purpose of this study was understand the participants' experiences and how those experiences shape individual development, the study meets this definition. As the social constructivism paradigm relies heavily on society's impact on individual behavior through historical and social interaction (Creswell, 2014), this paradigm was deemed the most appropriate for the study. 
Discussion of the methodology and methods, setting, participants, data collection tools, and data analysis will occur in the following sections.

\section{Methodology and Methods}

The methodology for this study was qualitative with no quantitative measures used in collecting data for this study. DuBois, Strait, and Walsh (2017) communicated support of sharing qualitative research data in their thorough discussion of current scientific, ethical, and policy-related issues and observations with its use. Through their study, they reviewed several of the researchers' own experiences with qualitative data (DuBois, Strait, \& Walsh, 2017).

Qualitative research provides many benefits including transparency, new opportunities to utilize existing data, economic responsibility, improvements in coding skills, and gaining public trust (DuBois, Strait, \& Walsh, 2017).

There are concerns and limitations when employing qualitative data in research (DuBois, Strait, \& Walsh, 2017; Roller \& Lavrakas, 2017). These concerns include potential subjectivity, the importance of context and relationships in data collection, misleading anonymization of data, questions of permission and ownership of data, and potential breach of confidentiality and harms (DuBois, Strait, \& Walsh, 2017; Roller \& Lavrakas, 2017). The researcher acknowledged these concerns and made every reasonable effort to keep these in mind and make allowances for their potential occurrence during data collection, analysis, discussion, and publication.

Using a multiple case study method advanced the collection of narrative and personal responses to questions through observations, interviews, and focus groups (Creswell, 2014; Merriam \& Tisdell, 2016; Seidman, 2013). After a thorough literature review, significant gaps indicated the need for qualitative research. There appeared to be a large number of quantitative studies conducted with the focus of self-efficacy, academic performance, educational settings, 
and STEM subjects. These recognized significant differences between male and female students and workers in STEM subjects, but the voices of these individuals and their experiences were missing for the middle school age group, which is a pivotal age in personal development as related to future occupational decisions. It is this type of qualitative understanding needed if meaningful differences are understood for these students and society as a whole (Merriam \& Tisdell, 2016).

Because of this need for understanding the thought processes behind the participants' creation of meaningful experiences, chosen was a multiple case study method as the research design for this study. It was determined a phenomenological or ethnographic study would most likely yield a larger quantity of usable data, but due to the participants and researcher position, it is not possible for the researcher to be immersed in the phenomenon without altering the results of the study (DuBois, Strait, \& Walsh, 2017; Merriam \& Tisdell, 2016). A multiple case study approach allowed the researcher to gain insight into bounded systems of school-based robotics programs with little impact on the normal current and future functioning of the participants and programs (Merriam \& Tisdell, 2016). Since studied were multiple bounded systems as the researcher met with participants from varied sites of these robotics programs, the study was termed a multiple case study (Merriam \& Tisdell, 2016). By clarifying elements such as place, context and culture, the researcher was able to provide a "thick description" which assisted in providing detail to the phenomena being addressed (Merriam \& Tisdell, 2016). To begin, the researcher gained pre-authorization from the University of Missouri Internal Review Board (IRB) (Appendix A) to complete the study as a means of providing a safeguard for study participants. 


\section{Study Setting}

The setting of this study included six middle school robotics programs across the state of Missouri. For the sake of continuity and reliability in comparison, chosen sites participated in the FIRST LEGO League (FLL) program. In choosing the schools for participation in the study, the researcher used purposeful sampling as discussed by Merriam and Tisdell (2016). In purposeful sampling, the sample is identified on attributes in order to gain particular information on the phenomenon to be studied. The researcher selected schools that meet the following requirements:

1. Middle school with an established robotics program

2. Robotics program competes in official FIRST LEGO League tournaments

3. School teams have been registered and active in FIRST LEGO League tournaments for at least three years

4. District, coaches, and participants are open and willing to allow researcher to conduct the study

Using the criteria listed above, the researcher identified a number of potential sites. Further narrowing of settings for the study occurred by ensuring a variety of settings in rural $(n=2)$, suburban $(n=2)$, and urban school communities $(n=2)$, terms defined according to data from World Population Review (2020). A variety of settings allowed the researcher to gain a more complete picture of robotics programs in Missouri and what Merriam and Tisdell (2016) term "maximum variation" (p. 98).

\section{Participants}

At each site of a selected school-based robotics program, interviewed were two female student participants for twelve total individual interviews. Each of these students had 
participated in a FIRST LEGO League program for at least one year. When possible, efforts were ensured one of these students planned to continue participating in robotics and the other was a student who planned to end their involvement with the program.

In addition to student interviews, conducted were focus groups made up of coaches at each site in order to gain qualitative data on the experiences of females within their program from the coach perspective. These coaches are currently involved with a FIRST LEGO League team or had been within the last two years. This secondary sampling is what Merriam and Tisdell labeled "two-tier sampling" (p. 99). The conducted focus groups gathered more information on the context or culture of the program as related to the female students and to gain the perspectives of the adults who are immersed in said context and culture. Depending on the availability of coaches, the focus groups consisted of two to three coaches each, with one focus group at each setting $(n=6)$. The sampling for the specific participants qualified as network sampling as the head coach at each site selected the specific participants within the program to participate in the interview and focus group process (Merriam \& Tisdell, 2016). The participants chosen by the head coaches were the only individuals the researcher had access due to IRB requirements (see Appendix A).

\section{Data Collection Tools}

The qualitative data collection tools used for this study were observations, interviews, and focus groups. The original plan was to conduct observations wherein the researcher observes a robotics practice or meeting and takes field notes on the observation form (see Appendix B) regarding the behaviors and interactions of the participants (Creswell, 2014). It was assumed the observations would only provide context data regarding the social structure of the robotics program, and would most likely not provide answers to the research questions. 
However, as Seidman (2013) stated, an understanding of context is necessary if the researcher is going to gain an understanding of the participants' point of view. Unfortunately, due to the onset of the COVID-19 pandemic and subsequent school shutdown as a safety precaution, only two sites were able to participate in observations.

The developed observation form used Creswell's (2014) recommendations. Listed on the observation form were specific data regarding the site, the personnel, and climate. These are points of note the researcher wanted to make certain were recorded in the observation in order to align the qualitative data in a similar format from site to site. The observation form lists the purpose of the observation, the location, date/time, length of observation, the number of male and female coaches, the number of male and female students, a list of other individuals in attendance, and an illustration of the layout of the practice area as data points to include in the observation. In addition to these specific items, clear and detailed field notes were recorded (Merriam \& Tisdell, 2016).

In addition to observations, the researcher conducted focus groups made up of coaches who work with the female students interviewed for this study in order to gain their perspective as individuals who are in close regular contact to students in the robotics programs. According to Merriam and Tisdell (2016), "a focus group is an interview on a topic with a group of people who have knowledge of the topic," (p. 114). Within the focus group, the coaches were able to freely discuss their robotics program and their opinions regarding the effects the program has specifically on the female students and their interactions (Krueger \& Casey, 2015). The researcher was sensitive to the fact that some coaches may be positionally subordinate to others, and this may affect coaches' ability to answer questions openly and honestly. One focus group was held one time for each site for a time of no longer than one hour. Due to the COVID-19 
school shutdown, conducted were five out of the six focus groups virtually via Zoom video conferencing.

The Coaches Focus Group Protocol (see Appendix C) details the list of questions asked during the focus groups at each site. The list of questions was developed in order to help the coaches feel comfortable, ascertain clear and precise answers to research questions, and to allow for freedom of discussion topics to potentially veer from the question into other relevant conversation that could provide detailed data pertaining to the research questions. Sixteen questions are listed on the protocol (see Appendix C). These questions were shared with other coaches who are not part of a focus group in order to take part in face validity (Merriam \& Tisdell, 2016) and ensure the language of the questions were understood and the desired response validity was achieved. Based on recommendations for clarity and understanding alterations were made. Focus groups were audio recorded with appropriate permissions given.

The researcher expected to gather significant data and the bulk of the answers to the research questions through interviews with female participants within the robotics programs. The interviews allowed the researcher to gain an understanding of the experiences of the students and the meaning they have constructed from those experiences as they related to their beliefs about school, robotics, and STEM (Seidman, 2013). The researcher anticipated interviewing each student one time for no longer than half an hour, with the potential for follow-up questions via digital means or through adult gatekeepers if clarification or further information about their responses is needed. Due to the COVID-19 school shutdown and subsequent cancellation of the fall FLL robotics season, conducted were ten out of the twelve interviews virtually via Zoom video conferencing. 
Due to having the resources for one formal interview per participant, used was the semistructured interview format discussed by Merriam and Tisdell (2016). This format required the researcher to have a predetermined list of questions or interview protocol (see Appendix D) for the interviewee to answer, but allowed the researcher to ask follow up questions based off of the interviewee's responses in order to gain clarification or more information in regard to the research questions. The protocol (see Appendix D) had a total of 17 questions that progress from simple information sharing to deeper questions requiring students to think more critically about their experiences and will generate responses to answer the research questions. The interview questions were shared with robotics students who are not participating in the interview process in order to ensure face validity and make sure the intended response information was understood (Creswell, 2014). Some question wording were simplified through this process. Interviews were audio recorded through digital means with appropriate permissions given.

Some of the pitfalls of observations, focus groups, and interviews are that the participants may not be completely honest regarding their experiences for a variety of reasons (Krueger \& Casey, 2015). This inaccuracy may initially affect the reliability of the data; however, through deep analysis of the data and the search for patterns across multiple interviews and focus groups the emerging data were deemed reliable due to a narrowing of unrepeated themes. The interviews and focus groups provided data to answer all the research questions guiding the study, including the primary research question of: How does participating in school-based robotics programs affect the learning and academic self-efficacy of female students? Additionally, the interviews and focus groups addressed the secondary research questions: Why do female students choose to participate in a robotics program? How do female students' perceptions of 
STEM fields change over time after participating in a robotics program? How does participation in a robotics program affect female students' career aspirations?

\section{Data Analysis}

Interviews and focus group sessions were typed and full transcripts reviewed by the researcher alone to ensure confidentiality. The typed transcripts using the Apple Voice Recorder app and the Otter app were analyzed as soon after collection as possible in order to keep the experience fresh in the researcher's mind (Merriam \& Tisdell, 2016). Coding took place across all the qualitative data to search for themes. The first level of coding used was open coding. In this type of coding, all ideas are possible codes and themes as the researcher keeps an open mind (Merriam \& Tisdell, 2016). Once the open coding was completed on all the interviews and focus groups, the researcher conducted axial coding, in which the researcher searched for recurrent themes in the data (Merriam \& Tisdell, 2016).

Krueger and Casey (2015) recommended four factors to consider when deciding which codes and themes are important. These factors are frequency, specificity, emotion, and extensiveness. Creswell (2014) identified three categories of coding as those codes expected due to information from the literature and common sense, surprising codes the researcher was not expecting, and unusual codes that could be deemed interesting to readers or other researchers. Merriam and Tisdell (2016) stated the criteria for categories, themes, and findings should be that they are exhaustive, mutually exclusive, sensitive to the data, and conceptually congruent. These recommendations from Krueger and Casey (2015), Creswell (2014), and Merriam and Tisdell (2016) were considered when conducting the axial coding process. 


\section{Ethics}

Within all research studies, great care should be taken to preserve the privacy of the participants (Seidman, 2013). Due to the use of minor students as participants in this study, there was an even greater attention to already careful security protocols. This security was enhanced and informed consent was gained from parents or guardians of minor participants in addition to the participants themselves. All audio recordings were secured and are password protected and equipped with location services that allowed the researcher to locate and deactivate them if stolen. Additionally, the names of specific participants were and will continue to be confidential. The locations of the robotics programs were given random identifiers within the final study and will not be revealed in the future as doing so could potentially compromise the privacy of the participants.

\section{Limitations, Assumptions, and Design Controls}

\section{Limitations}

Every study comes with its own unique set of limitations (Creswell, 2014). This study is no different in that respect. Limitations for this study include the use of qualitative as opposed to quantitative data, a small sample size due to convenience sampling, the potential for data contamination due to the researcher's involvement in robotics programs, and the use of only one robotics organization (FIRST LEGO League) within only the state of Missouri. The concerns with using qualitative data are discussed in the methodology section of this study, and every attempt was made to decrease the impact of those potential limitations while also capitalizing on the rich data a qualitative study potentially provides (DuBois, Strait, \& Walsh, 2017; Roller \& Lavrakas, 2017). These limitations are unavoidable and result in data that are unique to these situations, sites, and participants, thus are not generalizable to all robotics programs or students. 
As the purpose of this study was to hear the voices of these participants and gather themes and ideas to indicate further research paths that lead to increased female participation in STEM careers, these limitations are expected and acceptable as they contribute greatly to the field of study. The researcher encourages others to produce similar studies utilizing a variety of sites in order to gain data that cover a broader range of experiences.

In addition to the limitations typically encountered when conducting qualitative research, this study was also limited by the COVID-19 pandemic. This setback resulted in the researcher not being able to conduct observations at every site and the need for focus groups and interviews to be conducted virtually via Zoom video conferencing. There is no way to determine all the ways in which these changes affected the data collected. One most likely effect is that the student interview participants were students who the coaches themselves were directly connected to or felt comfortable contacting parents and asking for the students' participation instead of more randomly selecting a student who would be at practice on the day of the planned researcher visit. Additionally, the experience of the COVID-19 pandemic and resulting cancellation of many events, including robotics practices and competitions, may have affected the participants' views of the program during the study.

\section{Assumptions}

Some assumptions were made regarding the robotics programs being utilized as sites for this study. FIRST LEGO League has parameters and suggestions for its implementation in its annually updated coach's handbook. It is assumed that every site used the same coach's handbook and coaches received similar guidance and resources in implementing this robotics program. FIRST LEGO League also recommends each program have access to a variety of robotics materials including LEGO building sets, EV3 programmable bricks, and LEGO 
Mindstorms software with laptops or tablets for student use. It is assumed that all programs have access to these materials in a reasonable quantity to allow for successful participation in official FIRST LEGO League tournaments. A final assumption is made regarding the access students are given to the robotics programs. Within the researcher's program, all students have the opportunity to try out for a team; however, not all students who try out are selected. It is assumed every site in this study has a similar try out procedure where all students have the opportunity to choose to be a part of the program.

In addition to the assumptions made regarding the robotics programs utilized as sites, the researcher acknowledges ownership of a particular passion related to student access to robotics and career technical education, resulting in the pursuit of this study. An assumption of a similar experienced passion in other robotics coaches is made, but is most likely not an accurate representation of all or even the majority of robotics coaches.

\section{Design Controls}

Every effort was made to minimize the differences in sites, participants, and experiences that affect outcomes. For this reason, the use of parameters in site selection was used, the same list of questions was used for each semi-structured interview and focus group, and the same coding procedures were used in data analysis. These controls allowed the experiences of participants at different sites to be compared and analyzed.

To ensure the researcher adhered to multiple quality measures both qualitative validity and reliability checks were adopted (Creswell, 2014). Validity requires the researcher to "check... the accuracy of the findings" while reliability aims to ensure consistency throughout the research (Creswell, 2014, p. 185). Reliability or dependability within the study was addressed through a process of ensuring the data collected by the researcher were well recorded 
and transcribed (Creswell, 2014). Coding of data gathered from the research followed a distinct pattern of definitions and the researcher ensured that no shifting of meaning occurred during the process (Creswell, 2014). In addition, the researcher had a group of non-participating students and coaches establish face validity and modified the questions accordingly.

To address the issue of validity or credibility within the study the researcher confirmed "the way the respondents actually perceive social constructs [within their organization] and the way the researcher portrays their viewpoints" were exact (Mertens, 2005, p. 254). A process of member checking commenced whereby study participants reviewed and verified information (Stake, 2010). Each participant, upon the completion of the interviews and focus groups, verbally verified the data collected. Triangulation of data from focus groups, interviews and observations occurred and the themes which emerged from examining the convergence of information, added to the reliability process (Creswell, 2014).

\section{Definitions of Key Terms}

Defined for this inquiry were the following terms:

FIRST: An international student robotics organization founded by inventor Dean Kamen, FIRST is an acronym for "For Inspiration and Recognition of Science and Technology." FIRST currently has robotics teams and events all over the world. There are four different levels, or progressions for various age groups and robotics skill levels.

FIRST LEGO League: One progression of FIRST encompassing grades 4-8 in the United States. This progression utilizes LEGO building materials for constructing robots, EV3 bricks for controlling the robots, and LEGO Mindstorms programming software to program them. LEGO: A Danish company specializing in manufacturing plastic building block toys and sets for children. The company name, LEGO, is a combination of two Danish words, "leg godt," 
meaning, "play well." The capitalization of all letters in LEGO is part of the brand name. LEGO is a global sponsor of FIRST.

Middle school: For the purposes of this study, middle school is defined as grades 5-8 in the state of Missouri.

Robotics program: For the purposes of this study, a robotics program is defined as any schoolbased program established in order to allow students to use STEM skills to program robotic components in the completion of given tasks.

Rural: Located within counties with a population density of less than 100 people per square kilometer according to the World Population Review (2020)

STEM: A common educational and career acronym for studies in science, technology, engineering, and mathematics fields

Suburban: Located within counties with a population density of 100-500 people per square kilometer according to the World Population Review (2020)

Urban: Located within counties with a population density greater than 500 people per square kilometer according to the World Population Review (2020)

\section{Significance of the Study}

The data collected through this study was qualitative in nature, providing an understanding of STEM participation from the perspective of female middle school students. Located were no other studies that captured these experiences in the participants' own words. Additionally, with significant research pointing to the importance of adolescence as a pivotal time in life when critical social and personal skills are developing (John, Stoebenau, Ritter, Edmeades, \& Balvin, 2017). The researcher sought to understand the specific experiences of middle school females who have shown an interest in STEM fields early in their educational 
career and later may or may not choose to continue participating. As evidence revealed a global shortage of post-secondary STEM students and workers, this study makes important contributions in both scholarship and practice.

\section{Scholarship}

This study makes three important contributions to the field of study as determined by the researcher. First, this study provided important understanding of the personal and social factors that are affecting middle school females who are currently participating in STEM subjects. This knowledge is imperative because data show some will choose to remain in STEM and others will choose to pursue other career paths. Second, this study allowed comparisons to be made to future studies to determine at what point the desire to continue participating in STEM subjects is either dampened or encouraged, leading to these females either choosing to remove themselves from continuing their education in STEM subjects or furthering their resolve to remain a member of this group. Third, this study allowed a better understanding of what areas require further qualitative and quantitative research in order to solve the global shortage of individuals entering STEM careers at a time when there is an ever-growing need for individuals in these careers.

\section{Practice}

This study provided valuable actionable information to teachers, administrators, and policymakers currently working with and on behalf of students of all ages, preschool through post-secondary. The knowledge gained through this study allows educational institutions at all levels to modify and add to their current STEM offerings in order to make STEM career paths more attractive and available to all potential participants and remove barriers to access for females and other underrepresented groups. It is only through increasing the number of students 
utilizing the STEM career pipeline from education through occupation that the global shortage of STEM workers will be relieved.

\section{Summary}

Discussed within this introduction to the dissertation in practice is the problem of a global shortage of workers in STEM fields, occurring to an even greater degree in the United States and the evidence that this field is experiencing an underrepresentation of females. Conducted was a qualitative multiple case study for gaining a deeper understanding of the experiences of female students currently participating in a middle school robotics program. Analyzed through the theoretical framework of social cognitive theory and the conceptual frameworks of self-efficacy theory of education and gender schema theory in order to better understand the personal and social factors that may be influencing female students to either remain in or leave STEM fields was this inquiry. This study should make three important contributions: to deepen the understanding of the experiences of these students, facilitate comparisons to determine when students are choosing their career paths within or out of STEM, and suggest topics for future studies that will help to solve the global shortage of STEM workers, specifically for females. 
SECTION TWO

PRACTITIONER SETTING FOR THE STUDY 


\section{Introduction}

The practitioner setting is an important consideration for any study, as the practitioner viewpoint affects the study's analysis and interpretation. The practitioner setting was described through the lenses of the background of the organization, organizational analysis, leadership analysis, and implications for research in the practitioner setting as they apply to this dissertation in practice. The researcher utilized Bolman and Deal's (2013) four frames in order to analyze the organization of middle school. Analyzed through the leadership styles of authentic leadership and adaptive leadership was this organization. Finally, this section discussed implications for research as suggested by the organizational and leadership analyses.

\section{Background of the Organization}

The study took place within the organization of public middle schools within the state of Missouri. Merriam-Webster (2020) defined middle school as a school that includes grades five to eight or six to eight, and mentions the first use of the term middle school using this definition dates back to 1870 . Most effectively structuring education within the grades between clear elementary and secondary school ages has long been an area of concern to educators and parents as there is not complete agreement on what the middle school organization should look like (Carolan, Weiss, \& Matthews, 2015).

Wentzel (1998) stated, "For most students, early adolescence is a time of change and transition,” (p. 202). Students of middle school age typically demonstrate unique developmental needs which are often not successfully supported by any known middle school model of education (Carolan, Weiss, \& Matthews, 2015). There are many models of educating middle level students with varying degrees of success (Carolan, Weiss, \& Matthews, 2015). One fact remains consistent in all of the literature about middle schools: middle school is a time of 
transition for students in every developmental aspect (Bowman, 2013; Carolan, Weiss, \& Mathews, 2015; Wentzel, 1997; Wentzel, 1998). These difficulties include social, academic, personal, emotional, and biological changes that are challenging for every human being in this stage of development. Therefore, the middle school organization must facilitate students' life changes in order to demonstrate any measure of success in student outcomes.

\section{Organizational Analysis}

In making sense of organizations in general, Bolman and Deal (2013) developed four frames through which individuals can view organizations. They defined a frame as the assumptions and ideas one uses to filter and understand organizational situations (Bolman \& Deal, 2013). These identified frames include the structural frame, human resource frame, political frame, and symbolic frame. Bolman and Deal (2013) further described these frames into easy to understand terms, categorizing organizations into factories (structural frame), families (human resource frame), jungles (political frame), and temples or carnivals (symbolic frame). These metaphors paint a picture of individuals' perceived understandings at the heart of organizations. The organization of middle school was analyzed using these four frames. Also discussed in this section are descriptive data for each of the specific sites that will be used for this study.

\section{Structural Frame}

Bolman and Deal's (2013) structural frame is concerned with how an institution is organized. This includes procedures, policies, positions, and workflow. The structural frame utilizes strategic thinking and planning in meeting organizational goals for the future. The larger an organization and the loftier its goals, the more complex the organization becomes (Bolman \& Deal, 2013). Additionally, how an organization structures its people into groups or teams, the 
policy and procedures governing organizational behavior, and the defined expectations for an organization all work together to make an impact on the organization, whether positive or negative (Bolman \& Deal, 2013).

Historically, middle schools progressed from structures of departmental teams consisting of several teachers in the same subject and often grade level departments in the 1970s and 1980s to more interdisciplinary teams in which teachers of varying subjects educate shared students in the 1990s and 2000s (Thompson \& Homestead, 2004). Both of these structural models are regularly seen in today's middle schools (Carolan, Weiss, \& Mathews, 2015). Current recommended models of middle school structure include, “[o]rganizational structures [that] foster purposeful learning and meaningful relationships," (Cook, Faulkner, \& Howell, 2016, p. 2). The most successful middle school organizations feature interdisciplinary teaching teams, common planning time for teams, a flexible block schedule for students, intramural activities for students, and intentional advisory programs (Cook, Faulkner, \& Howell, 2016). These "are key structural elements providing the means for middle grade schools to meet the various needs of its students in a developmentally responsive manner," (Cook, Faulkner, \& Howell, 2016, p. 7).

\section{Human Resource Frame}

Bolman and Deal (2013) stated, "The human resource frame centers on what organizations and people do to and for one another," (p. 113). The interplay of relationships between the organization and the people is at the heart of the human resource frame. When viewing an organization through this frame, there is a belief that people come first. Through the human resource frame, it is an organization's responsibility to ensure people's needs are met to the greatest extent possible while still achieving organizational goals. Bolman and Deal (2013) emphasized that without caring about people, an organization will fail. When people feel valued 
and appreciated, they work harder, are more productive, and there is less turnover (Bolman \& Deal, 2013). Therefore, investing in people has significant long-term payoffs for organizations.

Wentzel's $(1997 ; 1998)$ extensive research on the organization of middle school found that a focus on the human aspect was key in creating successful environments in which middle school students can thrive. In a study, Wentzel (1997) found that student perception of a caring student-teacher relationship was positively correlated with motivation and academic achievement. These findings indicated that a student simply believing a teacher cared had a significant impact on student success. In another study, Wentzel (1998) found that peer support was positively correlated with goal pursuit, teacher support with school and class interest, and social responsibility goal pursuit, and parent support with school interest and goal orientation. Wentzel (1998) also found peer and parental support negatively correlated with emotional distress.

Findings such as these indicate the importance of positive relationships and human interactions in middle schools and create the expectation that structural aspects of middle schools must strongly support the human resources frame (Bolman \& Deal, 2013). The human resources frame deals with human interaction not only between a superior and subordinate but also in how teams of teachers interact. Levi (2017) defined teams as, "a special type of group in which people work interdependently to accomplish a goal,” (p. 3). Duong, Pullman, Buntain-Ricklefs, Lee, Benjamin, Nguyen, \& Cook (2019) found that when middle schools focus on training teams of teachers to build positive student-teacher relationships, there were significant positive impacts on students. Their study showed improvements not only in student-teacher relationships, but also demonstrated higher academic engagement and in fewer disruptive behaviors (Duong et.al, 2019). 


\section{Political Frame}

Bolman and Deal's (2013) political frame centers on the idea that there are limited resources in any organization and acknowledges each person works to ensure they receive the resources they need or want. These resources can include money, people, time, space, and anything else of which there is a limited supply. While the term "political" has garnered a negative reputation in American government, Bolman and Deal (2013) stated, “A jaundiced view of politics constitutes a serious threat to individual and organizational effectiveness," (p. 183). Without those who utilize the political framework, an organization would cease to make progress. One must learn to build relationships and capitalize on those relationships for the good of the organization (Bolman \& Deal, 2013).

Within the middle school organization, the political frame comes into play when looking at the limited resources most public schools must utilize in the most effective ways possible while under strong scrutiny from many stakeholders (Bolman \& Deal, 2013). These resources often include materials, space, schedule, personnel, training, students, class offerings, and extracurricular opportunities (Thompson \& Homestead, 2004). Teachers, administrators, and students are required to make decisions on how best to use each of these resources in order to ensure the highest levels of student learning and success. Having a shared vision of the school's priorities and guiding beliefs will help decision makers determine how to best allocate these resources (Cook, Faulkner, \& Howell, 2016).

\section{Symbolic Frame}

The final organizational frame described by Bolman and Deal (2013) is the symbolic frame. This frame refers to the symbols, traditions, images, and values that convey deeply intellectual messages to an organization's stakeholders and inspire an emotional response 
(Bolman \& Deal, 2013). Those who understand the world from a primarily symbolic frame feel powerfully connected to the meanings they construct from images, ceremonies, items, or other symbols (Bolman \& Deal, 2013). These symbols take on a greater significance to the individual than the organization itself due to the feelings they attach to it (Bolman \& Deal, 2013). Symbols can be powerful motivators of behavior in organizations and society as a whole and can greatly influence culture (Bolman \& Deal, 2013).

The middle school organization itself is a symbol of change and transition (Carolan, Weiss, \& Matthews, 2015; Wentzel, 1998). Not only are students usually transitioning to a new school facility with a more student-directed learning environment, they are also experiencing great biological and psychological changes as they begin to develop emotional independence from adults and peer groups (Wentzel, 1998). Middle school becomes a symbol of a student taking some of their first steps toward leaving childhood and becoming who they will be in society. Traditions such as block scheduling, advisory classes, lockers, and after school activities become symbols of growing up which lead to a myriad of feelings within middle school students and their parents (Cook, Faulkner, Howell, 2016). It is the responsibility of the middle school organization to help students and parents interpret these symbols of change and maturity in healthy and productive ways (Bowman, 2013).

\section{Specific Sites}

In selecting sites for this study of female middle school students participating in middle school robotics programs, a variety of sites was necessary in order to make every effort at attaining the greatest range of ideas. Therefore, identified were schools according to the population density of the Missouri County in which they are located according to World Population Review (2020). Identified as those with fewer than 100 people per square kilometer 
wee rural counties. School 1 and School 2 are in counties labeled as rural. Suburban counties are those with 100-500 people per square kilometer. School 3 and School 4 are in counties labeled as suburban. Urban counties are those with greater than 500 people per square kilometer. School 5 and School 6 are in counties labeled as urban.

School 1. School 1 is located in a rural county near Lake of the Ozarks. The town's current population is around 4,000. The community depends on tourism and the many lake properties in the area that are not the owners' full time homes, as indicated in the town's comprehensive development plan. Both the town and the school district were formed shortly after Bagnell Dam was built, creating Lake of the Ozarks.

The school district was formed in 1930 with the consolidation of six neighboring districts. The district was reorganized again in 1947, and gained 15 more neighboring districts. The district reorganized a third time in 1951, and gained four more schools. Today, three school campuses serve over 4,200 students. The district houses two K-2 elementary schools, two 3-4 schools, one 5-6 intermediate school, one 7-8 middle school, and one 9-12 high school. Current district enrollment is just over 4,000 students. In 2019, the district reported a per pupil expenditure of $\$ 11,125$ in 2019 , an attendance rate of $87.1 \%$, and a 4 -year graduation rate of 91.7\% (Missouri Department of Elementary and Secondary Education [DESE], 2020).

The FIRST robotics program started in the school district with a FIRST Robotics Challenge (FRC) team at the high school. Since that time, the robotics program has grown exponentially with significant community support. In the last five years, the program has started 106 teams at all levels of FIRST, mentored 88 teams, and helped 310 other teams in some capacity. The teams have earned national and international recognition for their commitment to FIRST and STEM opportunities. 
School 1 is set in the largest of three school grounds in the district. The high school, middle school, and three elementary schools of varying levels are in close proximity to one another and connected by a large parking lot for the entire compound. Within this school grounds, one school level graduates into the next. Most students in the robotics program at School 2 are in grades 4-6, as most progress to the next level of FIRST robotics in grade 7 when they graduate to the middle school.

School 2. School 2 is located in a town of nearly 3,000 people located in a rural central Missouri county. The town founded in the 1850's with a focus on farming. With the addition of the railroad in 1860 , the town thrived and overcame a fire, which destroyed most of the main street in 1867. Today, the town's economy still depends on farming, but the addition of a military base inspires considerable pride in the townspeople. This has also led to many residents who work in engineering and mechanics, both military and civilian, to settle in the town. The town maintains a balance of modernization and appreciation of nature due to its close proximity to a state park and mostly isolated location.

The school district in which School 2 is located has of two elementary schools housing grades K-5, one middle school with grades 6-8, and one high school with grades 9-12. The district serves almost 1,600 students, and two out of every three students are connected to the military in some way. Its 2019 per pupil expenditure was \$11,249 (DESE, 2020). The district reported a $87.3 \%$ attendance rate and a 4-year graduation rate of 93.42\% in 2019 (DESE, 2020).

School 2 has students in grades 6-8, with robotics activities beginning in the elementary schools and feeding into the middle school returning for robotics activities. The school currently has approximately 350 students in attendance. It is located in the center of the town. There are few places of note within the town itself, as it appears to be a typical Missouri small town. The 
district began a robotics program with students in grades 6-12 in 2015, and quickly expanded their program offerings to include elementary and middle school.

School 3. The suburban town in which School 3 is located approximately ten minutes outside of Springfield. The town has a population of 19,022 according to the 2010 Missouri Census Data Center (MCDC). The community made up of many homes, several small businesses, and an active, supportive community. Originally established as a farming community due to the area's fertile soil and numerous rivers and creeks running through it, the community grew to include livestock and a tomato canning factory was opened in 1889 . With the Great Depression and the construction of a highway connecting the town and Springfield, came a decrease in demand for the area's crops and livestock. As Springfield continued to grow as the commercial center for the area, School 3's town became a residential hub in the 1960s and 1970s due to the ease of transportation to and from the city. Today, the town continues to be mostly residential, with some small businesses and franchise businesses catering to retail, convenience, and restaurant options.

The school district was formed in 1899 . When first established, the district had no school board, no teacher, no school building, and no land on which to build one. A one-room schoolhouse was built in 1901 on land donated by the first president of the board of education. From humble beginnings as a one-room schoolhouse, the school district now serves over 6,000 students and has twelve school buildings, including one high school, one alternative high school, one junior high, two intermediate schools, one STEM school, four elementary schools, and two preschool buildings. The district reported a per pupil expenditure of $\$ 8,731$, an attendance rate of 93\%, and a 4-year graduation rate of 94.7\% in 2019 (DESE, 2020). 
School 3 is a K-4 building located on the southwest side of town. The school shares a driveway with the high school, and many partnerships exist between the high school and the classrooms in School 3 due to its proximity. The school currently educates over 500 students. The robotics program at School 3 began 2015 and is made up of students in grades 4-8. Former students in grades 5-8 are bused to School 3 where they join current fourth grade students for robotics activities.

School 4. School 4 is within a suburban college town on the banks of the busy river. The city is located about an hour and a half outside a major metropolitan city and has a population of 39,000. Founded in 1733 as a trading post for river travelers and Native American tribes, and later established as a Spanish military base. The town established in 1806 and thrives as a river boomtown with the prominence of the steamboat. Today, the town draws many people from the surrounding rural communities who commute daily for work in education, commerce, and medical care.

The school district within which School 4 is located has an early childhood center, five elementary schools, one middle school, one junior high, two high schools, and a career and technology center. The district's website offers few details regarding the grade levels offered at each building or the student population at individual schools. The school district reported a total student population of 4,096 , a per pupil expenditure of $\$ 10,342$, an attendance rate of $90.3 \%$, and a 4-year graduation rate of $85.29 \%$ in 2019 (DESE, 2020).

School 5. School 5 is located just outside a large, densely populated city in an urban county. The city located where the Missouri and Mississippi Rivers converge, makes it a prime location for a booming city to thrive when it was first settled in 1769 . Founded by a fur trader, the city was controlled by the Spanish government until the Louisiana Purchase. The city 
continued to grow as two of the main trails used for westward expansion, the Oregon Trail and the Santa Fe Trail, both began near the settlement. The current population of the city is 65,000 . With a vibrant cultural scene, redevelopment of older parts of the city, and a focus on preserving the city's rich history, it continues to be a thriving metropolis.

The size and population of the city support multiple school districts. The school district within which School 5 is located educates over 16,000 students in 24 different buildings across the city. There are currently ten elementary schools, five middle schools, four high schools, three early learning schools, and one alternative school. The district reported a per pupil expenditure of $\$ 11,227$, an attendance rate of $88.9 \%$, and a 4 -year graduation rate of $96.99 \%$ in 2019 (DESE, 2020).

The robotics program at School 5 has students from across the district. Practices are held in the evenings so that students can attend. Students are chosen through a competitive tryout process. The district supports robotics activities beginning in the elementary ages and continuing through high school, similar to that offered at School 2.

School 6. School 6 is located in an urban county. The city in which it is located is part of the Kansas City metropolitan area. The city has a population of 24,475 . It began as a farming community and incorporated in 1912 when the farmers grew tired of traveling to the nearest post office a day's ride away. The town continued to grow due to its close proximity to Kansas City and the ease of transportation offered by the railroad. The town became a military town with the addition of an Air Force Base in 1944. The base closed in 1994, and the city had to establish a new means of growth. Today, the city prides itself on innovation and becoming a walkable community. 
The school district was established in 1914, shortly after the town was created. Over 4,300 students attend school in the district at one high school, one middle school, one K-8 school, four elementary schools, and one early childhood school within the district. The district's student population is diverse, with $52 \%$ of students African American, $20 \%$ white, $20 \%$ Hispanic, and 8\% Asian, Indian, or other minority and reported a per pupil expenditure of $\$ 12,194$, an attendance rate of $83.3 \%$, and a 4-year graduation rate of $86.4 \%$ in 2019 (DESE, 2020).

\section{Leadership Analysis}

Northouse (2016) defined leadership as "a process whereby an individual influences a group of individuals to achieve a common goal," (p. 6). The idea of leadership as a process, as opposed to a set of skills is a key component in the development of the study of leadership. This indicates an individual's leadership capacity is learned, honed, and improved upon as it is practiced (Northouse, 2016). The following analysis discusses the leadership styles of authentic and adaptive leadership. Discussed will be how these approaches are appropriate and necessary within the middle school environment.

\section{Authentic Leadership}

In analyzing authentic leadership, George, Sims, McLean, and Mayer (2011) stated, "No one can be authentic trying to imitate someone else," (p. 163). Northouse (2016) discussed five characteristics of authentic leadership. Authentic leaders understand their purpose, have a strong sense of right and wrong, build trusting relationships, practice self-discipline based on their values, and are passionate about goals. One's individual experiences and path in life inform their leadership practices. Authentic leaders possess self-awareness that allows them to know who they are and how to achieve their goals (Northouse, 2016). 
Northouse (2016) identified four components of authentic leadership: self-awareness, internalized moral perspective, balanced processing, and relational transparency. Self-awareness is the understanding leaders have of themselves (Northouse, 2016). This self-awareness extends to an understanding of personal strengths, weaknesses, and the effect one has on others (Northouse, 2016). In the middle school setting, a leader must "have a strong anchor for their decisions and actions," (Northouse, 2016, p. 203). Leaders in middle school settings must have self-awareness in order to stay grounded in reality, rely on their strengths, find others who can compensate for their weaknesses, and approach others in ways that will be accepted and help to cultivate the desired results.

The second component of authentic leadership identified by Northouse (2016) is that of internalized moral perspective. This requires leaders to use personal morals and values to guide their actions and decisions (Northouse, 2016). Anyone who works with students in any setting should possess a strong moral compass and a sense of their "true north," a guiding set of principles authentic leaders use to navigate their daily lives (Northouse, 2016, p. 198). In the middle school setting, there is an opportunity for authentic leaders to help students through a difficult developmental journey (Wentzel, 1997). Providing a role model for students who are struggling to discover who they are demands an unrelenting commitment to high ethical standards (Wentzel, 1997).

Northouse's (2016) third component of authentic leadership is balanced processing. Balanced processing is the act of gathering a variety of perspectives in a situation before making decisions that will affect others (Northouse, 2016). The authentic leader understands not everyone will share the same perspective and understanding of a situation or problem (Northouse, 2016). Therefore, it is the responsibility of the authentic leader to seek out different 
perspectives to gain a better picture of the situation. This commitment to understanding differing perspectives reflects the authentic leader's self-awareness in the limitations of their own knowledge and allows for an objective consideration of viewpoints with which the authentic leader might disagree (Northouse, 2016). In any school setting, including the middle school, many individuals care about the students, the curriculum, and the teachers. These individuals are passionate about their work, but may have opposing ideas on the best courses of action in order to solve a particular problem or issue (Cook, Faulkner, \& Howell, 2016). The authentic leader in the middle school setting will be able to carefully consider each idea and opinion and come to a shared decision that will most effectively benefit students (Northouse, 2016).

The final component of authentic leadership discussed by Northouse (2016) is that of relational transparency. Relational transparency is the open and honest presentation of one's self to others and building meaningful, appropriate relationships based on trust and consistency (Northouse, 2016). Leaders in middle schools must have the ability to build trusting relationships with staff and students in order to create a culture of authenticity (Duong et al., 2019; Northouse, 2016; Wentzel, 1997; Wentzel, 1998). Strong relationships are one of the greatest predictors of student achievement and success in the middle school setting (Cook, Faulkner, \& Howell, 2016; Duong et al., 2019)

Bowman (2013) discussed the importance of middle school students to find the leader within themselves by learning who they are as individuals and what they stand for. This is the foundation of authentic leadership (Northouse, 2016). In order for students to become authentically engaged in the middle school setting, leaders must be authentic about who they are and build trust and consistency in their interactions with staff and students (Bowman, 2013). 
This authentic engagement by adults will set an example for students to also embrace their authentic selves.

\section{Adaptive Leadership}

Adaptive leaders have the ability to adjust to situations and face issues as they arise (Northouse, 2016). This can be accomplished no matter the positional authority an individual possesses as adaptive leadership utilizes a systems perspective by acknowledging individuals are part of intricately connected organizations (Northouse, 2016). Heifetz and Laurie (2011) stated, “...adaptive challenges are murky, systemic problems with no easy answers,” (p. 59). This leadership style builds upon the behavioral approach as it considers internal and environmental factors affecting follower behaviors, and recognizes components of servant leadership in its sensitivity to others' needs (Northouse, 2016).

Adaptive leadership is one of the few approaches outlining specific skills leaders can improve upon (Northouse, 2016). These skills can be applied to leaders in the middle school setting in order to incorporate what Northouse (2016) described as a necessary combination of a systems perspective, biological perspective, service orientation, and psychotherapy perspective. These perspectives allow the adaptive leader to handle situational challenges that are either technical, adaptive, or some of both (Northouse, 2016). Cook, Faulkner, and Howell (2016) stated the modern middle school should be responsive, empowering, and equitable. The adaptive leader within a middle school will be able to find ways to solve these situational issues and create unique and productive solutions.

Northouse (2016) described six leader behaviors on which the adaptive leader should focus. The first of these is termed "get on the balcony," (p. 263). Getting on the balcony refers to an adaptive leader's need to find perspective when a situational challenge is occurring. A 
middle school environment comes with situational challenges that will seem overwhelming with no easy solutions (Carolan, Weiss, \& Matthews, 2015). It is imperative the adaptive leader can take a moment and learn the perspective of many stakeholders before making a decision. The second leader behavior Northouse (2016) described for an adaptive leader is the need to identify what adaptive challenges exist in order to "analyze and diagnose these challenges," (p. 264). The adaptive leader must have a clear view of what the challenges are, especially in an environment such as a middle school where there are many people, programs, and influences at work (Thompson \& Homestead, 2004; Wentzel, 1997; Wentzel, 1998).

The third adaptive leadership behavior Northouse (2016) discussed is the ability to regulate distress. This skill involves helping "others recognize the need for change but not become overwhelmed by the need for the change itself," (p. 266). A leader's job is to help followers navigate difficult transitions through change, and the adaptive leader's followercentered approach is key in helping middle school teachers and students handle the stress that comes with change in productive and healthy ways (Cook, Faulkner, Howell, 2016; Northouse, 2016). There is a delicate balance with the fourth adaptive leadership behavior as Northouse (2016) suggested the maintaining of disciplined attention. When adapting, "the leader needs to encourage people to focus on the tough work they need to do," (p. 269). Middle school work is tough work (Carolan, Weiss, \& Matthews, 2015; Cook, Faulkner, \& Howell, 2016). The adaptive leader must help everyone stay focused on this tough work until it is finished.

In doing this, the adaptive leader must also engage in Northouse's (2016) fifth adaptive leadership behavior: give work back to the people. It is necessary for the leader to trust the followers enough so that they feel confident in their ability to solve problems and free to develop creative solutions to systemic problems (Bowman, 2013; Northouse, 2016). An overabundance 
of leader involvement can stifle creative capacity and handicap the followers' leadership capacity and self-belief (Northouse, 2016). The adaptive leader can use this step back in leadership to complete Northouse's (2016) final leadership behavior: protect leadership voices from below. An adaptive leader must seek out those voices that are not considered mainstream within the middle school organization (Northouse, 2016). If a middle school is truly meant to be a successful educational environment for all students, the voices of those who are not having their needs met must be heard (Cook, Faulkner, \& Howell, 2016).

\section{Implications for Research in the Practitioner Setting}

Much remains to be understood about the middle school setting and how best to organize and lead students and staff in this setting. Future research should continue to focus on how best to help students gain success, and how to most effectively help teachers do their jobs. Datnow and Park (2014) suggested there are four P's creating the context of educational reform that should inform educational decisions. These four P's are people, policies, practices, and patterns.

One focus of future research in the middle school setting could be on how policy is affecting the middle school setting. Policies include the formal written regulations that the organization agrees to carry out while conducting business (Datnow \& Park, 2014). Another area for future research could be practices, specifically the programs in place to help struggling students and provide diverse learning opportunities (Datnow \& Park, 2014).

One area that appears to be lacking in research about the middle school setting and the policies and practices that affect its operation is that of qualitative research that seeks to share the voices of those who are involved within the setting (Merriam \& Tisdell, 2016). Bolman and Deal (2013) stated, “...policymakers often don't understand the problem well enough to get the solution right, and a sizable body of research records a continuing saga of perverse ways in 
which the implementation process undermines even good solutions," (Bolman \& Deal, 2013, p. 9). Policy affects action, and it is the responsibility of educators to get involved in policy making (Bardach \& Patashnik, 2016). Educators are the experts, and too often, those who are making the policies are not (Loss \& McGuinn, 2016). As a result, significant policy decisions are made without input from those trained in child development, learning strategies, and instructional tools (Goldhaber \& Brown, 2016). This leads to a lack of productive communication, leading to frustration, failure, and feelings of mistrust between policymakers and educators (Goldhaber \& Brown, 2016).

This study aimed to shed light on the policies and practices of robotics programs within the middle school setting using qualitative data from the students and coaches involved. Qualitative data in this setting are imperative, as researchers have identified that issues and inequities between school goals and performance exist, but seem to fall short when it comes to potential causes and solutions. Qualitative research has the potential to fill in gaps in knowledge left by focusing on the numbers in quantitative research (DuBois, Strait, \& Walsh, 2018; Roller \& Lavrakas, 2018). Qualitative research allows middle school leaders to practice the balanced processing approach of authentic leadership, adapt to situational challenges through adaptive leadership (Northouse, 2016), and create structures that support the individuals within the organization of middle school through Bolman and Deal's (2013) structural and human resources frames.

\section{Summary}

An analysis of the middle school setting through Bolman and Deal's (2013) four frames allows for understanding of the differing perspectives of those who operate in other frames and how they may perceive a situation. Bolman and Deal (2013) described organizations as 
surprisingly deceptive and ambiguously complex. They stated, "The ability to reframe is one of the most powerful capacities of great artists. It can be equally powerful for managers and leaders," (p. 39). In addition, using authentic leadership and adaptive leadership through which to focus a qualitative study in the middle school setting ensures leaders focus on effectively serving middle school students and staff. 
SECTION THREE

SCHOLARLY REVIEW FOR THE STUDY 


\section{Introduction}

Many factors contribute to a child's personal development (Abdullah, 2019; Bandura, 1977; Bandura, 1986b). Psychologists determined these factors come from both internal and external inputs (Bandura, 2002; Cobb \& Bowers, 1999). As children grow, adolescence is a pivotal period during which the brain makes connections and develops schema that will affect understanding of events and situations for the rest of their lives (Bandura, Bandura, Barbaranelli, Caprara \& Pastorelli, 2001; Bem, 1983). Adolescence is the period in one's life when critical social and personal skills such as self-efficacy (John, Stoebenau, Ritter, Edmeades, \& Balvin, 2017) and gender schema (Bem, 1981) develop.

Experts identified self-efficacy as one internal input that has the potential to significantly impact a child's development, especially in educational settings (Bandura, 1986; Caprara, Fida, Vecchione, Bove, Vecchio, Barbaranelli, \& Bandura, 2008; Usher \& Pajares, 2008). In SelfEfficacy: The Exercise of Control (1997), Albert Bandura defined self-efficacy as "beliefs in one's capabilities to organize and execute the courses of action required to manage prospective situations" (p. 2). Pajares (1996) expanded on Bandura's work and focused explicitly on selfefficacy in educational settings and the importance of one's belief in his or her ability to perform academic tasks. Self-efficacy beliefs in children and adolescents can have a significant impact on their future career goals and aspirations (Bandura, Barbarnelli, Caprara, \& Pastorelli, 2001).

In addition to self-efficacy shaping the development of children and adolescents, the majority of lasting gender socialization effects takes root during childhood and adolescence (Bandura, Caprara, Barbaranelli, Gerbino, \& Pastorelli, 2003). Researchers found significant differences in self-efficacy between genders at varying ages and across different subject areas, (Pajares, 2002). Bem's (1981) pioneering work in developing gender schema theory laid a 
foundation for researchers and those who work with children to gain a greater understanding and awareness of the social mechanisms through which children and adolescents make cognitive sense of their developing gender ideas and identities. While psychology research in the complex area of gender socialization is ongoing, it is clear that social pressures have a significant impact on the gender identity development of children and adolescents (Martin, Fabes, Hanish, Leonard, \& Dinella, 2011; Menon, 2016).

At this time, there is a global shortage of adults and students of both traditional genders entering science, technology, engineering, and math (STEM) career fields, especially in the United States (Kandlhofer \& Steinbauer, 2016). Of additional concern is the fact that while many female students participate in STEM-based academic classes at the secondary level, the number of female students entering these fields at the post-secondary and career levels is far below that of men (Lemons \& Parzinger, 2007; Zeldin \& Pajares, 2000). Individuals currently working in STEM fields or closely connected to these fields of study have contributed several potential solutions to the personnel shortage. One of these possible solutions is the broad introduction of school-based robotics programs (Jung \& Won, 2018).

Robotics programs effectively and engagingly provide school-based early exposure to STEM fields for students (Ospennikova, Ershov, \& Iljin, 2015). Economic factors indicate robotics skills will be vital for future careers and industries (Kelley \& Knowles, 2016). However, even with demonstrated benefits for students engaged in a robotics program and the need for more individuals entering STEM fields, female students are not experiencing these benefits and receiving these opportunities to the same degree as males (Kucuk \& Sisman, 2017). This scholarly review of literature will analyze the socio-cognitive frameworks of self-efficacy and gender socialization and discuss the impact these frameworks have on females in STEM 
careers and robotics programs, particularly the impact these frameworks demonstrate on children and adolescents. Much needs to be understood about the shortage of individuals in STEM fields, especially the experiences of females in these areas and their reasons for choosing not to enter or continue STEM careers.

\section{Conceptual and Theoretical Frameworks}

Analyzed through the conceptual framework of Bandura's (1977) social cognitive theory was this study. While initially termed social learning theory, Bandura later adapted and termed his version of similarly named theories into social cognitive theory. As Bandura's research progressed, he sought to differentiate his approach from other social learning theories, and recognized his theory focused more on the cognitive processes involved in learning and altered his terminology to reflect this focus (1986b).

Viewed first through the theoretical lens of social cognitive theory, then narrowed down to two related conceptual frameworks was this inquiry. The purpose of this two-pronged analysis was due to a plethora of research utilizing social cognitive theory as a theoretical framework that recognized both internal and external social influences in development (Cobb \& Bowers, 1996). The first conceptual framework used was self-efficacy theory of education, an approach first suggested by Bandura through extensive work developing social cognitive theory and the concept of self-efficacy (Bandura, 1986a). Pajares (1996) further developed Bandura's work, as he analyzed the effects of self-efficacy specifically within educational settings.

The second conceptual framework employed in this analysis was Bem's (1981) gender schema theory. Gender schema theory proposed that individuals are gendered at an early age through the social interactions they observe or participate in with family, friends, communities, and media sources throughout childhood and adolescence (Bem, 1981). Through this social 
gendering process, individuals become what Bem termed sex-typed (1981). Bem (1981) stated, "Sex-typing results, in part, from the fact that the self-concept itself gets assimilated into the gender schema," (p. 355). Therefore, once sex-typed, individuals' behaviors are filtered through their developed gender schema before being put into action.

This study makes use of school-based middle school robotics programs as a site for data collection. As such, the analysis of theoretical frameworks included robotics programs due to their potentially unique culture and societal structure, which are believed to impact the research study significantly. The review discussed evidence in the literature that suggests robotics programs are a valuable research site in order to gather data in a socio-cognitive environment that uniquely affects female students due to both the involvement of robotics programs in STEM fields and their potential to impact students through social support structures.

\section{Social Cognitive Theory}

Bandura first introduced his version of social learning theory in his 1977 book Social Learning Theory. His work was recognized by other experts in the field of psychology for its unique contributions discussing reciprocal determinism, a model explaining the effects of both personal internal factors and the external environment on human behavior (Olsen, 1979). This idea of dual causality was novel at the time of the book's publication since psychologists had not previously considered the strong effects both personal and environmental factors can have, instead research focused on strictly biological factors when analyzing human social behavior up to this point (Bandura, 1977). Bandura's research and development of social cognitive theory reflected his personal concerns regarding the infinitely complex processes by which people understand their own capabilities, and the desire to comprehend how these self-beliefs affect the thoughts and actions of individuals in different social situations (Bandura, 1979). 
Bandura (1986b) further developed this theory as he explored the potential causal factors affecting the thinking and learning of an individual within a given social context. Bandura's research added a previously undeveloped psychological perspective on the importance of personal agency, or an individual's ability to make things happen in his or her life through their own beliefs and actions (Bandura, 2001). He rejected the traditional notion at the time that human behavior is a function of simple input and output relationships in favor of a model made of more complex social interactions, including intentionality, forethought, self-reactiveness, selfreflectiveness, fortuity, collective efficacy, and self-efficacy (Bandura, 2001).

Bandura, Barabaranelli, Caprara, and Pastorelli (1996) continued to develop social cognitive theory as it focused on the impact and interplay of socioeconomic, familial, and relationship factors on self-regulated behaviors. As Bandura et al. (2002) stated, "Viewed from the sociocognitive perspective, human nature is characterized by a vast potential that can be fashioned by direct and vicarious experience into a variety of forms within biological limits," (p. 271-272). The complexity of Bandura's social cognitive theory and the multitude of factors involved in the development of one's personal agency have had lasting impact in the field of psychology due to its acknowledgement of the intricate nature of human brain development (Abdullah, 2019).

Even though Bandura's proposed theory was innovative and well-received for its ability to help explain human behavior, he warned other researchers of the dangers of oversimplifying human behavior to only individual versus collective origins (2002). Bandura (2002) described three types of agency experienced by an individual: personal agency, proxy agency, and collective agency. Each of these provides societal influences on an individual (Bandura, 2002). As researchers continue to analyze and understand human behavior, the more apparent the vast 
complexity of thought processes and cognition affecting human behavior becomes (Bandura, 2002; Caprara, Fida, Vecchione, Del Bove, Vecchi, Barbaranelli, \& Bandura, 2008). Bandura's work continues to be relevant as a field of study due to the human desire to seek a deeper understanding of themselves (Abdullah, 2019).

Keeping Bandura's (2002) warnings in mind, the two paths identified for further research stemming from social cognitive theory remain clear. Cobb and Bowers (1999) accurately concluded these two paths could not be studied in isolation due to their unavoidable influential overlap. The first of these paths is a concentration on the individual and the specific personal inputs that lead one to choose a particular course of action. The second path is a focus on society and the mechanisms behind its cognitive effects on individual decision-making (Bandura, 2001). Bandura's (2002) research emphasized that individuals are affected not only by their own beliefs in their personal abilities but also by the collective and individual beliefs others have in their skills. Therefore, a two-pronged approach including both personal and social factors is appropriate when seeking to understand individuals' decision-making processes.

The individual research path suggested by Bandura's work on social cognitive theory centered on identifying the impact an individual can have on their own task performance through what he termed "self-regulative factors," (Bandura, 2001, p. 5). These factors include a variety of personal agency and reflective behaviors, including monitoring personal awareness of one's thoughts, motivation, and actions (Caprara, et al., 2008). Bandura identified another one of these personal agency factors as self-efficacy, or “one's perceived capabilities for learning or performing actions at designated levels," (Bandura, 1997, p. 1). He believed one's belief in his or her ability to achieve a goal is an influential factor in whether or not a person accomplishes 
that goal. Previous psychology researchers had not explored the effects of merely believing in oneself on personal achievement (Olsen, 1979; Usher \& Pajares, 2008).

The societal research path suggested by social cognitive theory is the impact social factors can have on an individual's behavior. Bandura (2001) stated, "Within this theoretical framework, human functioning is analyzed as socially interdependent, richly contextualized, and conditionally orchestrated within the dynamics of various societal subsystems and their complex interplay," (p. 5). Individuals cannot easily remove themselves from the context of the society and culture to which they belong (Pajares, 1996). It is through these two research paths identified through Bandura's work that the conceptual frameworks of self-efficacy theory of education and gender schema theory were chosen to guide this study.

\section{Self-Efficacy Theory of Education}

Bandura (1986a) published research marking the first written suggestion of self-efficacy as a theory in its own right and not only a contributing factor in social cognitive theory. His research established significant positive relationships between self-efficacy and goal setting, ability, memory performance, cognitive effort, and motivation, and a significant negative correlation between self-efficacy and depression, anxiety, and behavior issues (Bandura, 1993). According to self-efficacy theory, individuals form their beliefs in themselves through four sources: perceptions of past performances (mastery experiences), observation of others (vicarious experiences), verbal messages from others (verbal persuasions), and their physical and emotional states of being (Bandura, 1986; Zeldin \& Pajares, 2000). These inputs then enter the cognition of an individual who then makes choices resulting in behavior (Bandura, 1986).

As his research focused on self-efficacy progressed, Bandura came to believe selfefficacy was the most critical factor in personal achievement (Bandura 2001; Bandura et al., 
1996). A study by Bandura, Caprara, Barbaranelli, Gerbino, and Pastorelli (2003) found that perceived self-efficacy performed a central function in self-management due to its influence on all other determinants of behavior. So convinced of the power of self-efficacy on human behavior, Bandura and Locke (2003) negated any research attempting to refute self-efficacy as a significant contributing factor in achievement. Usher and Pajares' (2008) review of proposed sources of self-efficacy posited that individual perceptions of mastery as a much more powerful predictor of success than even objective assessment results. Caprara, Fida, Vecchione, Del Bove, Vecchio, Barbaranelli, and Bandura (2008) similarly found a significant predictive relationship between decreases in self-efficacy beliefs and the likelihood students would drop out of school.

There is considerable evidence to support the importance of student self-efficacy on academic achievement. Hattie (2008) identified factors affecting student achievement such as collective teacher efficacy with an effect size of 1.57 , self-reported grades at 1.33 , and prior ability at .94. Since that time, Hattie (2018) has updated these factors identifying student selfefficacy with a significant effect size of .92, making it one of the most influential factors on student success, with the "potential to considerably accelerate student achievement," (Hattie, 2018, p. 1). Denner, Valdes, Dickson, and Laursen (2019) found self-concept and interest significantly positively correlated in their study of Latino/a students participating in a middle school math program. These studies provide compelling evidence that when students believe in their abilities in a particular subject area, they are more interested in the subject, work harder, and are more successful in that subject.

Additionally, Bandura, Barbaranelli, Caprara, and Pastorelli (2001) identified that selfefficacy played a significant role in occupational decisions. The belief that individuals have in 
their own ability to complete educational requirements and perform the conditions of a given occupation contributes actively to the effort and perseverance they put into setting and achieving specific professional goals, as well as affects the variety of occupations they consider pursuing (Bandura et al., 2001). A study conducted by Bandura et al. (2001) discovered, closely correlated with their beliefs in their academic abilities rather than actual academic performance, was children's occupational self-efficacy, or their confidence in their ability to perform a specific occupation. Students with higher self-efficacy are more eager to participate in educational tasks, work harder, persevere, are more interested in learning, and experience greater overall academic achievement (Schunk \& DiBenedetto, 2016).

Both Bandura (1986a, 1993, 2001) and Pajares (1996; 2002b) are commonly cited in studies utilizing self-efficacy as a conceptual framework, many of which focused on technology and STEM subjects (Leonard, Mitchell, Barnes-Johnson, Unertl, Outka-Hill, Robinson, \& Hester-Croff, 2018). Pajares (1996; 2002b) based his self-efficacy work on Bandura's definition and focused specifically on self-efficacy in educational settings. Pajares' work further developed self-efficacy theory in educational settings into a framework of its own due to the unique personal and social determinants of behavior found in schools. Pajares conducted studies individually and with colleagues to determine the role of self-efficacy on student achievement in specific subjects, including writing (Pajares \& Johnson, 1994; Pajares, Johnson, \& Usher, 2003), mathematics (Pajares \& Miller, 1994), and foreign language reading (Mills, Pajares, \& Herron, 2006).

However, due to the confounded nature of behavioral constructs and the absence of a generally accepted tool for measuring self-efficacy, ascribing a causal relationship to any single self-regulation factor such as self-efficacy is inadvisable (Pajares, 1996; Usher \& Pajares, 2008). 
Known, nevertheless, are social factors influence an individual's affective state, or the willingness to engage in particular tasks. Affective states, in turn, influence self-efficacy and vice versa since, it is difficult to build self-efficacy in responsibilities in which one does not join (Bandura et al., 2003). Not surprisingly, people choose to participate in tasks when they feel confident in the activity and avoid tasks in which they lack confidence (Pajares, 1996). This behavior becomes evident in the relationship between self-efficacy, amount of effort given, number of strategies attempted, and perseverance individuals apply toward accomplishing a task (Pajares, 1996). Therefore, the theory suggests that belief in oneself has the potential to affect whether individuals will meet their academic goals. Many of Pajares' recommendations focused on offering suggestions for educational strategies to increase student self-efficacy in schools (Usher \& Pajares, 2008).

Additionally, Deemer and Sharma's (2018) study of adolescents participating in a six-day educational science program provided evidence that interventions with the express goal of increasing interest and self-efficacy in a particular skill or subject can have significant positive effects on both factors, even in a short amount of time. Conversely, Vongkulluksn, Matewos, Sinatra, and Marsh (2018) found inconclusive results regarding the effects of a semester-long maker space intervention on elementary student self-efficacy. They found while some students' interest and self-efficacy grew, the inquiry process frustrated others over a period.

In other studies focused on self-efficacy, Bandura (Bandura, Barbaranelli, Caprara, \& Pastorelli, 2001; Bussey \& Bandura, 1999; Caprara et al., 2008) and Pajares (Pajares, 2002; Zeldin \& Pajares, 2000), along with their colleagues, took note of gender differences in selfefficacy beliefs. Bussey and Bandura (1999) acknowledged clear gender differences in selfefficacy and in their analysis and discussed ways in which society places social sanctions on 
individuals who do not behave within acceptable social limits for their gender. These social rebukes later become enforced through self-sanctions, and tend to have stronger effects on behavior in girls than in boys (Bussey \& Bandura, 1999). Similarly, Usher and Pajares (2006) noted girls appeared to be more influenced by what they termed social persuasions, indicating girls may be more sensitive to taking the opinions of others into account while considering their beliefs in their abilities when compared to boys. Moreover, Usher and Pajares (2008) argued, "Girls' academic efficacy beliefs... may be more strongly informed by the messages they receive from significant others than by their actual academic accomplishments," (p. 779).

Pajares (2002a) noted gender differences in self-efficacy appear regularly in studies involving middle school students. Girls consistently reported higher levels of overall academic self-efficacy (Vantiegham, Vermeersch, \& Van Houtte, 2014). This information is in sharp contrast to studies examining specifically STEM subjects, in which girls reported lower selfefficacy (Pajares, 2002a). In their qualitative study of women in STEM careers, Zeldin and Pajares (2000) identified a significant other such as an influential family member or teacher in a majority of the participants' lives who contributed significant verbal and social encouragement that developed perseverance and resilience, strengthening self-efficacy and negating potential sources of self-doubt.

Socio-cognitive analyses of self-efficacy and achievement have provided ample evidence to acknowledge the existence of gender differences, but have failed to explain the causal factors behind them (Bandura \& Bussey, 1999). Both Bandura and Bussey (1999) and Pajares (2002a) have provided several potential factors, but none that satisfactorily account for consistently strong gender differences in self-efficacy when looking at particular educational subjects, thus leading to the inclusion of gender schema theory in this analysis. 


\section{Gender Schema Theory}

Gender schema theory helps explain the gender differences in self-efficacy and achievement in specific subject areas. Bem (1981a) acknowledged the connection between social learning theory and gender schema theory due to the powerful influence societal factors play in rewarding gender-appropriate behavior and penalizing gender-inappropriate behavior. Through these societal mechanisms, individuals create personal schema for how they think they should behave based on gender expectations and therefore become sex-typed (Bem, 1981a). Prior to Bem's development of gender schema theory, psychologists had not deeply considered the effects of social factors on gender development and their impact on behavior (Martin, Ruble, \& Szkrybalo, 2002).

Bem (1983) based her development of gender schema theory on both social learning theory and cognitive development theory. Through these theories, Bem (1983) further concluded children developmentally established a self-concept and a value system built on the premise of their gender identity (Martin, Ruble, \& Szkrybalo, 2008). Children begin to develop their gender identity at an early age, self-labeling themselves as either male or female and behaving according to their identified gender and their interpretation of said gender (Bussey \& Bandura, 1999).

In addition to developing a gender identity, children begin to exhibit gender segregation, in which they choose to interact more frequently with children who behave in similar ways to themselves (Martin, Fabes, Hanish, Leonard, \& Dinella, 2011). Through the development of gender schema theory, Bem identified that as a society, ideas of gender norms are "pervasively and gratuitously used in children's environments," (Liben \& Bigler, 2017, p. 545.). However, in their study of 3- to 6-year-old children, Carter, Levy, and Cappabianca (1985) found young children do not yet exhibit gender constancy, in which they demonstrate a preference for one 
gender type over another, indicating gender segregation is a phenomenon developed over time and could be avoided.

The dichotomous nature of gender-typing in modern society leads individuals to adhere to male or female behaviors, especially when they feel their gender schema may be threatened or questioned by society (Bem, 1981). Children develop these gender stereotypes and identities as young as six years of age (Master, Cheryan, Moscatelli, \& Meltzoff, 2017). Starr and Zurbriggen (2016) stated, "people become gendered from an early age and the impact of this gendering on their cognitive and categorical processing [is evident] throughout the lifetime," (p. 2). Therefore, gender schema theory suggests young children process all social experiences through the filter of their gender schema in order to understand situations and create meaningful constructs that serve to further their gender identity (Bem, 1983). This is especially true for females, as there is evidence that young girls are taught and come to believe at an early age that being skilled in femaleness restricts them from making impactful contributions to society, and rejecting their femaleness in favor of traditionally gender-inappropriate behaviors results in negative societal consequences (Morgan \& Ayim, 1984).

There is much research to suggest parental and societal gender beliefs have a significant impact on children's development of gender identity. Perry and Morgan (1993) found correlational relationships between mothers' gender schema beliefs, their daughters' beliefs about occupations, and their sons' choices of toys. Colaner and Rittenour (2015) found mothers' intentional efforts at encouraging their daughters to participate in both traditionally feminine and masculine behaviors had a significant positive impact on girls' self-efficacy and broadened their career aspirations. Pinto, Bigozzi, Vettori, and Vezzani (2018) provided evidence that the girls they studied showed a higher affinity for viewing learning as a social and cultural process than 
did the males, indicating that the gender schemas of female students are greatly impacted by familial and social factors.

Bem's ideas of gender schema were informed by previous research with her spouse. The Pennsylvania Department of Education asked the authors to research the societal impacts of the growing phenomenon of women in the workforce (Bem \& Bem, 1973). Their report, Training the Woman to Know Her Place: The Social Antecedents of Women in the World of Work (1973) discussed sex discrimination, social sex-role conditioning, and the ideas of family and career being incompatible in a woman. The results of this report have had far-reaching effects as they determined women work for the same reasons men do: self-fulfillment and economics; however, the jobs available to women were inferior to those available to men (Bem \& Bem, 1973). Beyond the obvious concerns of unequal pay differences and the lack of jobs available to women, they found overwhelming evidence that women were inexplicably choosing lowerpaying jobs and shying away from long-term, higher-paying careers (Bem \& Bem, 1973). These findings indicated other forces beyond discrimination and job availability affected women in the workforce.

Many other researchers used gender schema theory when analyzing the experiences of women and men in different careers. Woodington (2010) found women in the law profession are immediately considered less qualified than males by their male counterparts based solely on their femaleness. Lavallee and Pelletier (1992) utilized gender schema theory as they compared the gender schemas of women working in traditional and non-traditional occupational roles, finding that women working in non-traditional occupations exhibit a significantly higher masculine schema type. Additionally, in their study of female college major selection, Morgan, Gelbgiser, and Weeden (2013) found compelling evidence to suggest significant correlations between 
occupational decisions and what they termed the educational pipeline leading females into their chosen professions. This study identified gender differentiation and gender schema developed in adolescence as significant contributing factors in the future occupations of females (Morgan, Gelbgiser, \& Weeden, 2013).

Starr and Zurbriggen (2016) suggested two weaknesses of Bem's work. The first of these was her persistence in conducting research and developing gender schema theory in isolation as opposed to collaborating with colleagues. The second weakness was the fact many of the sample sizes used in her studies were quite small, making it impossible to generalize her findings to broader society confidently. As a result, gender schema theory did not initially receive the attention and development it deserved as "lofty theoretical and experimental work" with the potential for "far-reaching consequences for social change," (Morgan \& Ayim, 1984, p. 188). In defense of gender schema theory, Larsen and Seidman (1986) found the theory and Bem's measurement tool the Bem Sex Role Inventory (BSRI) to hold construct validity as a measurement of sex typing, however, very little further development of gender schema theory occurred in the years immediately following Bem's (1981) publication. Much of her research in gender schema theory has found its way into more recent studies as psychology research has recognized the powerful impact gender schema has on behavior (Keener \& Mehta, 2017).

Bem (1983) later clarified the theory, stating, "Gender schema theory assumes sex-typing is a learned phenomenon and hence, that it is neither inevitable nor unmodifiable," (p. 603). Rather, society continually draws attention to individuals behaving outside of gender norms by identifying their perceived "differentness" (Bem, 1981b). Bem called for a more "aschematic" society, one that is equal and accepting in its treatment of all individuals and their respective 
gender identities, (Bem, 1981, p. 363). Ringrose (2007) termed this philosophy as postfeminism, in that society will eventually reach a point where gender is a non-issue.

Gender schema theory is unique compared to other gender theories in that Bem suggested an individual has personal agency over whether to reinforce or reject a particular gender identity, as is the case when an individual chooses a career path that is considered more gender-typical of the opposite sex (Bem, 1983). Socially, this concept may have been ahead of its time as the focus of gender studies in psychology at the time of Bem's 1981 proposal. Therefore, the early development of the theory failed to capitalize on the less obvious influences of sex-typing such as those factors that may affect educational and career aspirations (Starr \& Zurbriggen, 2016). However, researchers currently are utilizing gender schema theory to study these areas.

Lemons and Parzinger's (2007) quantitative study of women's experiences in informational technology (IT) careers used gender schema theory as a theoretical framework for analysis. Not surprisingly, they found the ratio of men to women in IT careers vastly favored men. Also not surprisingly, of the women they surveyed, the women who worked in IT exhibited a significantly higher level of non-traditional gender schemas than those who were not in IT careers. One remarkable finding from the study was that the men they surveyed exhibited a significantly higher level of traditional gender schemas compared to those who were not in IT careers. This confirmed an earlier study that found men with highly masculine gender schemas have a tendency to expect conversely women to be highly feminine (Hudak, 1993). Lemons and Parzinger (2007) found 52\% of the women working in IT believed the gender stereotypes of their male coworkers to be the most influential factor inhibiting their careers.

Several recent studies on gender in STEM subjects provided relevant evidence to support continued research into gender schema theory. For example, Vantiegham and Van Houtte 
(2018) found gender conformity pressure might lead females to adapt to academic settings in certain subjects better than others might. Additionally, Sullivan and Bers (2012) found no significant difference between the computer programming abilities in kindergarten girls and boys participating in a robotics program. They later established in a follow-up study of students in grades kindergarten through second grade that the older primary students had begun to develop significant differences in their beliefs about gender-appropriate robotics tools (Sullivan \& Bers, 2016). Also discovered was a substantial decrease in female students' interest in computer programming as they got older (Witherspoon, Schunn, Higashi, \& Baehr, 2006). Coyle and Liben's (2016) study compared girls' gender differentiation before and after playing video games utilizing characters with varying degrees of feminine characteristics. They found girls with high levels of gender salience became more sex-typed through exposure to the characters, while girls with lower levels of gender salience saw no effect on their gender schema. Each of these studies leads to more questions about how gender schema affects decision making from childhood through adolescence and into adulthood.

Several studies point to potential future solutions to the issue of lower numbers of females in STEM professions. Xu and Li (2018) studied the impact of teacher gender on student performance. They found teacher gender had no impact on the academic performance of male students; however, there was a significant positive correlation between the academic performances of females when the teacher was also a female, especially in STEM subjects (Xu \& Li, 2018). Morgan, Gelbgiser, and Weeden (2013) suggested increasing opportunity for STEM engagement and a focus on career education. Agosto (2004) found girls' first experiences with computers were often negative, and recommended that educators and parents find ways to create positive first experiences in STEM. 
The phenomena of gender schema as it relates to females in STEM subjects needs to be further analyzed through the lens of gender studies to collect more insight specifically on the female experience in these areas (Hussenius, 2013). There is significant evidence that gender schema is an important factor in educational achievement in particular subjects, however, there is much to be discovered about how individuals use this information in practical decision making and how educators and parents can best support students in their gender development and career aspirations.

\section{Robotics Programs and Females in STEM}

Identified as an ideal site for this study due to their unique positioning at the convergence of middle school students and STEM were robotic programs. School-based competitive robotics programs were Robotics programs can provide a variety of social, personal, and academic benefits in even the youngest of students (Bers, Flannery, Kazakoff, \& Sullivan, 2014). Aguchi (2016) identified some of these benefits, including increased technological confidence, a better understanding of the relevance of science and technology concepts in solving real-world problems, and a more significant interest in pursuing a future career in technical, math, or science fields. Furthermore, identified were increased appreciation for teamwork, greater selfconfidence, an enhanced understanding of particular sciences such as physics, programming, mechanical engineering, electronics, and science, and greater communication skills.

Robotics programs have also been shown to improve team and personal development skills (Li, Huang, Jiang, \& Chang, 2016), problem solving skills (Mauch, 2001; Nugent, Barker, Grandgenett, \& Welch, 2016), cognitive and social skills (Ioannou \& Makridou, 2017), and promote higher levels of meaningful learning (Kaloti-Hallok, Armoni, \& Ben-Ami, 2015; Nugent, Barker, Grandgenett, \& Adamchuk, 2010). Students realized these potential benefits to 
a greater degree the longer they participated in a robotics program, and these skills have the potential to significantly increase students' overall academic ability in all subject areas, not only STEM (Nugent et al, 2010; Nugent et al., 2016). Additionally, Mosley, Ardito, Scollins, and Van Cortlandt (2016) found that while both problem based learning and robotics cooperative learning had significant positive impacts on overall learning in middle school students, robotics cooperative learning affected critical thinking skills to a greater degree.

Bers et al. (2014) found children as young as four years of age are capable of realizing social, personal, and academic benefits through structured robotics programs in schools. In their scholarly review of research regarding educational robotics with young children, Toh, Causo, Tzuo, Chen, and Yeo (2016) identified four areas in which positive evidence has been found to support the use of robotics as an educational tool for young children. These areas are an increase in problem solving and collaboration abilities, higher achievement scores in all subjects, language acquisition, and STEM participation (Toh et al., 2016). Jung and Won (2018) suggested a need to clarify robotics instruction for young children and acknowledge children's existing learning contexts in robotics education, and incorporate these contexts into robotics instruction. Of particular note, as identified by Flannery and Bers (2013), is a need for children's educational robotics to focus on production of robotics learning as opposed to consumption. The most effective student learning outcomes from robotics education came when students were in control of robot performance not only watching the robots perform pre-programmed actions (Flannery \& Bers, 2013).

In middle school, researchers noted concern with waning student interest in STEM subjects at a critical time of personal development (Bae \& DeBusk-Lane, 2019). Mosley et al. (2016) suggested utilizing robotics cooperative learning as a middle school intervention due to 
evidence that such experience can promote long-lasting student interest in STEM. Additionally, Hollman, Hollman, Shimerdla, Bice, and Adkins (2019) noted the lack of knowledge of STEM careers in the 645 students they surveyed. As middle school is often a time when students are considering future careers and taking steps to prepare for these careers, knowledge in potential STEM careers is paramount in ensuring these students are aware of STEM careers and the knowledge they will need in order to pursue them (Hollman et al., 2019). Burack, Melchior, and Hoover (2018) found evidence that students who participate in a school-based robotics program in middle school have an increased likelihood of choosing a career in STEM, especially those careers in an engineering or computer programming pathway. Blotnicky, Franz-Odendaal, French, and Joy (2018) similarly found that students who participate in a middle school robotics program gained increased knowledge of STEM careers and are more likely to choose STEM careers as adults.

In response to the need for workers, more schools are integrating STEM curricula into their educational offerings (Ntemngwa \& Oliver, 2018). In a study of students participating in a school-based robotics program, Williams, Igel, Poveda, Kapila, and Iskander (2012) found significant gains in student understanding of critical math and science concepts at the elementary, middle school, and high school level. Moreover, they recognized the opportunity these types of programs have in supporting the required curriculum and applying this knowledge in real world situations. Some studies, such as the one conducted by Veltman, Davidson, and Deyell (2012) found STEM knowledge and interest in both robotics and computer programming of male and female students of all ages rose significantly when participating in a school-based robotics program. Additionally, Bae and DeBusk-Lane (2019) found robotics programs have the potential to affect self-efficacy and engagement in science learning. Each of these factors has the 
ability to increase long-term STEM participation (Bae \& DeBusk-Lane, 2019; Veltman, Davidson, \& Deyell, 2012; Williams et al., 2012).

School-based robotics programs are a relatively recent phenomenon, with most programs added within the last 10-15 years (Bazylev, Margun, Zimenko, Kremlev, \& Rukujzha, 2014). The use of robotics programs in schools is continuing to increase, capitalizing on evidence that robotics programs have positive effects on student interest in STEM activities (Grubbs, 2013). These programs provide opportunities for schools to better prepare students for STEM careers (Afari \& Khine, 2017) and are aided by the availability and affordability of educational robots and programming software needed for students (Cristoforis, Pedre, Nitsche, Fischer, Pessacq, \& Di Pietro, 2013). Groome and Rodriguez (2014) analyzed after school robotics programs in New York City, noting that schools interested in implementing a school-based robotics program should plan for recruitment, training, site selection, mentors, and ongoing support in order to increase program success.

Much of the current research on robotics programs focused on the importance of professional development to prepare teachers to facilitate robotics programs and the concern for teaching STEM concepts to carry student interest into the future (Khanlari, 2013). When taught effectively, robotics is an ideal method for teaching science content knowledge in a rich context (Williams, Ma, Prejean, Ford, \& Lai, 2007). However, adults who are tasked with leading such programs often come with their own feelings of inadequacy related to their STEM abilities (Groome \& Rodriguez, 2014). A study by Rich, Jones, Belikov, Yoshikawa, and Perkins (2017) found long-term professional development for teachers in teaching computing and engineering had significant effects at increasing teacher efficacy, which translated into increased student learning for these concepts. 
Khanlari (2013) proposed robotics is "an effective tool to effectively prepare students for the 21 st century," (p. 26). Petre and Price's (2004) investigation of teams of students in robotics competitions found, in addition to a variety of other lessons learned through their participation, one team credited their participation in robotics with teaching them how "to think," (p. 152). While robotics programs have been repeatedly determined to have the potential to provide an effective doorway for students to develop the skills necessary for working in real-world settings (Yuen, Boecking, Tiger, Gomez, Guillen, Arreguin, \& Stone, 2014), more research specifically examining how to use robotics in teaching academic subjects most effectively needs to be conducted (Jung \& Won, 2018). Melchior, Hoover, and Burack (2018) corroborated evidence of the positive impact after-school robotics programs can have on STEM attitudes and engagement, noting that school-based robotics programs were particularly meaningful for female students. Additionally, Karp and Maloney's 2013 study of middle school students participating in a robotics program showed increased excitement and engagement in STEM subjects, especially in females and underrepresented groups.

Several studies focused specifically on gender differences in a variety of age groups participating in a school-based robotics program. Bae and DeBusk-Lane (2019) found no evidence that gender had any correlation to potential engagement or self-efficacy in science within the sample, indicating neither females nor males are more likely to participate in STEM activities based only on gender differences. Atmatzidou and Demetriadis (2016) also found girls and boys equally capable of learning high-level computational thinking skills through a schoolbased robotics program using LEGO Mindstorms software. Among the gender differences identified, the study found evidence that girls had a tendency to excel at written communication 
skills and needed more time than boys to learn computational thinking skills, which the researchers attributed to differences in learning modalities (Atmatzidou \& Demetriadis, 2016).

One study analyzed descriptive and qualitative data of participants in international robotics festival (Riedo, Friere, Fink, Ruiz, Fassa, \& Mondada, 2013). These findings indicated a significant negative correlation between female participation and age (Riedo et al., 2013). In another study, Liu (2010) found that early adolescent girls had a greater tendency to view educational robots as toys, whereas boys more frequently viewed them as an avenue into future employment. Veltman, Davidson, and Deyell (2012) found that interventions aimed at increasing female student participation in robotics programs at the middle school and high school levels were effective at increasing self-efficacy, positive attitudes, and STEM career consideration for both female and male students. The strategies used in this study included creating mostly female teams, having female students participate in both computer programming and robot engineering, and employing female mentors (Veltman, Davidson, \& Deyell, 2012).

Focused on negative perceptions of adults currently working in a career or careerreadiness programs is the current academic discussion of females in STEM career fields (Lemons \& Parzinger, 2007). It is not a far leap from robotics programs in secondary schools to postsecondary and career fields they have the potential to impact. Some researchers, such as Kucuk and Sisman (2017), go so far as to suggest it is the female students themselves who are less motivated and need more help in acquiring the necessary skills in STEM subjects, while other researchers, such as Sullivan and Bers (2016) found no such innate gender differences. On the contrary, Witherspoon et al. (2016) showed "gender differences are socially and culturally constructed," (p. 1). Perceptions of gender bias in robotics skills must be overcome (Alimissis \& Moro, 2016) with an educational system working to create an environment that ensures female 
students can thrive in STEM subjects (Fluck, Webb, Cox, Angeli, Malyn-Smith, Voogt, \& Zagami, 2016).

With current educational trends pushing for greater inclusion of computers and STEM subjects, educators must not fall victim to what Papert (1987) called "technocentric thinking," in which the focus is more on the technology itself and not enough on the students and teachers involved in its educational delivery. Furthermore, Papert (1987) emphasized the fact that no educational tool, whether robotics, computers or something else, can be removed from social structures. Other researchers echoed this concern and warned educators to be aware of robotics programs only being used to further robotics-specific skills when there is significant research suggesting robotics programs can have substantial benefits outside of building and programming robots (Barreto \& Benitti, 2012; Spoloar \& Benitti, 2017). It is clear robotics programs have the potential to significantly impact the educational pipeline into STEM careers (Burack, Melchior, \& Hoover, 2018; Morgan, Gelbgiser, \& Weeden, 2013), especially for female students (Karp \& Maloney, 2013; Melchior, Burack, \& Hoover, 2018).

\section{Summary}

The connections provided in this scholarly review of literature utilized currently available research on social cognitive theory, self-efficacy theory of education, gender schema theory, robotics programs, and females in STEM subjects. A better understanding of the interplay between gender schema and academic self-efficacy in middle school female students is necessary to attempt to address the issue of low numbers of females in much-needed STEM career fields. Through a closer qualitative analysis of female middle school females' experiences in robotics program, it is hoped this deeper understanding has the potential to lead to improved STEM 
programs that work to guide all students, particularly female students, from STEM subjects in secondary school into STEM careers to fill this continually growing need for skilled employees. Sections four and five of this dissertation proposal will include a plan for disseminating the results of this research to other practitioners. Presented in section four will be the results of this study, along with recommendations. Section five will be a condensed version of the results and will be targeted for publication in an educational journal and section six will be the authors' reflection. 


\section{SECTION FOUR}

CONTRIBUTION TO PRACTICE 


\section{Introduction}

There is a widespread need for skilled workers in the Science, Technology, Engineering, and Math (STEM) (Jung \& Won, 2018; Kandlhofer \& Steinbauer, 2016). Concurrently, the United States is experiencing a shortage of adults and students entering these career fields as compared to other countries, resulting in educators and those working in these fields being concern regarding the economic impact of this shortage (Kandlhofer \& Steinbauer, 2016).

Significantly underrepresented in STEM subject and careers are female students (Zeldin \& Pajares, 2000). However, shown to provide engaging exposure to STEM subjects at an early age are robotic programs (Ospennikova, Ershov, \& Iljin, 2015). Furthermore, robotics is an area where STEM and female students can come together at an impactful age and perhaps make a difference in female engagement. While there are many studies identifying the benefits of robotics programs and their ability to increase students' academic ability in STEM fields (Eguchi, 2016), females are not experiencing these benefits to the same degree as males (Kucuk \& Sisman, 2017).

This investigation attempted to advance qualitative data regarding the personal and societal factors affecting female students currently involved in school-based robotics programs. Outlined within this section are the studied problem, the purpose of the study, and the research questions answered. Also discussed within the theoretical frameworks of social cognitive theory, self-efficacy theory of education, and gender schema theory will be the findings. Followed by conclusions, and implications. The executive summary will end this section.

\section{Problem of Practice}

The problem in this study was the global underrepresentation of females in STEM subjects and careers. There are many factors contributing to this overall shortage (Fluck, Webb, 
Cox, Angeli, Malyn-Smith, Voogt, \& Zagami, 2016), and experts believe STEM fields will remain an area of concentrated career need in the near future (Lemons \& Parzinger, 2007). When the workforce cannot keep up with societal needs in a particular field, potential careers and advancements are lost. These losses indicated this is a problem worthy of attention. In addition to the overall shortage, this shortage reflects an under-representation of female students and workers compared to males in the same areas (Heybach \& Pickup, 2017; Lemons \& Parzinger, 2007; Witherspoon, Schunn, Higashi, \& Baehr, 2016). There are also indications that female interest level in STEM drops significantly before adulthood, leading to fewer females than males entering post-secondary STEM programs and careers (Grubbs, 2013; Zeldin \& Pajares, 2000). Therefore, it is reasonable to assume that this is at the very least a contributing factor in the global shortage of individuals entering careers in these areas.

It is imperative for researchers and educators to gain a deeper understanding of the experiences of female students as they relate to STEM subjects in order to begin to comprehend the causes behind their underrepresentation in STEM fields. This lack of understanding results in the absence of meaningful action with the express purpose of eliminating the unequal ratio of males to females in these subjects and careers. Heybach and Pickup (2017) pointed out this underrepresentation of females in STEM results in stagnation in the growth of knowledge in STEM areas as the voice of this part of the population is largely absent across these career fields. The question of what advances could have already been achieved with the input and participation of a significant portion of the population should be of concern to all educators, parents, and members of society. 


\section{Purpose of the Study}

The purpose of this study was to examine closely the experiences of twelve female middle school students participating in school-based robotics programs in order to gain a deeper understanding of the connection between their gender beliefs and academic self-efficacy as it relates to STEM subjects, ultimately leading to their decisions to remain in STEM fields or pursue other career paths. An understanding of the personal and social factors affecting middle school females and limiting the number of females choosing to remain in STEM fields from

early secondary education to career was gained from this investigation. Through the gathering of data, identifying patterns, and discerning direction interventions can be identified and implemented and more research can be conducted that will allow for potential solutions to this problem.

\section{Research Questions}

The study focused on a narrow scope of research questions, consisting of one primary research question and three secondary research questions. These research questions were addressed through a variety of qualitative data collection methods including observations of robotics practices, focus groups with coaches of robotics teams, and interviews of female students who participated in a middle school robotics program for a significant length of time. The primary research question guiding this study was:

How does participating in school-based robotics programs affect the learning and academic self-efficacy of female students?

The secondary research questions were:

Why do female students choose to participate in a robotics program? 
How do female students' perceptions of STEM fields change over time after participating in a robotics program?

How does participation in a robotics program affect female students' career aspirations?

\section{Conceptual/Theoretical Frameworks}

Discussed are the conceptual framework of Social Cognitive Theory and the theoretical frameworks of Self-Efficacy Theory of Education and Gender Schema Theory as they guided the analysis of the data. Also presented are the contextual framework of robotics programs and females in STEM as they pertain to the analysis of female middle school students in robotics programs.

\section{Social Cognitive Theory}

Bandura's (1977) book, Social Learning Theory, introduced his theory of human behavior and the perspective that both internal personal factors and external societal factors affect the behavior of individuals. Based on the interconnected network of socioeconomic, familial, and relationships and their effect on human social functioning is this theory (Bandura, Barbaranelli, Caprara, \& Pastorelli, 1996). The literature review made clear the impact both personal self-efficacy beliefs and social influences can potentially have on the behavior of female students, therefore, social cognitive theory was chosen as a theoretical framework to guide this study.

The work of Bandura and others developing social cognitive theory suggested that human behavior is the output of a complex system of thought and action within individuals (Bandura, 2002; Caprara, Fida, Vecchione, Del Bove, Vecchi, Barbaranelli, \& Bandura, 2008). Through this work, two paths of understanding emerged. The first focused on the individual and selfdirected thoughts leading to a chosen action. The second path suggested focused on society and 
its effects on the individual (Bandura, 2001). Therefore, a dual research approach including both personal and social factors was appropriate when seeking to understand individuals' decisionmaking processes. Suggested from Bandura's work and the two research paths it identified, the conceptual frameworks for self-efficacy theory of education and gender schema theory guided this study.

\section{Self-Efficacy Theory of Education}

Self-efficacy has produced a unique impact in educational settings as it relates to student behavior (Bandura et al, 1996; Mills, Pajares, \& Herron, 2006; Pajares, 1996), and self-efficacy is the most powerful factor influencing an individual's personal achievement (Bandura 2001; Bandura et al., 1996) as identified by research. Because of this analysis, self-efficacy theory of education became the first conceptual framework through which to understand this study. Several other researchers observed and supported Bandura's assertion that self-efficacy is a significant factor contributing to student success (Bandura et al., 2001; Caprara et al., 2008; Hattie, 2008; Usher \& Pajares, 2008)

In relation to females in STEM subjects and careers, Bandura, Barbaranelli, Caprara, and Pastorelli (2001) found self-efficacy also played a significant role in the career choices of individuals, regardless of gender. Higher self-efficacy in educational tasks translates into greater perseverance, interest, and academic achievement (Schunk \& DiBenedetto, 2016). The observed effects of self-efficacy on academic performance carry into STEM subjects as well (Leonard, Mitchell, Barnes-Johnson, Unertl, Outka-Hill, Robinson, \& Hester-Croff, 2018). Significant gender differences in self-efficacy beliefs were also noted in a 1999 study by Bussey and Bandura, who further suggested society confers judgment on those whose behavior is deemed socially unacceptable and enforces social punishments and are seen more strongly in girls than in 
boys (Bussey \& Bandura, 1999). Later confirmed by Usher and Pajares (2008) was this concept and was developed further through the second conceptual framework, gender schema theory in this inquiry.

\section{Gender Schema Theory}

The societal influences suggested by Bandura's (1986) social cognitive theory as they apply to female students can be understood through the conceptual framework of Bem's (1981a) gender schema theory. This theory helps explain some of the impact gender socialization has on the behavior of individuals in a gender dichotomous society without implying intentional othering or ostracization. Gender schema theory proposed society instructs children on what behaviors are considered socially acceptable. Family, friends, communities, and media throughout the impressionable formative years of development (Bem, 1981a) accomplish this through repeated exposure to socially acceptable gender behavior.

Bem (1983) suggested gender identities provide a filter through which individuals understand situations and constructs, however, individuals have the ability to choose whether to accept or reject a gender schema and allow it to dictate their behavior. Evidenced in the participants of Lemons and Parzinger's (2007) study of women in informational technology (IT) careers were these behaviors. The women in this study exhibited a significantly higher level of non-traditional gender schemas than women who were not in IT (Lemons \& Parzinger, 2007).

Other recent studies also utilized gender schema theory when analyzing the experiences of women and men in different careers. These studies suggest women are often considered less qualified by their male counterparts based solely on their femaleness (Lavallee \& Pelletier, 1992; Woodington, 2010). Others found compelling evidence to suggest significant correlations between occupational decisions and the educational pipeline leading females into their chosen 
professions (Morgan, Gelbgiser, \& Weeden, 2013). Gender schema theory helps understand some of these results and the impact gender schema can have on female behavior throughout development.

\section{Robotics Programs and Females in STEM}

In addition to self-efficacy theory of education and gender schema theory, the chosen site of middle school robotics programs was identified as an additional conceptual framework for the purposes of this study. Middle school robotics programs have the unique perspective of bringing STEM subjects and females together into one social phenomenon, making it an ideal locus for this study (Benitti, 2012; Sniderman, 2014).

\section{Methods}

Used in this qualitative study were the data collection methods of observations of practices, focus groups with robotics coaches, and interviews with current and former robotics students. A multiple case study method allowed for the collection of narrative and personal responses to questions through observations, interviews, and focus groups (Creswell, 2014; Merriam \& Tisdell, 2016; Seidman, 2013). After a thorough literature review, significant gaps indicated the need for qualitative research. A multiple case study approach allowed the researcher to gain insight into bounded systems of school-based robotics programs with little impact on the normal current and future functioning of the participants and programs (Merriam \& Tisdell, 2016). By clarifying elements such as place, context and culture, the researcher was able to provide a "thick description" which assisted in providing detail to the phenomena being addressed (Merriam \& Tisdell, 2016). 


\section{Study Setting}

The setting of this study included six middle school robotics programs across the state of Missouri. For the sake of continuity and reliability in comparison, included were six sites participating in the FIRST LEGO League (FLL) program. The researcher chose schools based on a myriad of requirements ranging from having an established robotic program to engaging for at least three years in FIRST LEGO League tournaments

Using the criteria listed above, the researcher identified a number of potential sites. Further narrowing of settings for the study occurred by ensuring a variety of settings in rural $(n=2)$, suburban $(n=2)$, and urban $(n=2)$ school communities, terms defined according to data from World Population Review (2020). A variety of settings allowed the researcher to gain a more complete picture of robotics programs in Missouri and what Merriam and Tisdell (2016) term "maximum variation" (p. 98).

\section{Participants}

Two female students participated at each site of a selected school-based robotics program for a total of twelve individual interviews. Each of these students participated in a FIRST LEGO League program for at least one year and ranged between the ages of 12 and 19. When possible, made were efforts to ensure one of these students planned to continue participating in robotics and the other was a student who planned to end their involvement with the program, although not all students were decided on their future participation plans.

In addition to student interviews, conducted were focus groups made up of coaches from each site in order to gain qualitative data on the experiences of females within their program from the coach perspective. All of the coaches were currently involved with a FIRST LEGO League team or had been within the last year. Depending on the availability of coaches, the 
focus groups consisted of two to three coaches each, with the exception of Site 6. The school employed two coaches, but one had resigned and did not wish to participate in this study, so only one coach was interviewed. One focus group was conducted at each setting ( $n=6$ focus groups, with 13 participants total). The student participants chosen by the head coaches were the only individuals the researcher had access to, per IRB requirements (see Appendix A).

\section{Data Collection Tools}

The qualitative data collection tools used for this study were observations, interviews, and focus groups. The original plan was to conduct observations wherein the researcher observes a robotics practice or meeting and takes field notes on the observation form (see Appendix B) regarding the behaviors and interactions of the participants (Creswell, 2014). Unfortunately, due to the onset of the COVID-19 pandemic and subsequent school shutdown as a safety precaution, only two sites were able to participate in observations. This was deemed minimally impactful to the study by the researcher, as the purpose of the observations was only to gain contextual information.

Due to the COVID-19 school shutdown, five out of the six focus groups were conducted virtually via Zoom video conferencing. The Coaches Focus Group Protocol (see Appendix C) details the list of questions asked during the focus groups at each site. Focus groups were audio recorded through digital means with appropriate permissions given.

Finally, the researcher conducted interviews with female participants within the robotics programs. Due to having the resources for one formal interview per participant, the researcher used the semi-structured interview format discussed by Merriam and Tisdell (2016). This format required the researcher to have a predetermined list of questions or interview protocol (see Appendix D) for the interviewee to answer, but allowed the researcher to ask follow up questions 
based off of the interviewee's responses in order to gain clarification or more information in regard to the research questions. Because of the COVID-19 school shutdown and subsequent cancellation of the fall FLL robotics season, ten out of the twelve interviews were conducted virtually via Zoom video conferencing. Interviews were audio recorded through digital means with appropriate permissions given.

\section{Results and Discussion}

Presented in the following section are the results of analyzing data from interviews and focus groups and includes a discussion of how these results answer the intended research questions and relate to the conceptual and theoretical frameworks.

\section{Data Analysis}

Interviews and focus group sessions were typed and full transcripts reviewed by the researcher alone to ensure confidentiality. Coding took place across all the qualitative data to search for themes. The first level of coding to be used was open coding. Through this process, the codes of coaching, influence, impact, and student descriptors were identified. Once open coding was completed on all the interviews and focus groups, the researcher conducted axial coding, in which the researcher searched for recurrent ideas within the data of each theme (Merriam \& Tisdell, 2016). Each theme and code were color coded for maximum visual representation of the data. The identified codes and their corresponding themes were:

1. Influence: Positive and Negative

2. Coaching: Strategies and Recruitment

3. Impact: Skills, Long Term, Careers, and Post-Secondary

4. Student Descriptors: General, Male, Female, and Male-Female Percentage 


\section{Demographics of the Coaches and Students}

Thirteen coaches participated in focus groups for this study (see Table One). Their experience in education ranged from parent volunteer to 27 years, with a mean of just over 10 years. Seven of the coaches are currently elementary teachers in some capacity, and the rest are secondary teachers or hold leadership positions in their district robotics program. FIRST LEGO League coaching ranged from one year to eight years, with six of the coaches having one or two years coaching experience. Four of the coaches hold advanced degrees in a STEM related field. Table 1 Participants from Coaches Focus Group

\begin{tabular}{|c|c|c|c|}
\hline Participant & Role in District & $\begin{array}{c}\text { Years in } \\
\text { Education }\end{array}$ & Years Coaching \\
\hline Site 1, C1 & Librarian & 16 & 2 \\
\hline Site 1, C2 & Elementary Teacher & 4 & 2 \\
\hline Site 2, C1 & Robotics Teacher & 5 & 2 \\
\hline Site 2, C2 & Librarian & 27 & 4 \\
\hline Site 2, C3 & FIRST Coordinator & 10 & 3 \\
\hline Site 3, C1 & Elementary Teacher & 4 & 1 \\
\hline Site 3, C2 & Elementary Teacher & 8 & 8 \\
\hline Site 3, C3 & Elementary Teacher & 1 & 1 \\
\hline Site 4, C1 & Middle School Math Teacher & 17 & 7 \\
\hline Site 4, C2 & Parent Volunteer & N/A & 5 \\
\hline Site 5, C1 & Middle School PLTW Teacher & 10 & 8 \\
\hline Site 5, C2 & Middle School PLTW Teacher & 9 & 22 \\
\hline Site 6, C1 & Middle School Guidance Counselor & & \\
\hline
\end{tabular}

Note: $\mathrm{n}=13$ participants 
Revealed within these findings, the adult participants held a variety of roles within their own district. There were four elementary teachers, three middle school teachers, two librarians, a counselor, a parent, a coordinator, and a robotic teacher. Their range of experience in education ranges from one year to twenty-seven years, with the majority with less than ten years. The years of the coaches working within the robotic program again varied with the range from one year to eight years.

Twelve students participated in interviews for this study (see Table 2). Their experience in FIRST LEGO League ranged from one year to four years; although five of them went on to participate in FIRST Tech Challenge (FTC) or FIRST Robotics Competition (FRC) at the high school level. The students ranged in age from 12 to 19 . Whether or not each student planned to continue participating in robotics was indicated. 
Table 2 Student Participants from each site

\begin{tabular}{|c|c|c|c|}
\hline Participant & Age & Years in Robotics & Continued Robotics? \\
\hline Site 1, SA & 12 & 2 & Unsure \\
\hline Site 1, SB & 12 & 4 & Yes \\
\hline Site 2, SA & 13 & 1 & Yes \\
\hline Site 2, SB & 13 & 1 & Yes \\
\hline Site 3, SA & 12 & 2 & No \\
\hline Site 3, SB & 13 & 3 & No \\
\hline Site 4, SA & 14 & 3 & Unsure \\
\hline Site 4, SB & 14 & 4 & Yes \\
\hline Site 5, SA & 19 & 8 & Yes \\
\hline Site 5, SB & 14 & 3 & No \\
\hline Site 6, SA & 15 & 4 & No \\
\hline Site 6, SB & 14 & 4 & \\
\hline
\end{tabular}

Note: $\mathrm{n}=12$ participants

\section{Presentation of Findings}

Following will be the findings of this inquiry framed within the codes and themes. The identified codes and their corresponding themes were:

1. Influence: Positive and Negative

2. Coaching: Strategies and Recruitment

3. Impact: Skills, Long Term, Careers, and Post-Secondary

4. Student Descriptors: General, Male, Female, and Male-Female Percentage 


\section{Influences: Positive and Negative}

Contributing factors in the decision to either remain in robotics or leave the program were identified within the category of influence. Labeled as positive were descriptors, individuals, or events that guided or encouraged students toward a decision to join or remain in robotics. Labeled as negative were factors that were not enjoyed or pushed students to consider leaving robotics. Of these, the coaches noted 166 positive influences and 43 negative influences, and the students noted 258 positive influences and 94 negative influences, which indicated the positive factors outweighed the negative by a significant number. Positive factors represented $75 \%$ of the responses in the influence category.

Notable positive influences included a variety of individuals who provided support for the female students in robotics. Some of the individuals mentioned were coaches, parents, teachers, and friends. The most often mentioned people were friends, especially those who were also in the robotics program. One student called it "a large support group." Another student compared her team to a family. The word "fun" was used 54 times across the interviews and focus groups. Many students expressed surprise at how much they enjoyed the robotics program, with one saying, "I found out that I actually liked the whole idea of programming something and seeing your program work."

Of the negative responses, stress, frustration, and difficulty were the most frequently mentioned factors by both students and coaches. The most influential factors resulting in students leaving the robotics program according to this study were the desire to participate in other activities and limited time to do so. One student said, "I really wanted to focus on, like my different sports and stuff like basketball and softball." Another said, "I wouldn't be opposed to doing robotics again, but I joined the volleyball team, and that takes up more of my time because 
that's an everyday thing and I don't want to miss two practices a week for LEGO League robotics." Another said, "If I don't get really busy, I probably will continue it." One student wisely remarked, 'If you don't have someone, you know, kind of like watching and making sure that you're not, you know, balancing your time well, it's very easy for it to start impacting other parts of your life quite negatively."

The data from both the coaches and the students emphasized the need for a myriad of positive ways that students view the robotic program and the time needed to be involved. The data also revealed that understanding both the negative and positive influences on students is a valuable tool to have when sustaining student engagement.

\section{Coaching: Strategies and Recruitment}

The coaches had significantly more to contribute to the conversation in this area, as more of the focus group questions focused on this aspect, however, several of the female students mentioned coaching strategies and recruitment within their interviews. For the most part, coaching strategies aligned with the idea of the coach as facilitator. Coaches mentioned specific activities like creating agendas, setting goals, keeping students on task, and putting new or weaker students with stronger or more experienced students or buddies. The students referred to their coach's activities as encouraging, teaching, mentoring, and other descriptors that created a picture of the coach as facilitator at each school.

Interestingly, all of the coach's focus groups felt their coaching process and strategies were identical whether the student or students needing help were male or female. When a team or student struggled, each of the focus groups described a process of pulling the student, group, or team aside and having a discussion about the problem at hand and how best to solve it. All of 
the students had positive things to say about their past and present coaches. None of the students specifically mentioned any differences with how they were treated by coaches.

On the recruitment side, schools varied in how they attracted new students. One school in which the robotics program is in very high demand, a lottery system was used. Students who scored in the proficient and advanced ranges on the iReady standardized assessment were entered into a lottery and those students selected were given the opportunity to participate. Another school had a similarly high number of interested students who completed an application and interview process in which chosen were only $10 \%$ of the students. Most of the schools implemented a tryout process where students had to attend a tryout, and numbers were somewhat limited, but most students who wanted to participate were able to do so. One school that has invested significant resources into their robotics program shared they have an over $50 \%$ participation rate in FIRST LEGO League robotics across the entire student population. Some schools also utilized a robotics enrichment class at the middle school level to expose more students to robotics. Overwhelmingly, coaches and students stated that the highest success rate for recruitment strategies was when a student had either a friend already in the program or made friends with students in the program.

\section{Impact: Skills, Long Term, Careers, and Post-Secondary}

Skills included general skills that were practiced or learned throughout the program. Long term referred to behaviors or skills that had a lasting effect. Careers related to discussions referencing future career options or choices, and post-secondary described any impact that was expected or occurred after high school. 


\section{Skills}

Both students and coaches mentioned a significant number of skills practiced and gained within the robotics program. The most frequently mentioned skill in interviews and focus groups was that of teamwork. Students and coaches described teamwork in a variety of ways, including work together, talk to people, collaboration, work with people, share ideas, respect others' ideas, stick together, don't exclude others, get along, come together, and cooperation. It was clear that teamwork is a large part of any successful robotics program.

Many of the skills mentioned by students revolved around accomplishing the three main tasks in FIRST LEGO League: building robots out of LEGOs, programming said robots to perform missions, and giving presentations on real-world research problems. Along these lines, students mentioned different variations of programming, building, research, and presentations or skits in all of the interviews. In addition to these FIRST-specific skills, many coaches and students brought up and/or discussed FIRST's core values. These are the central components of what FIRST believes students should gain from participating in their program, and include discovery, innovation, impact, inclusion, teamwork, and fun.

Many students discussed the communication skills they gained from participating in robotics. As one student stated,

Being in an activity like robotics, it kind of forces you to communicate with people you know. Because, like, you'll have this idea in your head, and you have to, you know, figure out a way to get this idea that's in your head that you understand completely, but no one else knows about, and you have to figure out a way to communicate it from you to everyone else so they understand it just as well as you." 
Other students also noted that they worked harder on talking to their team members about how to get their ideas so others understood what was needed. Almost all of the students said communication was a skill that was important. While one coach related a story about a former student who was able to earn a scholarship to a prestigious college, and attributed it directly to the skills she gained in public speaking while participating in robotics.

\section{Long Term}

This category aligned closely to the skills category, but there is some overlap with the data in each of these groups, as discerning whether the impact of a skill was long term or remained in the skills category was largely dependent on the context in which it was described. Long Term for the purposes of this analysis was defined as those skills and behaviors that students and coaches described as having a broader impact on a student's life and had greater significance to the student or included skills that were applied in areas outside of robotics or discussing robotics. As one student described her robotics experience, "It definitely helps in real life."

Students and coaches mentioned the long-term impact robotics participation had on students' academic abilities, especially in math, science, and presentation skills. Participants described other powerful long-term impacts related to school and life performance in general and the ability to navigate life's challenges. These long-term impacts included perseverance, a shift in thinking, willingness to take risks, not being afraid of something new, dealing with adversity and the awareness that learning continues into adulthood.

Confidence was mentioned as a long-term impact 13 times across the student interviews and coaches focus groups. Some attributed this to finding like-minded individuals within the robotics program, and these personal connections allowed students to build confidence in who 
they are as people and students. One female participant said, "You can't just be silent all the time, you have to actually be a part of the team." Another student said, "It got me out of my zone." Additionally, one coach described a student he had and how she was able to come out of her shell. He attributed this to her participating in robotics, saying she now "turns it off and on as needed."

Leadership is another long-term impact that described frequently in interviews with coaches and students. Additionally, students and coaches described the broader perspective and increased awareness of their potential impact on the world and their responsibility to a higher purpose as they grow. One student stated, "I used to think I did not like the project at all, but without it, it feels like you're not doing as much as you should be doing." One coach made the prediction that her robotics students would "rule the world one day." Another praised the program's ability to encourage students to "take that purpose beyond just this room."

\section{Careers}

Students and coaches mentioned a variety of career possibilities in interviews and focus groups. Both groups agreed that the skills and attitudes learned through robotics would help students in whatever careers they chose. Coaches discussed the careers they predicted their students would enter, and students shared the careers they planned or considered entering. As the interviews progressed, both students and coaches mentioned different careers in response to other questions. None of the coaches discussed having specific plans to have career-related discussions in practices, but career discussions arose naturally, as they applied to different robotics activities. STEM careers were the most frequently mentioned by both students and coaches, with engineering as the most frequently identified career field. Four of the 12 students 
interviewed mentioned seriously considering careers in engineering and believed robotics to be a determining factor in that decision.

The students mentioned other potential careers, including therapist or psychologist, nurse, teacher, doctor, actress, photographer, rancher, veterinarian, scientist, and working with computers. Aside from engineering, coaches predicted their robotics students would enter a variety of STEM career fields, including science, technology, and math, as well as marketing, education, public speaking, law, architecture, computer programming, videography, nursing, and politics. While one focus group mentioned they might see their students enter vocational and technical careers, the majority predicted that robotics students would enter careers requiring college degrees, and agreed these would most likely be four-year college degrees. One coach stated he believed that his students would become "anything and everything" and "stuff that's not even created yet."

\section{Post-Secondary}

The coaches' focus groups agreed that participating in a robotics program significantly helps students with achieving whatever post-secondary goals they may have, whether those goals include college, career, or both. Coaches shared stories of past students who earned college acceptance, scholarships, stipends, and two-year, four-year, and technical degrees and directly attributed these achievements to the students' participating in their robotics programs. For the most part, the students did not mention post-secondary impacts from their robotics experience except for two students from the same urban school. One mentioned wanting to be selected for a NASA internship in the future, and the other was pursuing a degree in electrical engineering. Both students credit robotics with giving them the opportunity to follow these post-secondary goals and the confidence to make them a reality in their lives. 


\section{Student Descriptors}

The theme of student descriptors applied any time coaches and students described students or themselves in specific characteristics, traits, or behaviors. Further categorization of the theme resulted in the codes of general, male, female, and male-female percentage. The majority of observations regarding specific gender-related behavior fell into this theme.

\section{General}

The general category included descriptions of students in general and some overall observations of both male and female students. One coach said in reference to trying different tasks and jobs within the team, "Students really like to, whether it's boy or girl, try to pigeonhole themselves into I like this, and they determine in their minds what they think they're going to like and they become very closed off." The same focus group also indicated students cared more about connecting with the coach of the team and less about worrying if they can do robotics or not when deciding to join.

Several focus groups noted the similarities between male and female students. One coach said, "Females and males both kind of show their emotions too, especially at this age." Another said of all students, "They want it to be done, and they want it done right." Another coach added, "They all have the desire to be there," and the focus group described their students as stronger and self-motivated than other students. None of the focus groups indicated any strong differences between male and female students in general, but one noted, "Guys are pushed into certain fields and girls aren't." When probed the coach said guys were in science and engineering classes perhaps more than the girls.

The students described robotics, STEM, and its stereotype as a male-dominated field. One student said, "I thought it was more of a boy thing, but then when I tried it, I thought that it 
was also a boy and girl thing because girls don't really do robotics things." Another student declared, "I know that there's no discrimination where I am. So, we were treated the same as boys." Most students indicated that participation is the same for male and female students, with one student stating, "It's an equal playing field. Everyone has the same opportunities and the same challenges and we all have to work together as equals, not as different people."

In addition to discussing the male-female stereotype, students also mentioned other stereotypes that arise in relation to robotics participation. One mentioned, "People think that robotics is for people who only, like are really smart, but you don't have to be really smart to be able to do it." Another student described the engineering field specifically, "There's like the stereotype in engineering that people aren't that great at communication." The same student also added,

You do meet a lot people you know who are very smart, they're very good, but they just kind of are those people that they take those, they take their classes, and they never really have to like, you know, fill that communication side of things because they weren't ever like really in clubs.

\section{Male}

The majority of students interviewed did not describe male students in any certain terms. The only student who discussed male students described how boys liked to play with LEGOs and could help with building because they played with LEGOs more. One focus group echoed these ideas, sharing their observations that boys are always building, they tinker, and build nonsense, ridiculous things.

Four of the focus groups noted that their male students are the ones who are more likely to take on the programming and coding responsibilities for the team, although that was not a 
consistent observation across all the schools. Coaches also described their male students as less focused, more easily distracted, procrastinate more, have less perseverance, more likely to play around and not take practice seriously, and more likely to flout rules in comparison to females. Coaches were also quick to note that these were observations that did not apply to all male students, but were commonalities that they observed during the course of their time as coaches.

\section{Female}

Both students and coaches shared descriptions of female students. Coaches described their female students in stereotypically negative terms such as bossy, chatty, and nitpicky. However, they overwhelmingly described females in positive terms such as very accepting, more on track, more focused, super driven, creative, organized, on time, supportive, competitive in a friendly way, taking more initiative, and more goal oriented in comparison to male students. Two of the focus groups described females as falling into one of two categories. They saw their females as either completely dedicated to their team, leading, and keeping everyone on track, or they stand back, do nothing, and only do what they are told. A few of the students participated in robotics on all-girls teams and felt that experience was encouraging and built confidence.

Several focus groups mentioned that the female students seemed to behave as if they had something to prove. The students supported this idea through their interviews. One student noted, "A lot of people don't expect the girls to be in robotics. They think it's for boys, which is kind of annoying, but it's also, at the same time, nice because then you can show them that girls can do it." Another student said, "Girls are like, smart and they can help do the programming. We could help them [the boys] with the programming." One coach related what he felt was a pivotal event that he observed on his high school team with one of the interviewed students. He shared, 
And what really changed for the whole program, and I'm not trying to just toot her horn, but [student name] got in there, and one of the boys, I watched it happen in front of me, tried to take a screwdriver out of her hand to say, here, let me do it. And she said, 'No, I'm fine. I can do it.' And she pushed him out of the way. And that was her sophomore year of high school. And from them on, she took over the electrical team, and it was hers until she was a senior and in charge of the whole team.

Students described other specific instances in which they felt discouraged by male students. One student related, "The boys would tell some of the girls they couldn't do it because they were girls." Another stated that most people are supportive of girls in STEM and robotics, but some of her experiences in college highlighted the stigma that is commonly associated with females in STEM. For example, she stated, "I was in a class today. There was maybe 70 of us. There was me and one other female in the class." She also described that males often assume females are treated better or are given opportunities they didn't deserve just because of their gender, sharing,

For example, when I had my internship my freshman year, I was excited, I told my friends about it because I was really excited. And then, there were people that would kind of overhear it and they would look at you and they're like, well, yeah, but you just got it because you were a female. They didn't actually think that you were qualified for it, that's the only reason you got it. And it's definitely discouraging.

\section{Male-Female Percentage}

Of the schools interviewed, both rural schools and one of the suburban schools stated the male to female percentage at their schools were even. At one of the rural schools, this was due to the lottery system they use to place students into the program. At the other rural school, this 
was credited to the district's push to have a high number of students participating. Both rural schools' robotics programs are strong and well-established, with FIRST programs from kindergarten through high school. The students at the suburban school with an even percentage of male and female students said that most girls at their school chose to participate, and those who did not participate regret passing up the opportunity. Of the remaining schools, one suburban school and one urban school stated their numbers were about $25 \%$ female and the other urban school estimated $30 \%$ female.

Other noted factors contributed to the analysis of this category. Several coaches mentioned that the percentage of males to females depended on class makeup and fluctuated from year to year. Only one urban school and one rural school utilized a specific plan for limiting gender bias in course selection. Additionally, the two urban schools also noted that a smaller percentage of male than female robotics students chose to continue to participate at the high school level. This phenomenon was not observed in the rural schools, and neither of the suburban schools had this opportunity available for comparison.

\section{Discussion}

Within this section is an analysis in response to answering the research questions guiding

the study. This study centered around the conceptual framework of Social Cognitive Theory and the theoretical frameworks of Self-Efficacy Theory of Education, Gender Schema Theory, and robotics programs and females in STEM. A discussion of each of these frameworks in light of the findings of the study follows.

\section{Social Cognitive Theory}

This study highlighted the assertion introduced through social cognitive theory (Bandura, 1977) that an individual's social constructs are complex and influenced by a variety of personal 
and social factors (Cobb \& Bowers, 1996). The students interviewed in the study each exhibited a unique sense of self, ideas of what an appropriate life path looked like for them, and opinions regarding the process involved in coming to these conclusions. It was impossible to separate the strength of the social impacts provided through friends, family, and other important individuals in each student's life from their own personal interpretation and choices. The students exemplified Bandura's (1977) idea of reciprocal determinism throughout their interviews by communicating their experiences with the interconnected influence of several factors.

The study analyzed the social context of a robotics program and identified both positive and negative factors that demonstrated a potential impact on the students. These findings are consistent with Social Cognitive Theory (1977) in that it provided evidence that there are myriad factors contributing to an individual's feelings and responses to any situation. It was clear through this study that the students experienced the pressures, directions, and guidance from society while simultaneously navigating their place within that society. The study also showed that participating in a robotics program had definite impacts on the study participants and demonstrated the potential to influence them toward STEM careers in the future.

While the study made clear the fact that participating in a robotics program had a significant impact, the students' decisions to remain in robotics or discontinue their participation in the program evidenced the complexity of thought that goes into decision making and provided further support for Bandura's (2001) later research in social cognitive theory. The student interviews and coaches' focus groups substantiated the concepts of personal agency, proxy agency, and collective agency that affect an individual's decisions (Bandura, 2002). Personal agency was seen in the students who described doing robotics simply because they enjoyed it, and is discussed more in the analysis of self-efficacy theory of education (Bandura, 1986a). 
Proxy agency was seen through both supporters and discouraging comments from others described by the students and is discussed more through the lens of gender schema theory (Bem, 1981). Finally, collective agency was seen in the students who joined robotics with other girls, made influential friendships within the program, or mentored new students, and is understood through the framework of robotics programs and females in STEM.

\section{Self-Efficacy Theory of Education}

Student participants in this study related that their middle school robotics experience gave them the realization that robotics was an area they were capable of excelling in, broadened their career choices, and increased their belief in their own abilities within STEM and beyond. Many studies in the literature review revealed the strong correlation between self-efficacy, or belief in oneself, and achievement (Bandura, 1986a; Bandura, 2001; Bandura et al, 2003; Caprara et al., 2008; Hattie, 2018; Pajares, 1996; Usher \& Pajares, 2008). These data answer the primary research question: How does participating in a school-based robotics program affect the learning and academic self-efficacy of female students?

The coaches and students in this study identified the most powerful impact of participating in a robotics program was increased overall confidence observed in the students. All participants noted and/or described this particular impact of increased confidence, and it was not only contained to academic areas. Students indicated experiencing feelings of confidence in all aspects of their lives. This confidence, which equated to self-efficacy in this analysis, identified in social situations, increased leadership within the program, and improved skills in academic STEM subjects. These findings supported Bandura's (1993) research establishing significant positive relationships between self-efficacy and goal setting, ability, memory performance, cognitive effort, and motivation as the students and coaches described similar 
observations and experiences in their robotics programs. The students also experienced increased self-efficacy in communication, as evidenced by higher confidence in sharing their thoughts and ideas and feeling comfortable working with others. This demonstrated that the academic self-efficacy benefits experienced by the student participants extended beyond STEM subjects.

The impact of mastery experiences, vicarious experiences, and verbal persuasions on academic self-efficacy was evidenced in several studies using self-efficacy theory of education as a framework (Bandura, 1986; Zeldin \& Pajares, 2000). The effect of mastery experiences, or individual experiences of success in particular academic tasks, was seen in this study for those student participants who chose to continue participating in robotics because they were able to envision their continued success. Vicarious experiences were also impactful in this study as students related the importance of participating with other female students on their teams and the coaches related the most successful recruitment strategy was female students convincing other female students to join. In addition, students shared the influence of verbal persuasions as both positive and negative factors on their confidence.

In addition to mastery experiences and vicarious experiences, student participants in this study described many positive verbal persuasions through encouragement from coaches, parents, and other students, but also experienced negative verbal persuasions in the form of genderrelated discouragement from classmates and teammates. However, the positive verbal persuasions in combination with their influential mastery experiences and vicarious experiences resulted in overwhelmingly positive robotics experiences for the students interviewed for this study and demonstrated clear observed and self-proclaimed growth in academic self-efficacy in all of the students who were interviewed. 


\section{Gender Schema Theory}

The study also illustrated the effects of gender schema (Bem, 1981) on female participation in robotics and answered the secondary research question: Why do female students choose to participate in a robotics program? The complex interplay of positive social influences and the personal decisions to embrace a non-traditional gender schema resulted in each of the students in this study choosing to participate in a robotics program in middle school.

Each of the coaches who participated in focus groups were aware of the impact gender schema can have on students, although only some of the schools had strategies in place to combat the societal tendency to label STEM in general or particular responsibilities as those intended for male or female students. These actions indicated two things. First, these behaviors demonstrated that the coaches were aware that gender identification occurred in their students prior to middle school (Master et al., 2017; Starr \& Zurbriggen, 2016). Second, the coaches directed efforts toward minimizing the impact prior gender socialization caused and created opportunities for students to reframe previously held gender constructs because they understood these constructs to be somewhat malleable (Bem, 1983).

Some of the younger students interviewed for this study stated ideas that indicated clear gender schema influences. For example, one student said,

I thought it was like more of a boy thing, but then when I tried it, I thought that it was also a boy and a girl thing, but I didn't think it was a girl thing because girls don't really do robotic things.

Older students noted negative social consequences they received from their peers because of participating in an activity other students viewed as inappropriate for their gender (Morgan \& Ayum, 1984). The experiences these students shared included being told they were not capable 
of doing a particular activity because of their gender and being made to feel they were unqualified to earn praise and recognition because of the perception that they received special treatment due to their gender. These were damaging experiences as children establish a selfconcept and a value system built on the premise of their gender identity (Martin, Ruble, \& Szkrybalo, 2008).

None of the students interviewed felt that they were treated any differently than males by the coaches in their robotics programs, as this is an indication that the coaches chose not to support the encouragement of traditional gender schemas within their programs and were able to counteract the dichotomous social influences of gender schema on their students. Each of the students interviewed expressed an awareness of the stereotype of robotics and STEM as a maledominated field prior to joining robotics and their responses indicated that they chose not to buy into a more rigid traditional gender mindset, instead choosing to try robotics as an activity they could enjoy. Many of the students noted the positive encouragement provided by teachers, parents, and coaches were powerful motivators in their decisions to join a robotics team. These findings supported Colander and Rittenour's (2015) assertion that intentional parental influence can significantly increase female students' self-efficacy in STEM subjects, and by extension, broaden their gender schema. This evidence also suggested that this influence was not limited to parents, but demonstrated by other adults who encouraged female participation in robotics.

One key takeaway resulting from the analysis of gender schema involved the reasons female students gave for discontinuing their participation in robotics. Several students, who stated their intention of not returning to the program, indicated this decision was because they wanted to explore other activities. Studies involving gender schema theory indicated this may be the result of gender segregation, or the separation of oneself into behaviors and activities and that 
are considered gender appropriate within a given society (Martin et al., 2011). This behavior at the middle school level was not previously identified in the review of existing literature. Prior studies of gender segregation noted these behaviors in preschool and primary age students, but none observed this phenomenon in middle school (Bem, 1983; Carter, Levy, \& Cappabianca, 1985; Liben \& Bigler, 2017; Martin et al., 2011).

Substantial evidence of the rejection of the traditional gender schema in the students who participated in this study is seen in the careers they considered or ultimately chose. Of the eighteen career options envisioned by the students, sixteen of those were in STEM fields. These STEM fields were not limited to skills directly related to robotics, but also included careers in science and medical fields. One of the students shared she experienced the type of verbal discrimination described by Woodington (2010), wherein a peer insinuated that her femaleness somehow made her less qualified. Although discouraged, this student realized this was not an accurate representation of her abilities and chose to continue working toward her goal of becoming an electrical engineer due to the gender schema and development she experienced in her middle school and high school robotics experiences. These findings are consistent with the findings of previous studies that showed females in STEM careers exhibited less traditional gender schemas (Lavallee \& Pelletier, 1992; Lemons \& Parzinger, 2007) and their gender schemas were heavily impacted by their adolescent experiences (Morgan, Gelbgiser, \& Weeden, 2013).

\section{Robotics Programs and Females in STEM}

Each of the conceptual and theoretical frameworks come together within the context of robotics programs and females in STEM and this combination answered the remaining research questions. Some of the female students interviewed described specific instances where they had 
been the recipients of negative social sanctions as discussed in Social Cognitive Theory because of their participation in robotics (Bandura, 1986; Morgan \& Ayum, 1984). However, instead of pushing these students away from STEM, these experiences strengthened their resolve to make their mark in the field. This observation answered the research question: How does participation in a robotics program affect female students' career aspirations? Several of the students indicated they planned to enter STEM fields as a career or had a STEM career as an option they were considering. Even those who did not plan to continue with STEM through their career suggested that they were aware STEM was a career path that was open to them.

The choice to join a traditionally male-dominated field such as robotics is strongly supported by the ideas in gender schema theory (Bem, 1981; Bem, 1983) and other studies that indicated females in STEM actively push back on activities that are considered more in line with traditional gender schemas (Lavallee \& Pelletier, 1992; Lemons \& Parzinger, 2007). This rejection of the more traditional gender schema would not be possible without the self-efficacy and belief in one's abilities to gain success in the field as identified in self-efficacy theory of education (Bandura, 1986; Pajares, 1996) and answered the final research question: How do female students' perceptions of STEM fields change over time after participating in a robotics program? As evidenced in previous research (Veltman, Davidson, \& Deyell, 2012), robotics programs have significant potential to increase self-efficacy, positive attitudes, and STEM career consideration for both female and male students. This study reinforced the findings from earlier studies that increasing access and opportunity to robotics programs at all age levels should be an area of educational focus in order to overcome perceptions of gender bias (Alimissis \& Moro, 2016) and develop an environment that ensures female students can thrive in STEM subjects (Fluck et al., 2016). 


\section{Implications}

Collectively, the data gained in this study contributed information to the field of study in the areas of significance to the field of study, recommendations for schools, and suggestions for further research.

\section{Significance to the Field of Study}

The data gained in this study indicated that individual gender schema is established by the middle school years, and it is a transformative moment in life when one must choose what to do with that knowledge. While this finding supported the idea found in gender schema theory that posits an individual has personal agency to accept or reject the traditional gender schema (Bem, 1983), the focus on middle school as a pivotal time when this acceptance or rejection occurs as it relates to one's future in STEM was not found in any of the previous studies.

Additionally, the evidence suggested that female students might choose to leave robotics programs to pursue other activities in middle school and high school due to the potential influence of gender segregation, a concept that had previously only been observed in very young children. This suggested that the transitions inherent to the middle school experience lead students to feel their gender identity is threatened, resulting in students exhibiting the need to recalibrate their gender identities and return to more traditional gender role and activities. This is not to suggest that this is the only factor influencing these students' decisions to leave robotics in favor of activities such as sports and drama, but it is an interesting factor to note. Especially in light of the fact this was a common theme in the students who chose not to continue in robotics.

This evidence of the transformative period students experience in middle school and the observed tendencies to rethink one's gender identity categorization when social contexts are in flux should be noted as a key finding of this study. The findings of this study implied that 
middle school students might feel the need to recalibrate gender identity on a cyclical basis. This information indicated action on behalf of schools and researchers to learn more about how to best encourage and reassure students who may lose confidence in their gender identity at this particular time in their lives. This focus has the potential to increase significantly the number of students who choose STEM career paths, and will especially benefit females and other marginalized groups underrepresented in STEM fields.

\section{Recommendations for Schools}

Based on the results of this study, several recommendations are made for schools. These recommendations include provide support for robotics programs, focus on both adult and student mentorship for students, and expand opportunity and eliminate obstacles so students have a better chance to participate and fewer reasons to discontinue.

\section{Support Robotics Programs in Schools}

Data gathered from the coaches' focus groups and student interviews indicated students who do not have middle school and high school robotics experiences do not feel as prepared entering STEM fields. This highlighted the need for school districts to support fully robotics programs. The most successful programs as indicated by the districts participating in this study were those that had implemented a clear progression of robotics activities from elementary to middle to high school. This was evident no matter the size of the district, with the most successful programs located in the rural and urban districts. These districts embedded robotics into the culture of their schools, with students taking great pride in being a part of the team and enjoying community-wide support in their successes. 


\section{Focus on Mentorship}

Schools can capitalize on the benefits students receive from participating in a schoolbased robotics program by focusing on the mentorship students have access to through robotics. There was not one single factor that led to students' decisions to remain in robotics or leave the program, but each of the students did mention adult support in their lives. This mentor focus should include coaches, parents, and experts from the community who can contribute time to helping lead robotics teams and students through practices, expert knowledge, and allowing students to put a face with careers. This can be especially impactful for female students when they have access to other females who are experts and leaders in their fields.

In addition to adult mentorship, also noted was student mentorship as powerful factor in encouraging female students to join and remain in robotics. This may be in the form of veteran students leading new students or former students coming back after college to volunteer time to the program.

\section{Expand Opportunity and Eliminate Obstacles}

Several students who participated in this study mentioned that the middle school level offered more opportunities for available activities. This expanded menu of options was a significant contributing factor in their decision to leave robotics as these activities competed for

time and space in the students' lives. Schools should look into ways to allow students to choose robotics and other potential career fields in addition to sports and fine arts by developing creative ways of structuring time before, during, and after the school day. This may include creating robotics classes so that it these academic activities can be completed during the school day, alternating practice days, or utilizing weekend practice schedules. 
In addition to these recommendations, schools should also look for ways to identify and decrease gender conformity pressures so students express less of a need to participate in gender segregation in middle school. This may take many forms including restructuring class schedules, rethinking class choices, and training teachers and coaches to identify and eliminate their own gender biases.

\section{Suggestions for Future Research}

A few research paths come to mind when considering the need for further research on this topic. First, research should examine more specific data regarding where gender schema comes into play at the elementary level and see what can be implemented at those levels to combat the traditional gender schema ideas that keep students from joining robotics in the later elementary years. Second, when middle school students have to choose between robotics and other activities in middle school, what is leading them to their decisions? Are they choosing the activities that they feel are more appropriate for their gender? Third, schools that are experiencing great success at producing students who enter STEM careers should be studied to gain both quantitative and qualitative data regarding what makes those schools unique and what systems they have put in place. These schools are actively combating the shortage of STEM workers and society needs to learn from their example in order to solve this issue in the future.

\section{Executive Summary}

This executive summary outlines the main points in the dissertation study A Multiple Case Study of Female Students' Academic Self-Efficacy While Participating in a Middle School Robotics Program. The problem of practice in this study was the global underrepresentation of females in STEM subjects and careers. While the purpose was to closely examine the experiences of female middle school students participating in school-based robotics programs in 
order to gain a deeper understanding of the relationship between their gender beliefs and academic self-efficacy as it relates to STEM subjects, ultimately leading to their decisions to remain in STEM fields or pursue other career paths. This study addresses the primary research question:

How does participating in school-based robotics programs affect the learning and academic self-efficacy of female students?

It also addresses the secondary research questions:

Why do female students choose to participate in a robotics program?

How do female students' perceptions of STEM fields change over time after participating in a robotics program?

How does participation in a robotics program affect female students' career aspirations?

\section{Conceptual/Theoretical Frameworks}

The study using the conceptual framework of Social Cognitive Theory and the theoretical frameworks of Self-Efficacy Theory of Education and Gender Schema Theory analyzed data from coaches and student participants. Also discussed were the contextual framework of robotics programs and females in STEM. These frameworks are appropriate for the study because they recognize the unique personal and societal factors at work in individual decisionmaking and discussed as they pertain to the analysis of female middle school students in robotics programs.

\section{Methods}

The study was conducted using qualitative methods, utilizing observations of practices, focus groups with robotics coaches, and interviews with current and former robotics students as data collection methods. These data were analyzed using open coding and axial coding to find 
recurrent themes and patterns within the data. The study setting included six middle school robotics programs across the state of Missouri. Conducted at each site was one focus group and two student interviews.

\section{Results and Discussion}

\section{Results}

This section outlines the themes and corresponding codes.

Experience. Thirteen coaches participated in focus groups for this study. Their experience in education ranged from parent volunteer to 27 years, with a mean of just over 10 years. FIRST LEGO League coaching ranged from one year to eight years, with six of the coaches having one or two years coaching experience. Twelve students participated in interviews for this study. Their experience in FIRST LEGO League ranged from one year to four years, and they ranged in age from 12 to 19.

Influence. Contributing factors in the decision to either remain in robotics or leave the program were noted in the category of influence. Of these, the coaches noted 166 positive influences and 43 negative influences, and the students noted 258 positive influences and 94 negative influences, which indicated the positive factors outweighed the negative by a significant number. Positive factors represented $75 \%$ of the responses in the influence category. Notable positive influences included a variety of individuals who provided support for the female students in robotics. Of the negative responses, stress, frustration, and difficulty were the most frequently mentioned factors by both students and coaches.

Coaching. This theme was divided into the codes of coaching strategies and recruitment. For the most part, coaching strategies aligned with the idea of the coach as facilitator. On the recruitment side, schools varied in how they attracted new students. 
Overwhelmingly, coaches and students stated that the highest success rate for recruitment strategies was when a student had either a friend already in the program or made friends with students in the program.

Impact. Divided into the coded impact areas of skills, long term, careers, and postsecondary impacts was this theme. Skills included general skills practiced or learned throughout the program. Long term referred to behaviors or skills that had a lasting effect. Careers related to discussions referencing future career options or choices, and post-secondary described any impact that was expected or occurred after high school.

Student Descriptors. The theme of student descriptors applied any time coaches and students described students or themselves in specific characteristics, traits, or behaviors. Further categorization of the theme resulted in the codes of general, male, female, and male-female percentage. The majority of observations regarding specific gender-related behavior fell into this theme.

\section{Discussion}

Briefly outlined are the results of this study in the context of the conceptual and theoretical frameworks.

Social Cognitive Theory. The study highlighted the assertion introduced through Social Cognitive Theory that an individual's social constructs are indeed complex and influenced by a variety of personal and social factors. The study made clear that participating in a robotics program had definite impacts on the students interviewed and had the potential to influence them toward STEM careers in the future.

Self-Efficacy Theory of Education. The most powerful impact of participating in a robotics program as noted by coaches and students who participated in the study was that of 
increased overall confidence in the students. This answers the primary research question of:

How does participating in a school-based robotics program affect the learning and academic selfefficacy of female students?

Gender Schema Theory. The study also laid bare the effects of gender schema on female participation in robotics and answered the secondary research question: Why do female students choose to participate in a robotics program?

Robotics Programs and Females in STEM. Each of the conceptual and theoretical frameworks come together within the context of robotics programs and females in STEM and this combination answered the remaining research questions.

\section{Implications}

Collectively, the data gained in this study contributed information to the field of study in the areas of significance to the field of study, recommendations for schools, and suggestions for further research.

\section{Significance to the Field of Study}

The data gained in this study indicated that individual gender schema is well-established by the middle school years, and it is a transformative moment in life when one must choose what to do with that knowledge.

\section{Recommendations for Schools}

\section{Support Robotics Programs in Schools}

The study highlighted the need for school districts to support fully robotics programs.

\section{Focus on Mentorship}

Schools can capitalize on the benefits students receive from participating in a schoolbased robotics program by focusing on the mentorship students have access to through robotics. 


\section{Expand Opportunity and Eliminate Obstacles}

Schools should look into ways to allow students to choose robotics and other potential career fields in addition to sports and fine arts by developing creative ways of structuring time before, during, and after the school day.

\section{Suggestions for further research}

First, research should examine more specific data regarding where gender schema comes into play at the elementary level and see what can be implemented at those levels to combat the traditional gender schema ideas that keep students from joining robotics in the later elementary years. Second, when middle school students have to choose between robotics and other activities in middle school, what is leading them to their decisions? Are they choosing the activities that they feel are more appropriate for their gender? Third, schools that are experiencing great success at producing students who enter STEM careers should be studied to gain both quantitative and qualitative data regarding what makes those schools unique and what systems they have put in place.

\section{Conclusion}

This section detailed the contribution to practice developed from the study entitled $A$ Multiple Case Study of Female Students' Academic Self-Efficacy While Participating in a Middle School Robotics Program. Included in this section was an executive summary, which shared a brief overview of the main parts of the study, and an analytic summary, which briefly shared the main parts of the study and included a full analysis of the results and implications. These documents will be shared with parties interested in learning from and applying the results. 
SECTION FIVE

CONTRIBUTION TO SCHOLARSHIP 


\section{Target Journal}

The target journal for the contribution to scholarship is The International Journal of STEM Education. This new journal is published online by Springer Open. The International Journal of STEM Education is a peer-reviewed journal dedicated to promoting STEM education around the world. The publishers are interested in research that includes "technology-rich learning environments, innovative pedagogies, and curricula in STEM education that promote successful learning in Pre K-16 levels including teacher education,” (Springer Open, 2020).

\section{Rationale for this Target}

This journal was selected for four reasons. The first reason it was selected is due to its relevance to the topic of female middle school students in robotics programs. As the implementation of robotics programs within middle schools continues its trajectory of growth, a larger base of knowledge in regards to its educational impact will be well-received by a journal focused on STEM education and its readers. The second reason this journal was selected is due to its international reach. Since the problem of practice is the global shortage of students continuing in STEM through education and career, a global understanding of the problem is required.

The third reason this journal was selected is due to its online format and the ease of dissemination this format offers. An online journal is able to complete the peer review process with a diverse range of editors and publish quickly so that research will be available globally in a timely manner. The final reason this journal was selected is the free use and authorship policies. This online journal offers open access so that it is available for free with no registration or subscription fees required from the reader. In addition, the authors of the articles retain the copyright and are free to disseminate and publish the articles elsewhere as they wish. As the 
researcher strongly believes in the open access of information in education and the importance of a researcher owning his or her work, these policies were important aspects of selecting a journal. There is a fee for publishing with this journal, however the University of Missouri is a member and covers the cost of publications from the College of Education.

\section{Plan for Submission}

The International Journal of STEM Education has an online submission process whereby the submission article is uploaded to their website. The article will be uploaded after successful defense of the Dissertation-in-Practice. After submission, the article will go through a doubleblind review process where it will be reviewed for scientific soundness, original research, and clarity before publication. 
Submission-Ready Article for the International Journal of STEM Education

Title Page

A MULTIPLE CASE STUDY OF FEMALE STUDENTS' ACADEMIC SELF-EFFICACY

WHILE PARTICIPATING IN A MIDDLE SCHOOL ROBOTICS PROGRAM

By Carey A. Davis and Dr. Barbara N. Martin

University of Missouri 


\begin{abstract}
An instructional focus on Science, Technology, Engineering, and Math (STEM) is a current popular educational due to the widespread need for skilled workers in these growing fields. Compounding this labor shortage is the fact that female students and workers are greatly underrepresented in STEM subjects. The purpose of this study was to examine the experiences of female middle school students participating in school-based robotics programs to gain a deeper understanding of the relationship between gender beliefs and academic self-efficacy related to STEM subjects. The results of this study were organized into the theme of experience, influence, coaching, impact, and student descriptors. Contributing factors in the decision to either remain in robotics or leave the program were noted in the category of influence. For the most part, coaching strategies aligned with the idea of the coach as facilitator and schools varied in how they attracted new students. Impact was divided into the coded impact areas of skills, long term, careers, and post-secondary impacts. The theme of student descriptors applied any time coaches and students described students or themselves in specific characteristics, traits, or behaviors. The majority of observations regarding specific gender-related behavior fell into this theme.

The data gained in this study contributed information to the field of study in the areas of significance to the field of study, recommendations for schools, and suggestions for further research. The results indicated that individual gender schema is well-established by the middle school years, and it is a transformative moment in life when one must choose what to do with that knowledge. Based on the findings of this study, school districts should fully support robotics programs, focus on mentorship, and expand opportunity while eliminating obstacles for students. First, research should be conducted to determine where gender schema comes into play at the elementary level. Second, research should be conducted to determine what factors
\end{abstract}


students use choosing between robotics and other activities in middle school. Third, schools that are experiencing great success at producing students who enter STEM careers should be studied.

\section{Keywords}

Robotics, females, STEM, FIRST LEGO League, Social Cognitive Theory, Self-Efficacy Theory of Education, Gender Schema Theory, middle school

\section{Introduction}

An instructional focus on Science, Technology, Engineering, and Math (STEM) is a current popular educational trend (Jung \& Won, 2018). This global educational push for STEM is due to the widespread need for skilled workers in these growing fields (Kandlhofer \& Steinbauer, 2016). As a result, economists predict proficiency in STEM-based skills will be vital to future careers and industries (Kelley \& Knowles, 2016). However, the United States is experiencing a greater shortage of adults and students entering these career fields as compared to other countries, which is a concern to educators and those working in these fields and should be a concern to all citizens as the economic impact of this shortage is already being seen (Kandlhofer \& Steinbauer, 2016).

Compounding this labor shortage is the fact that female students and workers are greatly underrepresented in STEM subjects and careers (Zeldin \& Pajares, 2000). An area where STEM and female students come together at an impactful age is the site of school-based robotics

programs. Robotics programs have been shown to provide effective and engaging exposure to STEM subjects at an early age (Ospennikova, Ershov, \& Iljin, 2015). While there are many studies extolling the benefits of robotics programs and their ability to increase students' academic ability in STEM fields (Eguchi, 2016), nevertheless, even with demonstrated benefits 
for students engaged in a robotics program, females are not experiencing these benefits to the same degree as males (Kucuk \& Sisman, 2017).

Given the purported importance of STEM subjects to future society and the unequal participation being experienced by females working in these fields, this study will attempt to advance qualitative data regarding the personal and societal factors impacting female students currently involved in school-based robotics programs. Outlined within this introduction to the dissertation in practice is the problem to be studied, including existing gaps in the literature, the purpose of the study to be conducted, and the research questions to be answered. Also discussed will be the theoretical frameworks of social cognitive theory, self-efficacy theory of education, and gender schema theory which are used to further understand the study as well as those not chosen for use in the study. Then, the specific design of the study, including the methodology, setting, participants, data collection tools, and data analysis will be shared. Finally, limitations and assumptions, definitions and key terms, and the study's significance will be examined.

\section{Summary of Existing Literature}

Not enough is understood about the reasons behind why females are not entering these areas as frequently as males or why they are choosing to leave these areas of study. In the literature review, no qualitative studies were found to analyze the phenomenology of female students participating in STEM subjects. Rather, as discussed by Heybach and Pickup (2017), there appears to be a broad deficit assumption across the literature that the lower numbers of females in STEM subjects are due to lack of access and confidence, approaching this issue as if one's femaleness is an obstacle to be overcome. Some studies even went so far as to blame females for their lack of participation in STEM subjects (Kucuk \& Sisman, 2017; Liu, 2010). 
This is not to say that efforts should not be made to increase access to and confidence in STEM for female students, but rather, if these were the only contributing factors, this problem would not persist. One mixed methods study by Lemons and Parzinger (2007) found significant differences in the experiences of female workers in STEM careers, but did not examine female students younger than post-secondary. Females represent a large subgroup of the population whose participation could potentially go a long way in helping to solve or at least alleviate the global shortage of workers. Much of the existing literature acknowledged gender differences in academics and especially STEM, but did not address potential factors or causality behind these gender differences (Veltman, Davidson, \& Deyell, 2012).

Additionally, there was no qualitative data found analyzing the experiences of female students as expressed by the girls themselves in order to better understand their reasons for continuing to be a part of STEM subjects or for leaving these subjects. Only quantitative data indicating evidence that such a difference exists was found (Morgan, Gelbgiser, Weeden, 2013). For these reasons, a multiple case study using qualitative methods of observations, interviews, and focus groups was chosen as the design of this study. The field of education needs to hear the voices of the female students who are standing at the precipice of both their secondary education and STEM fields in order to understand their experiences, including the pressures, influences, and thought processes guiding their decisions to continue STEM studies or travel a different educational path into a career at this crucial period of time.

\section{Problem of Practice}

The problem in this study is the global underrepresentation of females in STEM subjects and careers. Both educators and researchers have identified an amalgamation of factors contributing to the shortage of both male and female adults and students entering STEM fields 
(Fluck, Webb, Cox, Angeli, Malyn-Smith, Voogt, \& Zagami, 2016). Since experts established STEM as an area of concentrated career need in the future (Lemons \& Parzinger, 2007), any evidence of a workforce need going unfulfilled by society or career opportunities being lost by individuals is a problem worthy of attention.

Of particular concern is the fact that this shortage is even more pronounced among female students and workers than for males in the same areas (Heybach \& Pickup, 2017; Lemons \& Parzinger, 2007; Witherspoon, Schunn, Higashi, \& Baehr, 2016). While many female students take STEM-based classes in middle and high school, the number of female students entering these fields at the post-secondary and career levels is far below that of males (Grubbs, 2013; Zeldin \& Pajares, 2000). One can assume a large percentage of the population experiencing a significant drop in interest in STEM fields before adulthood is at least a contributing factor in the global shortage of individuals entering careers in these areas.

It is imperative for researchers and educators to gain a deeper understanding of the experiences of female students as they relate to STEM subjects in order to begin to comprehend the causes behind their underrepresentation in STEM fields. This lack of understanding results in the absence of meaningful action by educators, researchers, and organizations with the express purpose of eliminating the unequal ratio of males to females in these subjects and careers. Additionally, Heybach and Pickup (2017) pointed out this underrepresentation of females in STEM also results in stagnation in the growth of knowledge in STEM areas as the voice of this part of the population is largely absent across these career fields. The question of what advances could have already been achieved with the input and participation of a significant portion of the population should be of grave concern to all educators, parents, and members of society. 


\section{Purpose of the Study}

The purpose of this study was to closely examine the experiences of female middle school students participating in school-based robotics programs in order to gain a deeper understanding of the relationship between their gender beliefs and academic self-efficacy as it relates to STEM subjects, ultimately leading to their decisions to remain in STEM fields or pursue other career paths. The researcher strived to gain insight into the personal and social factors impacting middle school females and limiting the number of females choosing to remain in STEM fields from early secondary education to career. The researcher did not intend to be able to attribute causality to any of these potential factors, but rather intended to gather data, identify patterns, and discern direction for further quantitative and qualitative study in this area so further interventions can be identified and implemented and more research can be conducted that will allow for potential solutions to this problem. The literature review made clear the fact that there is not currently enough qualitative data to guide future study, and any previous attempts at marketing STEM to females has resulted in superficially "painting STEM pink," (Heybach \& Pickup, 2017, p. 621), which is an ineffective attempt at solving the problem.

\section{Methods}

A qualitative multiple case study method was used in the hopes of collecting narrative and personal responses to questions through observations, interviews, and focus groups (Creswell, 2014; Merriam \& Tisdell, 2016; Seidman, 2013). After a thorough literature review, significant gaps indicated the need for qualitative research. There appeared to be a large number of quantitative studies conducted with the focus of self-efficacy, academic performance, educational settings, and STEM subjects which recognized significant differences between male and female students and workers in STEM subjects, but the voices of these individuals and their 
experiences were missing as no qualitative studies were found for the middle school age group, which is a pivotal age in personal development as related to future occupational decisions. It is this type of qualitative understanding that is needed if meaningful differences are to be made for these students and society as a whole (Merriam \& Tisdell, 2016).

As a result of this need for understanding the thought processes behind the participants' creation of meaningful experiences, a multiple case study method was chosen as the research design for this study. It was determined a phenomenological or ethnographic study would most likely yield a larger quantity of usable data, but due to the participants and researcher position, it is not possible for the researcher to be immersed in the phenomenon without altering the results of the study (DuBois, Strait, \& Walsh, 2017; Merriam \& Tisdell, 2016). A multiple case study approach allowed the researcher to gain insight into bounded systems of school-based robotics programs with little impact on the normal current and future functioning of the participants and programs (Merriam \& Tisdell, 2016). Since multiple bounded systems were studied as the researcher met with participants from varied sites of these robotics programs, the study was termed a multiple case study (Merriam \& Tisdell, 2016). By clarifying elements such as place, context and culture, the researcher was able to provide a "thick description" which assisted in providing detail to the phenomena being addressed (Merriam \& Tisdell, 2016). To begin, the researcher gained pre-authorization from the University of Missouri Internal Review Board (IRB) (Appendix A) to complete the study as a means of providing a safeguard for study participants.

\section{Study Setting}

The setting of this study included six middle school robotics programs across the state of Missouri. For the sake of continuity and reliability in comparison, sites participating in the 
FIRST LEGO League (FLL) program were chosen. In choosing the schools for participation in the study, the researcher used purposeful sampling as discussed by Merriam and Tisdell (2016). In purposeful sampling, the sample is based on identified attributes in order to gain particular information on the phenomenon to be studied. The researcher selected schools which meet the following requirements:

1. Middle school with an established robotics program

2. Robotics program competes in official FIRST LEGO League tournaments

3. School teams have been registered and active in FIRST LEGO League tournaments for at least three years

4. District, coaches, and participants are open and willing to allow researcher to conduct the study

Using the criteria listed above, the researcher identified a number of potential sites. Further narrowing of settings for the study occurred by ensuring a variety of settings in rural $(n=2)$, suburban $(n=2)$, and urban school communities $(n=2)$, terms defined according to data from World Population Review (2020). A variety of settings allowed the researcher to gain a more complete picture of robotics programs in Missouri and what Merriam and Tisdell (2016) term “maximum variation" (p. 98).

\section{Participants}

At each site of a selected school-based robotics program, two female student participants were interviewed for a total of twelve individual interviews. Each of these students had participated in a FIRST LEGO League program for at least one year. When possible, efforts were made to ensure one of these students planned to continue participating in robotics and the 
other was a student who planned to end their involvement with the program. Specifically, twelve total female students were interviewed and their perspectives recorded.

In addition to student interviews, a focus group made up of coaches was conducted at each site in order to gain qualitative data on the experiences of females within their program from the coach perspective. These were coaches who are currently involved with a FIRST LEGO League team or had been within the last two years. This secondary sampling is what Merriam and Tisdell labeled "two-tier sampling" (p. 99). The focus groups were conducted for the purpose of gathering more information on the context or culture of the program as related to the female students and to gain the perspectives of the adults who are immersed in said context and culture. Depending on the availability of coaches, the focus groups consisted of two to three coaches each, with one focus group at each setting $(n=6)$. The sampling for the specific participants qualified as network sampling as the head coach at each site selected the specific participants within the program to participate in the interview and focus group process (Merriam \& Tisdell, 2016). The participants chosen by the head coaches were the only individuals the researcher had access to due to IRB requirements (see Appendix A).

\section{Data Collection Tools}

The qualitative data collection tools used for this study were observations, interviews, and focus groups. The original plan was to conduct observations wherein the researcher observes a robotics practice or meeting and takes field notes on the observation form (see Appendix B) regarding the behaviors and interactions of the participants (Creswell, 2014). It was assumed the observations would only provide context data regarding the social structure of the robotics program, and would most likely not provide answers to the research questions. However, as Seidman (2013) stated, an understanding of context is necessary if the researcher is 
going to gain an understanding of the participants' point of view. Unfortunately, due to the onset of the COVID-19 pandemic and subsequent school shutdown as a safety precaution, only two sites were able to participate in observations.

The observation form was developed using Creswell's (2014) recommendations. Specific data regarding the site, the personnel, and the atmosphere are listed on the observation form. These are points of note the researcher wanted to make certain were recorded in the observation in order to align the qualitative data in a similar format from site to site. The observation form lists the purpose of the observation, the location, date/time, length of observation, the number of male and female coaches, the number of male and female students, a list of other individuals in attendance, and an illustration of the layout of the practice area as data points to include in the observation. In addition to these specific items, clear and detailed field notes were recorded (Merriam \& Tisdell, 2016).

In addition to observations, the researcher conducted focus groups made up of coaches who work with the female students interviewed for this study in order to gain their perspective as individuals who are in close regular contact to students in the robotics programs. According to Merriam and Tisdell (2016), "a focus group is an interview on a topic with a group of people who have knowledge of the topic," (p. 114). Within the focus group, the coaches will be able to freely discuss their robotics program and their opinions regarding the effects the program has specifically on the female students and their interactions (Krueger \& Casey, 2015). The researcher was sensitive to the fact that some coaches may be positionally subordinate to others, and this may affect coaches' ability to answer questions openly and honestly. One focus group will be held one time for each site for a time of no longer than one hour. Due to the COVID-19 
school shutdown, five out of the six focus groups were conducted virtually via Zoom video conferencing.

The Coaches Focus Group Protocol (see Appendix C) details the list of questions that will be asked during the focus groups at each site. The list of questions was developed in order to help the coaches feel comfortable, ascertain clear and precise answers to research questions, and to allow for freedom of discussion topics to potentially veer from the question into other relevant conversation that could provide detailed data pertaining to the research questions. A total of 16 questions are listed on the protocol (see Appendix C). These questions were shared with other coaches who are not part of a focus group in order to take part in member checking (Merriam \& Tisdell, 2016) and ensure the language of the questions were understood and the desired response validity was achieved. Alterations were made based on recommendations for clarity and understanding. Focus groups were audio recorded with appropriate permissions given.

The researcher expected to gather significant data and the bulk of the answers to the research questions through interviews with female participants within the robotics programs. The interviews allowed the researcher to gain an understanding of the experiences of the students and the meaning they have constructed from those experiences as they related to their beliefs about school, robotics, and STEM (Seidman, 2013). The researcher anticipated interviewing each student one time for no longer than half an hour, with the potential for follow-up questions via digital means or through adult gatekeepers if clarification or further information about their responses is needed. Due to the COVID-19 school shutdown and subsequent cancellation of the fall FLL robotics season, ten out of the twelve interviews were conducted virtually via Zoom video conferencing. 
Due to having the resources for one formal interview per participant, the semi-structured interview format discussed by Merriam and Tisdell (2016) was used. This format required the researcher to have a predetermined list of questions or interview protocol (see Appendix D) for the interviewee to answer, but allowed the researcher to ask follow up questions based off of the interviewee's responses in order to gain clarification or more information in regard to the research questions. The interview protocol (see Appendix D) was developed in order to help students feel comfortable and confident in the interview process so that they felt secure giving candid responses about their experiences. The protocol (see Appendix D) has a total of 17 questions that progress from simple information sharing to deeper questions requiring students to think more critically about their experiences and will generate responses to answer the research questions. The interview questions were shared with robotics students who are not participating in the interview process in order to ensure validity and make sure the intended response information was understood (Creswell, 2014). Some question wording was simplified through this process. Interviews were audio recorded through digital means with appropriate permissions given.

Some of the pitfalls of observations, focus groups, and interviews are that the participants may not be completely honest regarding their experiences for a variety of reasons (Krueger \& Casey, 2015). This inaccuracy may initially affect the reliability of the data; however, it is hoped through analysis of the data and the search for patterns across multiple interviews and focus groups that the emerging data were reliable due to a thinning of unrepeated themes. The interviews and focus groups provided data to answer all the research questions guiding the study, including the primary research question of: How does participating in school-based robotics programs affect the learning and academic self-efficacy of female students? Additionally, the 
interviews and focus groups addressed the secondary research questions of: Why do female students choose to participate in a robotics program? How do female students' perceptions of STEM fields change over time after participating in a robotics program? How does participation in a robotics program affect female students' career aspirations?

\section{Results and Discussion}

The following section shares the results of analyzing data from interviews and focus groups and includes a discussion of how these results answer the intended research questions and relate to the conceptual and theoretical frameworks.

\section{Data Analysis}

Interviews and focus group sessions were typed and full transcripts reviewed by the researcher alone to ensure confidentiality. Coding took place across all the qualitative data to search for themes. The first level of coding to be used was open coding. Through this process, the themes of experience, coaching, influence, impact, and student descriptors were identified. Once open coding was completed on all the interviews and focus groups, the researcher conducted axial coding, in which the researcher searched for recurrent ideas within the data of each theme (Merriam \& Tisdell, 2016). Each theme and code were color coded for maximum visual representation of the data.

\section{Results}

The identified codes and their corresponding themes were:

1. Experience: Coaching, In Education, and Student Participant

2. Influence: Positive and Negative

3. Coaching: Strategies and Recruitment

4. Impact: Skills, Long Term, Careers, and Post-Secondary 
5. Student Descriptors: General, Male, Female, and Male-Female Percentage

\section{Experience}

A total of 13 coaches participated in focus groups for this study. Their experience in education ranged from parent volunteer to 27 years, with a mean of just over 10 years. Seven of the coaches are currently elementary teachers in some capacity, and the rest are secondary teachers or hold leadership positions in their district robotics program. FIRST LEGO League coaching ranged from one year to eight years, with six of the coaches having one or two years coaching experience. Four of the coaches hold advanced degrees in a STEM related field. A total of 12 students participated in interviews for this study. Their experience in FIRST LEGO League ranged from one year to four years, although five of them went on to participate in FIRST Tech Challenge (FTC) or FIRST Robotics Competition (FRC) at the high school level. The students ranged in age from 12 to 19 .

\section{Influence}

Contributing factors in the decision to either remain in robotics or leave the program were noted in the category of influence. Descriptors, individuals, or events that guided or encouraged students toward a decision to join or remain in robotics were labeled as positive, and factors that were not enjoyed or pushed students to consider leaving robotics were labeled as negative. Of these, the coaches noted 166 positive influences and 43 negative influences, and the students noted 258 positive influences and 94 negative influences, which indicated the positive factors outweighed the negative by a significant number. Positive factors represented $75 \%$ of the responses in the influence category.

Notable positive influences included a variety of individuals who provided support for the female students in robotics. Some of the individuals mentioned were coaches, parents, 
teachers, and friends. The most often mentioned people were friends, especially those who were also in the robotics program. One student called it "a large support group." Another student compared her team to a family. The word "fun" was used 54 times across the interviews and focus groups. Many students expressed surprise at how much they enjoyed the robotics program, with one saying, "I found out that I actually liked the whole idea of programming something and seeing your program work."

Of the negative responses, stress, frustration, and difficulty were the most frequently mentioned factors by both students and coaches. The most influential factors resulting in students leaving the robotics program according to this study were the desire to participate in other activities and limited time to do so. One student said, "I really wanted to focus on, like my different sports and stuff like basketball and softball." Another said, " I wouldn't be opposed to doing robotics again, but I joined the volleyball team, and that takes up more of my time because that's an everyday thing and I don't want to miss two practices a week for LEGO League robotics." Another said, "If I don't get really busy, I probably will continue it." One student wisely remarked, "If you don't have someone, you know, kind of like watching and making sure that you're not, you know, balancing your time well, it's very easy for it to start impacting other parts of your life quite negatively."

\section{Coaching}

This theme was divided into the codes of coaching strategies and recruitment. The coaches had significantly more to contribute to the conversation in this area, as more of the focus group questions focused on this aspect, however, several of the female students mentioned coaching strategies and recruitment within their interviews. For the most part, coaching strategies aligned with the idea of the coach as facilitator. Coaches mentioned specific activities 
like creating agendas, setting goals, keeping students on task, and putting new or weaker students with stronger or more experienced students or buddies. The students referred to their coach's activities as encouraging, teaching, mentoring, and other descriptors that created a picture of the coach as facilitator at each school.

Interestingly, all of the coach's focus groups felt their coaching process and strategies were identical whether the student or students needing help were male or female. When a team or student struggled, each of the focus groups described a process of pulling the student, group, or team aside and having a discussion about the problem at hand and how best to solve it. All of the students had positive things to say about their past and present coaches. None of the students specifically mentioned any differences with how they were treated by coaches.

On the recruitment side, schools varied in how they attracted new students. One school in which the robotics program is in very high demand, a lottery system was used. Students who scored in the proficient and advanced ranges on the iReady standardized assessment were entered into a lottery and those students selected were given the opportunity to participate. Another school had a similarly high number of interested students who completed an application and interview process in which only $10 \%$ of the students were chosen. Most of the schools implemented a tryout process where students had to attend a tryout, and numbers were somewhat limited, but most students who wanted to participate were able to do so. One school that has invested significant resources into their robotics program shared they have an over $50 \%$ participation rate in FIRST LEGO League robotics across the entire student population. Some schools also utilized a robotics enrichment class at the middle school level to expose more students to robotics. Overwhelmingly, coaches and students stated that the highest success rate 
for recruitment strategies was when a student either had a friend already in the program or made friends with students in the program.

\section{Impact}

Divided into the coded impact areas of skills, long term, careers, and post-secondary impacts was this theme. Skills included general skills that were practiced or learned throughout the program. Long term referred to behaviors or skills that had a lasting effect. Careers related to discussions referencing future career options or choices, and post-secondary described any impact that was expected or occurred after high school.

Skills. Both students and coaches mentioned a significant number of skills that were practiced and gained within the robotics program. The most frequently mentioned skill in interviews and focus groups was that of teamwork. Students and coaches described teamwork in a variety of ways, including work together, talk to people, collaboration, work with people, share ideas, respect others' ideas, stick together, don't exclude others, get along, come together, and cooperation. It was clear that teamwork is a large part of any successful robotics program.

Many of the skills mentioned by students revolved around accomplishing the three main tasks in FIRST LEGO League: building robots out of LEGOs, programming said robots to perform missions, and giving presentations on real-world research problems. Along these lines, students mentioned different variations of programming, building, research, and presentations or skits in all of the interviews. In addition to these FIRST-specific skills, many coaches and students brought up and/or discussed FIRST's core values. These are the central components of what FIRST believes students should gain from participating in their program, and include discovery, innovation, impact, inclusion, teamwork, and fun. 
Many students discussed the communication skills they gained from participating in robotics, and one student stated, "Being in an activity like robotics, it kind of forces you to communicate with people, you know, because, like, you'll have this idea in your head, and you have to, you know, figure out a way to get this idea that's in your head that you understand completely, but no one else knows about, and you have to figure out a way to communicate it from you to everyone else so they understand it just as well as you." One coach related a story about a former student who was able to earn a scholarship to a prestigious college, and attributed it directly to the skills she gained in public speaking while participating in robotics.

Long Term. This category was closely related to the skills category, so there is some overlap with the data in each of these groups, as discerning whether the impact of a skill was long term or remained in the skills category was largely dependent on the context in which it was described. Long Term for the purposes of this analysis was defined as those skills and behaviors that students and coaches described as having a broader impact on a student's life and had greater significance to the student or included skills that were applied in areas outside of robotics or discussing robotics. As one student described her robotics experience, "It definitely helps in real life."

Students and coaches mentioned the long term impact robotics participation had on students' academic abilities, especially in math, science, and presentation skills. Participants described other powerful long term impacts related to school and life performance in general and the ability to successfully navigate life's challenges. These long-term impacts included perseverance, a shift in thinking, willingness to take risks, not being afraid of something new, dealing with adversity, and the awareness that learning continues into adulthood. 
Confidence was mentioned as a long term impact 13 times across the student interviews and coaches focus groups. Some attributed this to finding like-minded individuals within the robotics program, and these personal connections allowed students to build confidence in who they are as people and students. One female participant said, "You can't just be silent all the time, you have to actually be a part of the team." Another student said, "It got me out of my zone." Additionally, one coach described a student he had seen and how she was able to come out of her shell when a situation required after participating in robotics, saying she now "turns it off and on as needed."

Leadership is another long term impact that was mentioned or described frequently in interviews with coaches and students. Additionally, students and coaches described the broader perspective and increased awareness of their potential impact on the world and their responsibility to a higher purpose as they grow. One student stated, "I used to think I did not like the project at all, but without it, it feels like you're not doing as much as you should be doing." One coach made the prediction that her robotics students would "rule the world one day." Another praised the program's ability to encourage students to "take that purpose beyond just this room."

Careers. Students and coaches mentioned a variety of career possibilities in interviews and focus groups. Both groups agreed that the skills and attitudes learned through robotics would help students in whatever careers they chose. Coaches discussed the careers they predicted their students would enter, and students shared the careers they planned or considered entering. As the interviews progressed, both students and coaches mentioned different careers in response to other questions. None of the coaches discussed having specific plans to have careerrelated discussions in practices, but career discussions arose naturally as they applied to different 
robotics activities. STEM careers were the most frequently mentioned by both students and coaches, with engineering as the most frequently identified career field. Four of the 12 students interviewed mentioned seriously considering careers in engineering and believed robotics to be a determining factor in that decision.

The students mentioned other potential careers, including therapist or psychologist, nurse, teacher, doctor, actress, photographer, rancher, veterinarian, scientist, and working with computers. Aside from engineering, coaches predicted their robotics students would enter a variety of STEM career fields, including science, technology, and math, as well as marketing, education, public speaking, law, architecture, computer programming, videography, nursing, and politics. While one focus group mentioned they might see their students enter vocational and technical careers, the majority predicted that robotics students would enter careers requiring college degrees, and agreed these would most likely be four-year college degrees. One coach stated he believed that his students would become "anything and everything" and "stuff that's not even created yet."

Post-Secondary. The coaches' focus groups agreed that participating in a robotics program significantly helps students with achieving whatever post-secondary goals they may have, whether those goals include college, career, or both. Coaches shared stories of past students who earned college acceptance, scholarships, stipends, and two-year, four-year, and technical degrees and directly attributed these achievements to the students' participating in their robotics programs. For the most part, the students did not mention post-secondary impacts from their robotics experience except for two students from the same urban school. One mentioned wanting to be selected for a NASA internship in the future, and the other was pursuing a degree 
in electrical engineering. Both students credit robotics with giving them the opportunity to follow these post-secondary goals and the confidence to make them a reality in their lives.

\section{Student Descriptors}

The theme of student descriptors applied any time coaches and students described students or themselves in specific characteristics, traits, or behaviors. Further categorization of the theme resulted in the codes of general, male, female, and male-female percentage. The majority of observations regarding specific gender-related behavior fell into this theme.

General. The general category included descriptions of students in general and some overall observations of both male and female students. One coach said in reference to trying different tasks and jobs within the team, "Students really like to, whether it's boy or girl, try to pigeonhole themselves into I like this, and they determine in their minds what they think they're going to like and they become very closed off." The same focus group also indicated students cared more about connecting with the coach of the team and less about worrying if they can do robotics or not when deciding to join.

Several focus groups noted the similarities between male and female students. One coach said, "Females and males both kind of show their emotions too, especially at this age." Another said of all students, "They want it to be done, and they want it done right." Another coach added, "They all have the desire to be there," and the focus group described their students as stronger and self-motivated than other students. None of the focus groups indicated any strong differences between male and female students in general, but one noted, "Guys are pushed into certain fields and girls aren't."

The students described robotics and STEM and its stereotype as a male-dominated field. One student said, "I thought it was more of a boy thing, but then when I tried it, I thought that it 
was also a boy and girl thing because girls don't really do robotics things." Another student declared, "I know that there's no discrimination where I am. So, we were treated the same as boys." Most students indicated that participation is the same for male and female students, with one student stating, "It's an equal playing field. Everyone has the same opportunities and the same challenges and we all have to work together as equals, not as different people."

In addition to discussing the male-female stereotype, students also mentioned other stereotypes that arise in relation to robotics participation. One mentioned, "People think that robotics is for people who only, like are really smart, but you don't have to be really smart to be able to do it." Another student described the engineering field specifically, "There's like the stereotype in engineering that people aren't that great at communication." The same student also added, "You do meet a lot people you know who are very smart, they're very good, but they just kind of are those people that they take those, they take their classes, and they never really have to like, you know, fill that communication side of things because they weren't ever like really in clubs."

Male. The majority of students interviewed did not describe male students in any certain terms. The only student who discussed male students described how boys liked to play with LEGOs and could help with building because they played with LEGOs more. One focus group echoed these ideas, sharing their observations that boys are always building, they tinker, and build nonsense, ridiculous things.

Four of the focus groups noted that their male students are the ones who are more likely to take on the programming and coding responsibilities for the team, although that was not a consistent observation across all the schools. Coaches also described their male students as less focused, more easily distracted, procrastinate more, have less perseverance, more likely to play 
around and not take practice seriously, and more likely to flout rules in comparison to females. Coaches were also quick to note that these were observations that did not apply to all male students, but were commonalities that they observed during the course of their time as coaches.

Female. Both students and coaches shared descriptions of female students. Coaches described their female students in stereotypically negative terms such as bossy, chatty, and nitpicky. However, they overwhelmingly described females in positive terms such as very accepting, more on track, more focused, super driven, creative, organized, on time, supportive, competitive in a friendly way, taking more initiative, and more goal oriented in comparison to male students. Two of the focus groups described females as falling into one of two categories. They saw their females as either completely dedicated to their team, leading, and keeping everyone on track, or they stand back, do nothing, and only do what they are told. A few of the students participated in robotics on all-girls teams and felt that experience was encouraging and built confidence.

Several focus groups mentioned that the female students seemed to behave as if they had something to prove. The students supported this idea through their interviews. One student noted, "A lot of people don't expect the girls to be in robotics. They think it's for boys, which is kind of annoying, but it's also, at the same time, nice because then you can show them that girls can do it." Another student said, "Girls are like, smart and they can help do the programming. We could help them [the boys] with the programming." One coach related what he felt was a pivotal event that he observed on his high school team with one of the interviewed students, sharing, "And what really changed for the whole program, and I'm not trying to just toot her horn, but [student name] got in there, and one of the boys, I watched it happen in front of me, tried to take a screwdriver out of her hand to say, here, let me do it. And she said, 'No, I'm fine. 
I can do it.' And she pushed him out of the way. And that was her sophomore year of high school. And from them on, she took over the electrical team, and it was hers until she was a senior and in charge of the whole team."

Students described other specific instances in which they felt discouraged by male students. One student related, “The boys would tell some of the girls they couldn't do it because they were girls." Another stated that most people are extremely supportive of girls in STEM and robotics, but some of her experiences in college highlighted the stigma that is commonly associated with females in STEM. For example, she stated, "I was in a class today. There was maybe 70 of us. There was me and one other female in the class." She also described that males often assume females are treated better or are given opportunities they didn't deserve just because of their gender, sharing, "For example, when I had my internship my freshman year, I was excited, I told my friends about it because I was really excited. And then, there was people that would kind of overhear it and they would look at you and they're like, well, yeah, but you just got it because you were a female. They didn't actually think that you were qualified for it, that's the only reason you got it. And it's definitely discouraging."

Male-Female Percentage. Of the schools interviewed, both rural schools and one of the suburban schools stated the male to female percentage at their schools were even. At one of the rural schools, this was due to the lottery system they use to place students into the program. At the other rural school, this was credited to the district's push to have a high number of students participating. Both rural schools' robotics programs are strong and well-established, with FIRST programs from kindergarten through high school. The students at the suburban school with an even percentage of male and female students said that most girls at their school chose to participate, and those who did not participate regret passing up the opportunity. Of the 
remaining schools, one suburban school and one urban school stated their numbers were about $25 \%$ female and the other urban school estimated $30 \%$ female.

Other noted factors contributed to the analysis of this category. Several coaches mentioned that the percentage of males to females depended on class makeup and fluctuated from year to year. Only one urban school and one rural school utilized a specific plan for limiting gender bias in course selection. Additionally, the two urban schools also noted that a smaller percentage of male than female robotics students chose to continue to participate at the high school level. This phenomenon was not observed in the rural schools, and neither of the suburban schools had this opportunity available for comparison.

\section{Discussion}

Discussed are the results of this study in the context of the conceptual and theoretical frameworks. Within this section is an analysis in response to answering the research questions guiding the study. This study centered around the conceptual framework of Social Cognitive Theory and the theoretical frameworks of Self-Efficacy Theory of Education, Gender Schema Theory, and robotics programs and females in STEM. A discussion of each of these frameworks in light of the findings of the study follows.

Social Cognitive Theory. This study highlighted the assertion introduced through Social Cognitive Theory (Bandura, 1977) that an individual's social constructs are complex and influenced by a variety of personal and social factors (Cobb \& Bowers, 1996). The students interviewed in the study each exhibited a unique sense of self, ideas of what an appropriate life path looked like for them, and opinions regarding the process involved in coming to these conclusions. It was impossible to separate the strength of the social impacts provided through friends, family, and other important individuals in each student's life from their own personal 
interpretation and choices. The students exemplified Bandura's (1977) idea of reciprocal determinism throughout their interviews by communicating their experiences with the interconnected influence of several factors.

The study analyzed the social context of a robotics program and identified both positive and negative factors that demonstrated a potential impact on the students. These findings are consistent with Social Cognitive Theory (1977) in that it provided evidence that there are myriad factors contributing to an individual's feelings and responses to any situation. It was made clear through this study that the students interviewed experienced the pressures, directions, and guidance from society while simultaneously navigating their place within that society. The study also showed that participating in a robotics program had definite impacts on the study participants and demonstrated the potential to influence them toward STEM careers in the future.

While the study made clear the fact that participating in a robotics program had a significant impact, the students' decisions to remain in robotics or discontinue their participation in the program evidenced the complexity of thought that goes into decision making and provided further support for Bandura's (2001) later research in Social Cognitive Theory. The student interviews and coaches' focus groups substantiated the concepts of personal agency, proxy agency, and collective agency that affect an individual's decisions (Bandura, 2002). Personal agency was seen in the students who described doing robotics simply because they enjoyed it, and is discussed more in the analysis of Self-Efficacy Theory of Education (Bandura, 1986a). Proxy agency was seen through both supporters and discouraging comments from others described by the students and is discussed more through the lens of Gender Schema Theory (Bem, 1981). Finally, collective agency was seen in the students who joined robotics with other 
girls, made influential friendships within the program, or mentored new students, and is examined through the framework of robotics programs and females in STEM.

Self-Efficacy Theory of Education. Student participants in this study related that their middle school robotics experience gave them the realization that robotics was an area they were capable of excelling in, broadened their career choices, and increased their belief in their own abilities within STEM and beyond. Many studies in the literature review revealed the strong correlation between self-efficacy, or belief in oneself, and achievement (Bandura, 1986a; Bandura, 2001; Bandura et al, 2003; Caprara et al., 2008; Hattie, 2018; Pajares, 1996; Usher \& Pajares, 2008). These data answer the primary research question of: How does participating in a school-based robotics program affect the learning and academic self-efficacy of female students?

The coaches and students in this study identified the most powerful impact of participating in a robotics program was increased overall confidence observed in the students. All participants noted and/or described this particular impact of increased confidence, and it was not only contained to academic areas. Students indicated experiencing feelings of confidence in all aspects of their lives. This confidence, which equated to self-efficacy in this analysis, was noted in social situations, increased leadership within the program, and improved skills in academic STEM subjects. These findings supported Bandura's (1993) research establishing significant positive relationships between self-efficacy and goal-setting, ability, memory performance, cognitive effort, and motivation as the students and coaches described similar observations and experiences in their robotics programs. The students also experienced increased self-efficacy in communication, as evidenced by higher confidence in sharing their thoughts and ideas and feeling comfortable working with others. This demonstrated that the 
academic self-efficacy benefits experienced by the student participants extended beyond STEM subjects.

The impact of mastery experiences, vicarious experiences, and verbal persuasions on academic self-efficacy was evidenced in several studies using Self-Efficacy Theory of Education as a framework (Bandura, 1986; Zeldin \& Pajares, 2000). The effect of mastery experiences, or individual experiences of success in particular academic tasks, was seen in this study for those student participants who chose to continue participating in robotics because they were able to envision their continued success. Vicarious experiences were also impactful in this study as students related the importance of participating with other female students on their teams and the coaches related the most successful recruitment strategy was female students convincing other female students to join. In addition, students shared the influence of verbal persuasions as both positive and negative factors on their confidence.

In addition to mastery experiences and vicarious experiences, student participants in this study described many positive verbal persuasions through encouragement from coaches, parents, and other students, but also experienced negative verbal persuasions in the form of genderrelated discouragement from classmates and teammates. However, the positive verbal persuasions in combination with their influential mastery experiences and vicarious experiences resulted in overwhelmingly positive robotics experiences for the students interviewed for this study and demonstrated clear observed and self-proclaimed growth in academic self-efficacy in all of the students who were interviewed.

Gender Schema Theory. The study also illustrated the effects of gender schema (Bem, 1981) on female participation in robotics and answered the secondary research question of: Why do female students choose to participate in a robotics program? The complex interplay of positive 
social influences and the personal decisions to embrace a non-traditional gender schema resulted in each of the students in this study choosing to participate in a robotics program in middle school.

Each of the coaches who participated in focus groups were aware of the impact gender schema can have on students, although only some of the schools had strategies in place to combat the societal tendency to label STEM in general or particular responsibilities as those intended for male or female students. These actions indicated two things. First, these behaviors demonstrated that the coaches were aware that gender identification occurred in their students prior to middle school (Master et al., 2017; Starr \& Zurbriggen, 2016). Second, the coaches directed efforts toward minimizing the impact prior gender socialization caused and created opportunities for students to reframe previously held gender constructs because they understood these constructs to be somewhat malleable (Bem, 1983).

Some of the younger students interviewed for this study stated ideas that indicated clear gender schema influences. For example, one student said, "I thought it was like more of a boy thing, but then when I tried it, I thought that it was also a boy and a girl thing, but I didn't think it was a girl thing because girls don't really do robotic things." Older students noted negative social consequences they received from their peers as a result of participating in an activity other students viewed as inappropriate for their gender (Morgan \& Ayum, 1984). The experiences these students shared included being told they were not capable of doing a particular activity because of their gender and being made to feel they were unqualified to earn praise and recognition because of the perception that they received special treatment due to their gender. These were damaging experiences as children establish a self-concept and a value system built on the premise of their gender identity (Martin, Ruble, \& Szkrybalo, 2008). 
None of the students interviewed felt that they were treated any differently than males by the coaches in their robotics programs, as this is an indication that the coaches chose not to support the encouragement of traditional gender schemas within their programs and were able to counteract the dichotomous social influences of gender schema on their students. Each of the students interviewed expressed an awareness of the stereotype of robotics and STEM as a maledominated field prior to joining robotics and their responses indicated that they chose not to buy into a more rigid traditional gender mindset, instead choosing to give robotics a try as an activity they could enjoy. Many of the students noted the positive encouragement provided by teachers, parents, and coaches were powerful motivators in their decisions to join a robotics team. These findings supported Colander and Rittenour's (2015) assertion that intentional parental influence can significantly increase female students' self-efficacy in STEM subjects, and by extension, broaden their gender schema. This evidence also suggested that this influence was not limited to parents, but was also demonstrated by other adults who encouraged female participation in robotics.

One key takeaway resulting from the analysis of gender schema involved the reasons female students gave for discontinuing their participation in robotics. Several students who stated their intention to not return to the program, indicated this decision was because they wanted to explore other activities. Studies involving Gender Schema Theory indicated this may be the result of gender segregation, or the separation of oneself into behaviors and activities and behaviors that are considered gender appropriate within a given society (Martin et al., 2011). This behavior at the middle school level was not previously identified in the review of existing literature. Prior studies of gender segregation noted these behaviors in preschool and primary 
age students, but none observed this phenomenon in middle school (Bem, 1983; Carter, Levy, \& Cappabianca, 1985; Liben \& Bigler, 2017; Martin et al., 2011).

Substantial evidence of the rejection of the traditional gender schema in the students who participated in this study is seen in the careers they considered or ultimately chose. Of the eighteen career options envisioned by the students, sixteen of those were in STEM fields. These STEM fields were not limited to skills directly related to robotics, but also included careers in science and medical fields. One of the students shared she experienced the type of verbal discrimination described by Woodington (2010), wherein a peer insinuated that her femaleness somehow made her less qualified. Although discouraged, this student realized this was not an accurate representation of her abilities and chose to continue working toward her goal of becoming an electrical engineer due to the gender schema and development she experienced in her middle school and high school robotics experiences. These findings are consistent with the findings of previous studies that showed females in STEM careers exhibited less traditional gender schemas (Lavallee \& Pelletier, 1992; Lemons \& Parzinger, 2007) and their gender schemas were heavily impacted by their adolescent experiences (Morgan, Gelbgiser, \& Weeden, 2013).

Robotics Programs and Females in STEM. Each of the conceptual and theoretical frameworks come together within the context of robotics programs and females in STEM and this combination answered the remaining research questions. Some of the female students interviewed described specific instances where they had been the recipients of negative social sanctions as discussed in Social Cognitive Theory as a result of their participation in robotics (Bandura, 1986; Morgan \& Ayum, 1984). However, instead of pushing these students away from STEM, these experiences strengthened their resolve to make their mark in the field. This 
observation answered the research question of: How does participation in a robotics program affect female students' career aspirations? Several of the students indicated they planned to enter STEM fields as a career or had a STEM career as an option they were considering. Even those who did not plan to continue with STEM through their career suggested that they were aware STEM was a career path that was open to them.

The choice to join a traditionally male-dominated field such as robotics is strongly supported by the ideas in Gender Schema Theory (Bem, 1981; Bem, 1983) and other studies that indicated females in STEM actively push back on activities that are considered more in line with traditional gender schemas (Lavallee \& Pelletier, 1992; Lemons \& Parzinger, 2007). This rejection of the more traditional gender schema would not be possible without the self-efficacy1 and belief in one's abilities to gain success in the field as identified in Self-Efficacy Theory of Education (Bandura, 1986; Pajares, 1996) and answered the final research question of: How do female students' perceptions of STEM fields change over time after participating in a robotics program? As evidenced in previous research (Veltman, Davidson, \& Deyell, 2012), robotics programs have significant potential to increase self-efficacy, positive attitudes, and STEM career consideration for both female and male students. This study reinforced the findings from earlier studies that increasing access and opportunity to robotics programs at all age levels should be an area of educational focus in order to overcome perceptions of gender bias (Alimissis \& Moro, 2016) and develop an environment that ensures female students can thrive in STEM subjects (Fluck et al., 2016). 


\section{Implications}

Collectively, the data gained in this study contributed information to the field of study in the areas of significance to the field of study, recommendations for schools, and suggestions for further research.

\section{Significance to the Field of Study}

The data gained in this study indicated that individual gender schema is well-established by the middle school years, and it is a transformative moment in life when one must choose what to do with that knowledge. While this finding supported the idea found in Gender Schema Theory that posits an individual has personal agency to accept or reject the traditional gender schema (Bem, 1983), the focus on middle school as a pivotal time when this acceptance or rejection occurs as it relates to one's future in STEM was not found in any of the previous studies.

Additionally, the evidence suggested that female students may choose to leave robotics programs to pursue other activities in middle school and high school due to the potential influence of gender segregation, a concept which had previously only been observed in very young children. This suggested that the transitions inherent to the middle school experience lead students to feel their gender identity is threatened, resulting in students exhibiting the need to recalibrate their gender identities and return to more traditional gender role and activities. This is not to suggest that this is the only factor influencing these students' decisions to leave robotics in favor of activities such as sports and drama, but it is an interesting factor to note as this was a common theme in the students who chose not to continue in robotics.

This evidence of the transformative period students experience in middle school and the observed tendencies to rethink one's gender identity categorization when social contexts are in 
flux should be noted as a key finding of this study. The findings of this study implied that middle school students may feel the need to recalibrate gender identity on a cyclical basis. This information indicated action on behalf of schools and researchers to learn more about how to best encourage and reassure students who may lose confidence in their gender identity at this particular time in their lives. This focus has the potential to significantly increase the number of students who choose STEM career paths, and will especially benefit females and other marginalized groups who are underrepresented in STEM fields.

\section{Recommendations for Schools}

Based on the results of this study, several recommendations are made for schools. These recommendations include provide support for robotics programs, focus on both adult and student mentorship for students, and expand opportunity and eliminate obstacles so students have a better chance to participate and fewer reasons to discontinue.

Support Robotics Programs in Schools. The results of the study indicated students who do not have middle school and high school robotics experiences do not feel as prepared entering STEM fields. This highlighted the need for school districts to fully support robotics programs. The most successful programs as indicated by the districts participating in this study were those that had implemented a clear progression of robotics activities from elementary to middle to high school. This was evident no matter the size of the district, with the most successful programs located in the rural and urban districts. These districts embedded robotics into the culture of their schools, with students taking great pride in being a part of the team and enjoying community-wide support in their successes.

Focus on Mentorship. Schools can capitalize on the benefits students receive from participating in a school-based robotics program by focusing on the mentorship students have access to 
through robotics. There was not a single factor that led to students' decisions to remain in robotics or leave the program, but each of the students did mention adult support in their lives. This mentor focus should include coaches, parents, and experts from the community who can contribute time to helping lead robotics teams and students through practices, expert knowledge, and allowing students to put a face with careers. This can be especially impactful for female students when they have access to other females who are experts and leaders in their fields.

In addition to adult mentorship, student mentorship was also noted to be a powerful factor in encouraging female students to join and remain in robotics. This may be in the form of veteran students leading new students or former students coming back after college to volunteer time to the program.

Expand Opportunity and Eliminate Obstacles. Several students who participated in this study mentioned that the middle school level offered more opportunities for available activities. This expanded menu of options was a significant contributing factor in their decision to leave robotics as these activities competed for time and space in the students' lives. Schools should look into ways to allow students to choose robotics and other potential career fields in addition to sports and fine arts by developing creative ways of structuring time before, during, and after the school day. This may include creating robotics classes so that it these academic activities can be completed during the school day, alternating practice days, or utilizing weekend practice schedules.

\section{Suggestions for Future Research}

A few research paths come to mind when considering the need for further research on this topic. First, research should be conducted to look at more specific data regarding where gender schema comes into play at the elementary level and see what can be implemented at those 
levels to combat the traditional gender schema ideas that keep students from joining robotics in the later elementary years. Second, when middle school students have to choose between robotics and other activities in middle school, what is leading them to their decisions? Are they choosing the activities that they feel are more appropriate for their gender? Third, schools that are experiencing great success at producing students who enter STEM careers should be studied to gain both quantitative and qualitative data regarding what makes those schools unique and what systems they have put in place. These are the schools that actively combat the shortage of STEM workers and society needs to learn from their example in order to solve this issue in the future.

\section{Summary}

This article detailed the contribution to practice developed from the study entitled "A Multiple Case Study of Female Students' Academic Self-Efficacy While Participating in a Middle School Robotics Program." Included in this section was an executive summary, which shared a brief overview of the main parts of the study, and an analytic summary, which briefly shared the main parts of the study and included a full analysis of the results and implications. These documents will be shared with parties interested in learning from and applying the results.

\section{List of Abbreviations}

STEM: Science, Technology, Engineering, and Mathematics

FIRST: For Inspiration and Recognition of Science and Technology, a global youth robotics program

FLL: FIRST LEGO League, a middle school progression of FIRST for students 11-14 or grades 4-8 


\section{Declarations}

Any declarations are listed in this section.

\section{Availability of Materials}

All data generated or analysed during this study are included in this published article and its supplementary information files.

\section{Competing interests}

The authors declare that they have no competing interests.

\section{Funding}

The authors received no funding for the completion of this study.

\section{Authors' contributions}

Not applicable

\section{Acknowledgements}

Not applicable 


\section{References}

Alimissis, D. \& Moro, M. (2016). Special issue on educational robotics: Editorial. Robotics and Autonomous Systems, 77, 74-75.

Bandura, A. (1977). Social learning theory. Englewood Cliffs, NJ: Prentice-Hall.

Bandura, A. (1986). The explanatory and predictive scope of self-efficacy theory. Journal of Social and Clinical Psychology, 4(3), 359-373.

Bandura, A. (1993). Perceived self-efficacy in cognitive development and functioning. Educational Psychologist, 28(2), 117-148.

Bandura, A. (1997). Self-efficacy: The exercise of control. New York, NY: W H Freeman/Times Books/ Henry Holt \& Co.

Bandura, A. (2001). Social cognitive theory: An agentic perspective. Annual Review of Psychology, 52, 1-26.

Bandura, A. (2002). Social cognitive theory in cultural context. Applied Psychology: An International Review, 51(2), 269-290.

Bandura, A., Barbaranelli, C., Caprara, G. V. \& Pastorelli, C. (1996). Multi-faceted impact of self-efficacy beliefs on academic functioning. Child Development, 67, 1206-1222.

Bandura, A., Barbaranelli, C., Caprara, G. V., \& Pastorelli, C. (2001). Self-efficacy beliefs as shapers of children's aspirations and career trajectories. Child Development, 72(1), 187-206.

Bandura, A., Caprara, G. V., Barbaranelli, C., Gerbino, M., \& Pastorelli, C. (2003). Role of affective self-regulatory efficacy in diverse spheres of psychosocial functioning. Child Development, 74(3), 769-782.

Bandura, A. \& Locke, E. A. (2003). Negative self-efficacy and goal effects revisited. Journal 
of Applied Psychology, 88(1), 87-99. https://doi.org/10.1037/0021-9010.88.1.87

Bem, S. L. (1981). Gender schema theory: A cognitive account of sex typing. Psychological Review, 88(4), 354-364.

Bem, S. L. (1983). Gender schema theory and its implications for child development: Raising gender aschematic children in a gender-schematic society. Signs, 8(4), 598-616.

Carter, D. B., Levy, G. D., \& Cappabianca, J. M. (1985). Stereotype knowledge, flexibility, and gender constancy: Applications of gender schema theory to sex-typing by preschoolers. Paper presented at biennial meeting of Society for Research in Child Development. Toronto, Ontario, Canada.

Caprara, G. V., Fida, R., Vecchione, M., Del Bove, G., Vecchio, G. M., Barbaranelli, C., \& Bandura, A. (2008). Longitudinal analysis of the role of perceived self-efficacy for self-regulated learning in academic continuance and achievement. Journal of Educational Psychology, 100(3), 525-534. https://doi.org/10.1037/0022-0663.100.3.525

Cobb, P. \& Bowers, J. (1999). Cognitive and situated learning perspectives in theory and practice. Educational Researcher, March, 4-15.

Colaner, C. W. \& Rittenour, C. E. (2015). "Feminism begins at home": The influence of mother daughter gender socialization on daughter career and motherhood aspirations as channeled through daughter feminist identification. Communication Quarterly, 63(1), 8198. DOI: $10.1080 / 01463373.2014 .965839$

Fluck, A., Webb, M., Cox, M., Angeli, C., Malyn-Smith, J., Voogt, J., \& Zagami, J. (2016). Arguing for computer science in the school curriculum. Educational Technology \& Society, 19(3), 38-46. 
Hattie, J. (2008). Visible learning: A synthesis of over 800 meta-analyses relating to achievement. New York City, NY: Routledge.

Hattie, J. (2018). Visible learning plus: 250+ influences on student achievement [PDF file]. Retrieved from www.visiblelearningplus.com

Lavallee, M. \& Pelletier, R. (1992). Ecological value of Bem's gender schema theory explored through females' traditional and nontraditional occupational contexts. Psychological Reports, 1992(70), 79-82.

Lemons, M. A. \& Parzinger, M. (2007). Gender schemas: A cognitive explanation of discrimination of women in technology. Journal of Business and Psychology, 22, 91-98.

Martin, C. L., Fabes, R. A., Hanish, L., Leonard, S., \& Dinella, L. M. (2011). Experienced and expected similarity to same-gender peers: Moving toward a comprehensive model of gender segregation. Sex Roles, 2011(65), 421-434. DOI 10.1007/s11199-011-0029-y

Master, A., Cheryan, S., Moscatelli, A., \& Meltzoff, A. N. (2017). Programming experience motivates higher STEM motivation among first-grade girls. Journal of Experimental Child Psychology, 160, 92-106.

Morgan, K. P. \& Ayim, M. (1984). Comment on Bem's gender schema theory and its implications for child development: Raising gender aschematic children in a genderschematic society. Signs, 10(1), 188-196.

Morgan, S. L., Gelbgiser, D., \& Weeden, K. A. (2013). Feeding the pipeline: Gender, occupational plans, and college major selection. Social Science Research 42, 989-1005.

Pajares, F. (1996) Self-efficacy beliefs in academic settings. Review of Educational Research, $66(4), 543-578)$. 
Pajares, F. (2002a). Gender and perceived self-efficacy in self-regulated learning. Theory into Practice, 41(2), 116-125.

Pajares, F. (2002b). Overview of social cognitive theory and self-efficacy. Retrieved from https://www.uky.edu/ eushe2/Pajares/eff.html

Pajares, F. \& Johnson, M. T. (1994). Confidence and competence in writing: The role of self-efficacy, outcome expectancy, and apprehension. Research in the Teaching of English, 28(3), 313-331.

Pajares, F., Johnson, M. T., \& Usher, E. L. (2003). Sources of writing self-efficacy beliefs of elementary, middle, and high school students. Research in the Teaching of English, 42(1), 104-120.

Pajares, F. \& Miller, M. D. (1994). Role of self-efficacy and self-concept beliefs in mathematical problem solving: A path analysis. Journal of Educational Psychology, 86(2), 193-203.http://dx.doi.org/10.1037/0022-0663.86.2.193

Starr, C. R. \& Zurbriggen, E. L. (2016). Sandra Bem's gender schema theory after 34 years: A review of its reach and impact. Sex Roles, March. https://doi.org/10.1007/s11199-016$\underline{0591-4}$

Usher, E. L. \& Pajares, F. (2006). Inviting confidence in school: Invitations as a critical source of the academic self-efficacy beliefs of entering middle school students. Journal of Invitational Theory and Practice, 12, 7-16

Usher, E. L. \& Pajares, F. (2008). Sources of self-efficacy in school: Critical review of the literature and future directions. Review of Educational Research, 78(4), 751-796.

Veltman, M., Davidson, V., \& Deyell, B. (2012). Advances in engineering education: Richer connections to robotics through project personalization. Paper presented at American 
Society for Engineering Education Summer 2012. Ontario, Canada.

Woodington, W. (2010). The cognitive foundations of formal equality: Incorporating gender schema theory to eliminate sex discrimination towards women in the legal profession. Law Psychology Review, 34(1), 135-152.

Zeldin, A. L. \& Pajares, F. (2000). Against all odds: Self-efficacy beliefs of women in mathematical, scientific, and technological careers. American Educational Research Journal, 37(1), 215-246. 
SECTION SIX

\section{SCHOLARLY PRACTITIONER REFLECTION}


My dissertation journey has been unique and full of surprises and lessons. This makes my personal experience not dissimilar to other dissertation journeys in that I am certain no one can predict the shape and course of their study. Through the course of learning the scholarly details and depth of analysis that go into scientific research I now appreciate. The analyzing the scholarly journals and sharing the research, and then applying this knowledge to my dissertation research, I have been the recipient of scholarly and leadership impacts that I have no doubt will continue to benefit me throughout my career as an educator and researcher.

\section{Scholarly Impacts}

While conducting research and analysis of my dissertation study, many influential global events occurred. The first was the COVID-19 pandemic. A type of novel Coronavirus and the disease it causes, COVID-19, continues to be a global viral threat of unknown proportions. In late January and early February of 2019, reports of individuals with a mysterious respiratory virus began to come out of China with alarming frequency and increasing seriousness. The reports detailed a highly contagious virus with an odd array of symptoms and catastrophic results in many patients. The virus quickly became categorized as a global pandemic. The United States watched as Italy's medical infrastructure collapsed, leaving many people without healthcare options, and many deaths that could have been prevented had their medical system not been overwhelmed. The world was stunned and began looking toward their own countries to prevent similar results.

Around most schools' scheduled spring break, all schools in the United States closed their doors for the near future at the order of their governors intending to stop the spread of COVID-19. As schools are known to be a hotbed of infectious disease on a good day, this was seen as a logical and necessary preventative measure in the face of a deadly global pandemic. 
Businesses were also shuttered, and one-by-one, every state's governor asked everyone except those deemed essential workers to stay home. Schools developed virtual instruction plans for students nearly overnight. Everyone scrambled to figure out the best ways to protect their families, figure out telework logistics, and decide the best course of action to stamp out the virus.

Words like social distancing, unprecedented, and pandemic became part of our daily vocabulary. The president began giving daily briefings as the virus crept across the country, hitting New York City especially hard. The virus appeared to strike the elderly and those with compromised immune systems or underlying health conditions the hardest, but there were also stories of many perfectly healthy individuals falling ill and dying. Also concerning, it became apparent our country's infrastructure was woefully unprepared for a global pandemic. Hospitals and medical staff were lacking in personal protective equipment, hand sanitizer, and ventilators for critically ill patients. For some still unknown reason, there was also no toilet paper to be found in stores. An apocalyptic feeling of doom settled over the citizens of many countries.

Parents were asked to be more involved than usual with teaching their children. Teachers prepared lessons to be completed at home and tried to provide support through videos, videoconferencing, and chatting. Many parents were working from home or still working in essential jobs, and it became overwhelming for many parents trying to juggle it all. Teachers like me tried our hardest to connect with students, reaching out as often as possible without trying to further burden families, but there was limits to the amount of support we could provide while caring of our families. The educational fallout is still to be determined, but by all accounts, it will be severe. 
At the time, I am writing this chapter, schools are attempting to reopen their doors to students by utilizing a wide variety of safety protocols to protect students and staff from COVID19. There are people claiming COVID-19 is a global hoax created to undermine the president and they are determined to not be controlled by the government or live in fear. Others are proceeding with caution, wearing masks, and continuing to limit their social interactions. Then there is my family and others like ours. My husband has a severe heart condition and my son has Type 1 diabetes, both of which have been labeled as high-risk conditions for the Coronavirus. We are staying at home as much as possible, the children are doing virtual learning, and I am teaching virtually. I still have to go into the school building, but my exposure to others is significantly reduced. The school does not look the way it typically has in the past, but society has determined the machine of economics must remain unchanged. Open schools have been deemed an essential part of that system, so we are opening them even in the face of a society that refuses to take the necessary steps to control the virus.

In addition to the COVID-19 pandemic, on May 25, 2019, a man named George Floyd was killed during a police encounter in Minneapolis, Minnesota. Arrested for allegedly using a counterfeit bill, Mr. Floyd was beaten and wrestled to the ground, where a police officer put his knee to the back of Mr. Floyd's neck for 8 minutes and 46 seconds. Mr. Floyd died of asphyxiation. Bystanders who could be heard crying out for the officers to stop as Mr. Floyd was repeatedly heard saying, "I can't breathe!" until he lost consciousness filmed this encounter. No medical care was given to Mr. Floyd until the ambulance arrived sometime later, and Mr. Floyd was pronounced dead. The event ended up being the final straw in a string of racially motivated murders of Black people and Black deaths associated with police brutality. After being locked at home for months, the United States was primed and ready for an uprising. 
The video of George Floyd's death circulated quickly through social media. Black Lives Matter (BLM) protests were organized all over the country and the world. Most of these protests were peaceful, but violence broke out in a few cities that resulted in significant damage, rioting, and looting. The president of the United States, Donald J. Trump, stirred the pot of instability by calling protesters "thugs" and suggesting the far-left resistance group Antifa was responsible for the violence even though no evidence of that has been found to date. It became known that farright white supremacist groups were responsible for instigating a large percentage of the damage, infiltrating BLM protests to cast doubt on the movement's intentions. Peaceful protests and violent riots alike continue to rage across the nation, increasing with intensity each time another Black person is killed by law enforcement.

It is against the backdrop of these historic events and unprecedented political turmoil that I attempted to complete data collection and analysis for my dissertation. Because of these events and the dissertation process itself, there were several personal impacts I experienced. These included the personal acceptance of a lack of control even in the most carefully planned studies, a greater commitment to the necessity of flexibility, and the knowledge that every study cannot help but be affected by its context, even if that context is not related to the topic or field of study.

Nothing ever occurs in a vacuum, and the current events and social atmosphere immensely affected the data collection process of my dissertation study. What was going to be in-person observations, interviews, and focus groups, now had to be conducted virtually. The University of Missouri permitted qualitative data to be collected virtually with no changes to the IRB protocol. Two observations were already completed before schools were shut down, but the other observations were scrapped as no robotics teams were meeting due to school closings, and 
my school district put travel restrictions on employees. I was able to connect and complete interviews and focus groups at two rural schools and two suburban schools with little difficulty as the virus had not yet reached most of the small towns of Missouri. It was the urban districts, however, that proved to be difficult. Due to the proximity in which many urban citizens live and the fact, these cities are global travel hubs, Kansas City and St. Louis quickly became coronavirus hot spots. Data collection prospects that I had lined up became unavailable and understandably had significantly larger issues to deal with than helping me work on my dissertation study. As these are the only areas classified as urban according to the parameters I set for my study, this proved a nearly insurmountable obstacle to the data collection process.

This experience demonstrated that as a researcher, even the best plans could be thrown off track by events that are completely outside anyone's control. Every study takes place within the context of the world that is being observed at a given moment in time. As a result, data are unavoidably affected by their context. I cannot help but wonder how my participants' responses were altered by these events and if their answers would have changed depending on if I had collected the data before or after these events. These are questions that will linger and I am sure are present in every research study. Experiencing this first hand showed me just how delicate and easily influenced data are and why all data and studies should be carefully scrutinized.

\section{Leadership Impacts}

Through the doctoral course of study, I gained significant knowledge regarding organizations through the perspective of Bolman and Deal (2016), educational institutions through the eyes of a variety of stakeholders, systemic issues from the viewpoint of the marginalized and oppressed, and leadership as seen by the leaders and the followers. As an educator with strengths of input, intellection, and analysis, I have always strived to see the bigger 
picture of education outside of my classroom and my sphere of influence. The lessons I learned and the people I connected to through the doctoral program allowed me to expand my mind and my ability to think critically about each of these topics from so many valuable perspectives. The ability to step back and view leadership situations from many perspectives is a leadership skill I will carry with me in my professional and personal life and has led to my development as an authentic leader.

The most personally transformative leadership impact the doctoral program and the dissertation process has had on me is that I have gained the confidence to become an authentic leader. Truthfully, I have always hidden behind political correctness and the type of person I thought I was supposed to be as dictated by the small rural community in which I was raised and the small suburban community my family and I currently call home. There are many reasons for this that I will not get into for this dissertation, but both communities are heavily influenced by traditional conservative values. As I stated in section two, authentic leaders should understand their purpose, have a strong sense of right and wrong, build trusting relationships, and are passionate about goals. The doctoral program and the dissertation process have strengthened these characteristics within me and solidified my dedication to their importance and my commitment to continuing to work toward authenticity.

I understand my purpose. As an educator, I have always put the needs of my students above all others. Teaching is a calling for me, and my students have influenced my life just as much or more than I have impacted theirs. My purpose is to help mold the next generation into productive citizens, critical thinkers, and all-around good people. This means helping them to overcome obstacles, teaching students to believe in themselves, and being a person they can count on to help them set goals and achieve them. My journey through the doctoral program and 
my dissertation has ingrained my purpose even more deeply. I believe I am exactly where I am supposed to be at this moment in time. I can more clearly see the struggles my students and their families face on socioeconomic, academic, and policy levels because of these experiences, and I am more equipped to make sure my school district has the tools to help them overcome these challenges.

As an authentic leader, I have a strong sense of right and wrong. The doctoral and dissertation journeys helped crystallize my personal beliefs of right and wrong and gave me increased confidence to stand up for social justice issues in my community, state, and around the nation. Through this gained confidence, the difficult events of the COVID-19 pandemic, and the re-energized national focus on racial equality, I find I am unable to remain quiet about social injustice, inequalities in education, and the experiences of teachers and students. While these social justice issues sometimes are framed to indicate they are at odds with traditional conservatism, I have found common ground in fighting for what is right. Those around me see me as a leader, and this journey has made me more comfortable using my voice to improve the lives of marginalized groups. From the very beginning of the doctoral journey when instructors asked students to learn about their strengths, I found ways to use my strengths of input, intellection, and analysis to research facts and information and educate those around me on important issues.

Authentic leaders also build trusting relationships. As I have gained confidence using my voice and standing up for what I believe, I have found those within my sphere of influence reaching out to me as a sounding board for ideas that might be unwelcome in certain spaces. Or as a collaborator on professional projects on which they want me to work with them, and for advice in professional and personal situations as they relate to the professional setting and 
personal impacts. I am humbled and honored to have built relationships that are trusting enough for these individuals to allow me into their confidence. I cannot help but feel this is because these individuals trust my opinions and advice, and know where my priorities lie and what I stand for.

Finally, authentic leaders are passionate about goals. This is the part of authentic leadership that I believe has led to my increased confidence and inability to remain silent about issues of right and wrong. Through the doctoral and dissertation journey, I have found my passion lies in education and the opportunities education should be providing for all students to set limitless goals on what they can accomplish in life. As an educator, my responsibility is to remove barriers and help students overcome obstacles that I cannot remove or change. Those around me have learned there are certain topics that I am enthusiastic about when I talk about them. All of these topics include issues of social justice, equity, and access to educational and career opportunities for all students, especially marginalized groups. My dissertation topic focused on females who are not receiving the support they need to help them reach STEM careers in the same capacity as male students. However, through the course of my dissertation study, I also came to be hyper-aware that females are not the only groups being disenfranchised from attaining STEM careers. I see many ways in which my research can be expanded to inform educational practices that will benefit many marginalized groups.

\section{Conclusion}

My doctoral and dissertation journeys left many lasting impacts on me as a researcher, educator, leader, and citizen. The social impacts of personal acceptance of a lack of control, a deeper commitment to flexibility and the awareness of the power of context will continue to be demonstrated and practiced throughout my future professional and personal experiences. 
Besides, the leadership impacts of a stronger understanding of the organizational structure, the perspectives of a variety of stakeholders, systemic issues from the viewpoint of the marginalized and oppressed, and my developing authentic leadership allow me to approach my future leadership roles with a wider lens than previously held. I am eternally grateful for the instruction, support, guidance, and assistance provided to me throughout my doctoral journey by the many stakeholders present in my life. I can only hope to pay it forward by putting these skills to use in a way that honors those who have believed in me along the way. 


\section{References}

Abdullah, S. M. (2019). Social cognitive theory: A Bandura thought review published in 1982-2012. Psychodimensional, 18(1), 85-100. DOI 10.24167/psidim.v18i1.1708

Afari, E. \& Khine, M. S. (2017). Robotics as an educational tool: Impact of Lego Mindstorms. International Journal of Information and Education Technology, 7(6), 437-442. https://doi.org/10.18178/ijiet.2017.7.6.908

Agosto, D. E. (2004). Using gender schema theory to examine gender equity in computing: A preliminary study. Journal of Women and Minorities in Science and Engineering, 10, 37-53.

Alimissis, D. \& Moro, M. (2016). Special issue on educational robotics: Editorial. Robotics and Autonomous Systems, 77, 74-75.

Atmatzidou, S. \& Demetriadis, S. (2016). Advancing students' computational thinking skills through educational robotics: A study on age and gender relevant differences. Robotics and Autonomous Systems, 75, 661-670.

Bae, C. L. \& DeBusk-Lane, M. (2019). Middle school engagement profiles: Implications for motivation and achievement in science. Learning and Individual Differences, 2019 (74). https://doi.org/10.1016/j.lindif.2019.101753

Bandura, A. (1977). Social learning theory. Englewood Cliffs, NJ: Prentice-Hall.

Bandura, A. (1979). Self-referent mechanisms in social learning theory. American Psychologist, May, 439-441.

Bandura, A. (1986a). The explanatory and predictive scope of self-efficacy theory. Journal of Social and Clinical Psychology, 4(3), 359-373.

Bandura, A. (1986b). Social foundation of thought and action: A social cognitive theory. 
Englewood Cliffs, NJ: Prentice-Hall.

Bandura, A. (1993). Perceived self-efficacy in cognitive development and functioning. Educational Psychologist, 28(2), 117-148.

Bandura, A. (1997). Self-efficacy: The exercise of control. New York, NY: W H Freeman/Times Books/ Henry Holt \& Co.

Bandura, A. (2001). Social cognitive theory: An agentic perspective. Annual Review of Psychology, 52, 1-26.

Bandura, A. (2002). Social cognitive theory in cultural context. Applied Psychology: An International Review, 51(2), 269-290.

Bandura, A., Barbaranelli, C., Caprara, G. V. \& Pastorelli, C. (1996). Multi-faceted impact of self-efficacy beliefs on academic functioning. Child Development, 67, 1206-1222.

Bandura, A., Barbaranelli, C., Caprara, G. V., \& Pastorelli, C. (2001). Self-efficacy beliefs as shapers of children's aspirations and career trajectories. Child Development, 72(1), $187-206$.

Bandura, A., Caprara, G. V., Barbaranelli, C., Gerbino, M., \& Pastorelli, C. (2003). Role of affective self-regulatory efficacy in diverse spheres of psychosocial functioning. Child Development, 74(3), 769-782.

Bandura, A. \& Locke, E. A. (2003). Negative self-efficacy and goal effects revisited. Journal of Applied Psychology, 88(1), 87-99. https://doi.org/10.1037/0021-9010.88.1.87

Bardach, E. \& Patashnik, E. M. (2016). A practical guide for policy analysis: The eightfold path to more effective problem solving (5th ed.). Los Angeles, CA: Sage.

Bazylev, D., Margun, A., Zimenko, K., Kremlev, A., Rukujzha, E. (2014). Participation in robotics competition as motivation for learning. Procedia Social and Behavioral 
Sciences, 152, 835-840.

Bem, S. L. (1981a). Gender schema theory: A cognitive account of sex typing. Psychological Review, 88(4), 354-364.

Bem, S. L. (1981b). The BSRI and gender schema theory: A reply to Spence and Helmrich. Psychological Review, 88(4), 369-371.

Bem, S. L. (1983). Gender schema theory and its implications for child development: Raising gender aschematic children in a gender-schematic society. Signs, 8(4), 598-616.

Bem, S. L. \& Bem, D. J. (1973). Training the woman to know her place: The social antecedents of women in the world of work. Pennsylvania State Department of Education: Harrisburg, PA.

Benitti, V. (2012). Exploring the educational potential of robotics in schools: A systematic review. Computers \& Education, 58, 978-988.

Bers, M. U., Flannery, L., Kazakoff, E. R., \& Sullivan, A. (2014). Computational thinking and tinkering: Exploration of an early childhood robotics curriculum. Computers \& Education, 72, 145-157.

Blotnicky, K. A., Franz-Odendaal, T., \& Joy, P. (2018). A study of the correlation between STEM career knowledge, mathematics self-efficacy, career interests, and career activities on the likelihood of pursuing a STEM career among middle school students. International Journal of STEM Education 5(22). doi:10.1186/s40594-018-0118-3

Bolman, L. G. \& Deal, T. E. (2013). Reframing organizations (5th ed.). San Francisco, CA: Jossey-Bass.

Burack, C., Melchoir, A., \& Hoover, M. (2018, June). Do after-school robotics programs expand the pipeline into STEM careers in college? Paper presented at 2018 American Society 
for Engineering Education Annual Conference and Exposition, Salt Lake City, UT.

Bussey, K. \& Bandura, A. (1999). Social cognitive theory of gender development and differentiation. Psychological Review, 106(4), 676-713.

Butler, D. (2016). College access and opportunity. In Loss, C. P. \& McGuinn, P. J. (Eds.) (p. 137-164). The convergence of K-12 and higher education: Policies and programs in a changing era. Cambridge, MA: Harvard Education Press.

Caffarella, R. S. \& Daffron, S. R. (2013). Planning programs for adult learners (3rd ed.). San Francisco, CA: Jossey-Bass.

Carter, D. B., Levy, G. D., \& Cappabianca, J. M. (1985). Stereotype knowledge, flexibility, and gender constancy: Applications of gender schema theory to sex-typing by preschoolers. Paper presented at biennial meeting of Society for Research in Child Development. Toronto, Ontario, Canada.

Caprara, G. V., Fida, R., Vecchione, M., Del Bove, G., Vecchio, G. M., Barbaranelli, C., \& Bandura, A. (2008). Longitudinal analysis of the role of perceived self-efficacy for self-regulated learning in academic continuance and achievement. Journal of Educational Psychology, 100(3), 525-534. https://doi.org/10.1037/0022-0663.100.3.525

Cobb, P. \& Bowers, J. (1999). Cognitive and situated learning perspectives in theory and practice. Educational Researcher, March, 4-15.

Colaner, C. W. \& Rittenour, C. E. (2015). "Feminism begins at home": The influence of mother daughter gender socialization on daughter career and motherhood aspirations as channeled through daughter feminist identification. Communication Quarterly, 63(1), 8198. DOI: $10.1080 / 01463373.2014 .965839$ 
Collins, J. (2011). Level 5 leadership. In Harvard Business Review (Ed.). HBR's 10 Must Reads: On Leadership (115-136). Boston, MA: Harvard Business Review Press.

Coyle, E. F. \& Liben, L. S. (2016). Affecting girls' activity and job interests through play: The moderating roles of personal gender salience and game characteristics. Child Development, 87(2), 414-428. DOI: 10.1111/cdev.12463

Creswell, J. W. (2014). Research design: Qualitative, quantitative, and mixed methods approaches (4th ed.). Los Angeles, CA: Sage.

Cristoforis, P., Pedre, S., Nitsche, M., Fischer, T., Pessacq, F., \& De Pietro, C. (2013). A behavior-based approach for educational robotics activities. IEEE Transactions on Education, 56(1), 61-66.

Dar, L. (2016). Institutional assessment and accountability. In Loss, C. P. \& McGuinn, P. J. (Eds.) (p. 103-114). The convergence of K-12 and higher education: Policies and programs in a changing era. Cambridge, MA: Harvard Education Press.

Datnow, A. \& Park, V. (2014). Data-driven leadership. San Francisco, CA: Jossey-Bass.

Deemer, E. D. \& Sharma, P. (2018). Situational interest and scientific self-efficacy: Influence of an energy science career intervention. The Career Development Quarterly, 67, 171-184. DOI: $10.1002 /$ cdq. 12179

Denner, J., Valdes, O., Dickson, D. J., \& Laursen, B. (2019). Math interest and self-concept among latino/a students: Reciprocal influences across the transition to middle school. Journal of Adolescence, 2019(75), 22-36.

DuBois, J. M., Strait, M. \& Walsh, H. (2017). Is it time to share qualitative research data? Qualitative Psychology, 5(3), 380-393.

Eguchi, A. (2016). RoboCupJunior for promoting STEM education, 21st-century learning 
skills, and technological advancement through robotics competition. Robotics and Autonomous Systems, 75, 692-699.

Flannery, L. P. \& Bers, M. U. (2013). Let's dance the "Robot Hokey Pokey!" Children's programming approaches and achievement through early cognitive development. Journal of Research on Technology in Education, 46(1), 81-101.

Fluck, A., Webb, M., Cox, M., Angeli, C., Malyn-Smith, J., Voogt, J., \& Zagami, J. (2016). Arguing for computer science in the school curriculum. Educational Technology \& Society, 19(3), 38-46.

For Inspiration and Recognition of Science and Technology (FIRST). (2017). FIRST: The impact. Retrieved from:https://www.firstinspires.org/about/impact?utm_medium=email\&utm_campaign=\& $\underline{\text { utm__source=first-newsletter\&utm } \_ \text {content }=\& u t m \_t e r m=\& \text { hsenc }=p 2 \mathrm{ANqtz}-}$ $\underline{\text { 8sdWHf1QfIezK- }}$ Yiwr5aE1RKOaIkRiebCva1Wsa5Yj69HVkiJuvVL4OqFoJ6a1iHiYDVDACWP9zA0ZwKLnS_Jf7n-sSaqan4g9dDIpPq-C06kx8\&_hsmi=58784819.

George, B., Sims, P., McLean, A. N., \& Mayer, D. (2011). Discovering your authentic leadership. In Harvard Business Review (Ed.), HBR's 10 Must Reads: On Leadership (163-177). Boston, MA: Harvard Business Review Press.

Gill, S. J. (2010). Developing a learning culture in nonprofit organizations. Thousand Oaks, CA: Sage Publications, Inc.

Golden, C.R. \& McHugh, M. C. (2017). The personal, political, and professional life of Sandra Bem. Sex Roles, 2017(76), 529-543. DOI 10.1007/s11199-016-0674-2

Goldhaber, D. \& Brown, N. (2016). Teacher policy under the ESEA and the HEA: A convergent 
trajectory with an unclear future. In Loss, C. P. \& McGuinn, P. J. (Eds.) (p. 87-102). The convergence of K-12 and higher education: Policies and programs in a changing era. Cambridge, MA: Harvard Education Press.

Groome, M. \& Rodriguez, L. M. (2014). How to build a robot: Collaborating to strengthen STEM programming in a citywide system. Afterschool Matters, 2014(Spring), 1-9.

Grubbs, M. (2013). Robotics intrigue middle school students and build STEM skills. Technology and Engineering Teacher, 2013(March), 12-16.

Hattie, J. (2008). Visible learning: A synthesis of over 800 meta-analyses relating to achievement. New York City, NY: Routledge.

Hattie, J. (2018). Visible learning plus: 250+ influences on student achievement [PDF file]. Retrieved from www.visiblelearningplus.com

Heifetz, R. A. \& Laurie, D. L. (2011). The work of leadership. In Harvard Business Review (Ed.), HBR's 10 Must Reads: On Leadership (57-79). Boston, MA: Harvard Business Review Press.

Heybach, J. \& Pickup, A. (2017). Whose STEM? Disrupting the gender crisis within STEM. Educational Studies, 53(6), 614-627.

Hollman, A. K., Hollman, T. J., Shimerdla, F., Bice, M. R., \& Adkins, M. (2019). Informational technology pathways in education: Interventions with middle school students. Computers \& Education, 2019(135), 49-60.

Hudak, M. A. (1993). Gender schema theory revisited: Men's stereotypes of American women. Sex Roles, 28(5/6), 279-293.

Hussenius, A. (2014). Science education for all, some, or just a few? Feminist and gender perspectives on science education: A special issue. Culture Studies of Science 
Education, 9, 255-262. https://doi.org/10.1007/s11422-013-9561-0

Ioannou, A. \& Makridou, E. (2018). Exploring the potentials of educational robotics in the development of computational thinking: A summary of current research and practical proposal for future work. Education and Information Technologies, 23, 2531-2544.

John, N. A., Stoebenau, K., Ritter, S., Edmeades, J., \& Balvin, N. (2017). Gender socialization during adolescence in low- and middle-income countries: Conceptualization, influences and outcomes. Innocenti Discussion Paper 2017-01, UNICEF Office of Research: Innocenti, Florence.

Jung, S. E. \& Won, E. (2018). Systematic review of research trends in robotics education for young children. Sustainability, 10(905). https://doi.org/10.3390/su10040905

Kaloti-Hallak, F., Armoni, M., \& Ben-Ari, M. (2015). The effectiveness of robotics competitions on students' learning of computer science. Olympiads in Informatics, $9,89-112$.

Kandlhofer, M. \& Steinbauer, G. (2016). Evaluating the impact of educational robotics on pupils' technical- and social-skills and science-related attitudes. Robotics and Autonomous Systems, 75, 679-685.

Karlsson, L. (2015). Just us, just discussing: Imagined homogeneities in the gender studies classroom. Gender and Education, 27(6), 654-665.

Karp, T. \& Maloney, P. (2013). Exciting young students in grades K-8 about STEM through an afterschool robotics challenge. American Journal of Engineering Education, 4(1), 39-54.

Keener, E. \& Mehta, C. (2017). Sandra Bem: Revolutionary and generative feminist psychologist. Sex Roles, 2017(76), 525-528. DOI 10.1007/s11199-017-0770-y

Kelley, T. R. \& Knowles, J. G. (2016). A conceptual framework for integrated STEM 
education. International Journal of STEM Education, 3(11).

https://doi.org/10.1186/s40594-016-0046-Z

Khanlari, A. (2013). Effects of robotics on 21st-century skills. European Scientific Journal, 9(27), 26-36.

Krueger, R. A. \& Casey, M. A. (2015). Focus groups: A practical guide for applied research (5th ed.). Los Angeles, CA: Sage.

Kucuk, S. \& Sisman, B. (2017). Behavioral patterns of elementary students and teachers in one-to-one robotics instruction. Computers and Education, 111, 31-43.

Larsen, R. J. \& Seidman, E. (1986). Gender schema theory and sex role inventories: Some conceptual and psychometric considerations. Journal of Personality and Social Psychology, 50(1), 205-211.

Lavallee, M. \& Pelletier, R. (1992). Ecological value of Bem's gender schema theory explored through females' traditional and nontraditional occupational contexts. Psychological Reports, 1992(70), 79-82.

Lemons, M. A. \& Parzinger, M. (2007). Gender schemas: A cognitive explanation of discrimination of women in technology. Journal of Business and Psychology, 22, 91-98.

Leonard, J. Mitchell, M., Barnes-Johnson, J., Unerlt, A., Outka-Hill, J., Robinson, R., \& Hester-Croff, C. (2018). Preparing teachers to engage students in computational thinking through robotics, game design, and culturally responsive teaching. Journal of Teacher Education, 69(4), 386-407. https://www.doi.org/10.1177/0022487117732317

Levi, D. (2017). Group dynamics for teams (5th ed.). Thousand Oaks, CA: Sage Publications. Li, Y., Huang, Z., Jiang, M., \& Chang, T. (2016). The effect on pupils' science performance 
and problem-solving ability through Lego: An engineering design-based modeling approach. Educational Technology \& Society, 19(3), 143-156.

Liben, L. S. \& Bigler, R. S. (2017). Understanding and undermining the development of gender dichotomies: The legacy of Sandra Lipsitz Bem. Sex Roles, 2017(76), 544-555. DOI $10.1007 / \mathrm{s} 11199-015-0519-4$

Liu, E. Z. (2010). Early adolescents' perceptions of educational robots and learning of robotics. British Journal of Educational Technology, 41(3), E44-E47. DOI: 10.1111/j.1467-8535.2009.00944.x

Loss, C. P. \& McGuinn, P. J. (2016). Framing convergence. In Loss, C. P. \& McGuinn, P. J. (Eds.) (p. 1-20). The convergence of K-12 and higher education: Policies and programs in a changing era. Cambridge, MA: Harvard Education Press.

Martin, C. L, Ruble, D. N., \& Skzrybalo, J. (2002). Cognitive theories of early gender development. Psychological Review, 28(6), 903-933. DOI: 10.1037//00332909.128.6.903

Martin, C. L., Fabes, R. A., Hanish, L., Leonard, S., \& Dinella, L. M. (2011). Experienced and expected similarity to same-gender peers: Moving toward a comprehensive model of gender segregation. Sex Roles, 2011(65), 421-434. DOI 10.1007/s11199-011-0029-y

Master, A., Cheryan, S., Moscatelli, A., \& Meltzoff, A. N. (2017). Programming experience motivates higher STEM motivation among first-grade girls. Journal of Experimental Child Psychology, 160, 92-106.

Mauch, E. (2001). Using technological innovation to improve the problem-solving skills of middle school students. The Clearing House, 74(4), 211-213.

Melchior, A. L., Burack, C., \& Hoover, M. (2018). Impacts of after-school robotics 
programming on STEM interests and attitudes. Roundtable presentation at Fostering STEM Interest and Engagement in Informal Settings. Presentation at 2018 American Educational Research Association Conference, New York, NY. DOI: 10.302/1314621

Menon, M. (2018). Multidimensional gender identity and gender-typed relationship styles in adolescence. Sex Roles, 74(3/4). DOI: 10.1007/s11199-016-0589-y

Merriam, S. B. \& Bierema, L. L. (2014). Adult learning. San Francisco, CA: Jossey-Bass.

Merriam, S. B. \& Tisdell, E. J. (2016). Qualitative research: A guide to design and implementation (4th ed.). San Francisco, CA: Jossey-Bass.

Mills, N., Pajares, F., \& Herron, C. (2006). A reevaluation of the role of anxiety: Self-efficacy, anxiety, and their relation to reading and listening proficiency. Foreign Language Annals, 39(2), 276-295.

Morgan, K. P. \& Ayim, M. (1984). Comment on Bem's gender schema theory and its implications for child development: Raising gender aschematic children in a genderschematic society. Signs, 10(1), 188-196.

Morgan, S. L., Gelbgiser, D., \& Weeden, K. A. (2013). Feeding the pipeline: Gender, occupational plans, and college major selection. Social Science Research 42, 989-1005.

Mosley, P., Ardito, G., Scollins, L., \& Van Courtlandt, P. (2016). Robotic cooperative learning promotes student STEM interest. American Journal of Engineering Education, $7(2), 117-128$.

Nelson, A. R. \& Strohl, N. M. (2016). From helping the poor to helping the middle class: The convergence of federal K-12 and higher education funding policy since 1965. In Loss, C. P. \& McGuinn, P. J. (Eds.) (p. 43-66). The convergence of K-12 and higher education: Policies and programs in a changing era. Cambridge, MA: Harvard Education Press. 
Northouse, P. G. (2016). Leadership: Theory and practice (7th ed.). Los Angeles, CA: Sage Publishing.

Ntemngwa, C. \& Oliver, J. S. (2018). The Implementation of integrated science technology, engineering and mathematics (STEM) instruction using robotics in the middle school science classroom. International Journal of Education in Mathematics, Science and Technology, 6(1), 12-40. DOI:10.18404/ijemst.380617

Nugent, G., Barker, B., Grandgenett, N., \& Adamchuk, V. I. (2010). Impact of robotics and geospatial technology interventions on youth STEM learning and attitudes. Journal of Research on Technology in Education, 42(4), 391-408.

Nugent, G., Barker, B., Grandgenett, N., \& Welch, G. (2016). Robotics camps, clubs, and competitions: Results from a US robotics project. Robotics and Autonomous Systems, 75, 686-691.

Olsen, L. A. (1979). Bandura's self-system sans Sullivan. American Psychologist, May, 439.

Ospennikova, E., Ershov, M., \& Iljin, I. (2015). Educational robotics as an innovative [sic] educational technology. Procedia: Social and Behavioral Sciences, 214, 18-26.

Pajares, F. (1996) Self-efficacy beliefs in academic settings. Review of Educational Research, 66(4), 543-578).

Pajares, F. (2002a). Gender and perceived self-efficacy in self-regulated learning. Theory into Practice, 41(2), 116-125.

Pajares, F. (2002b). Overview of social cognitive theory and self-efficacy. Retrieved from https://www.uky.edu/ eushe2/Pajares/eff.html

Pajares, F. \& Johnson, M. T. (1994). Confidence and competence in writing: The role of self-efficacy, outcome expectancy, and apprehension. Research in the Teaching of 
English, 28(3), 313-331.

Pajares, F., Johnson, M. T., \& Usher, E. L. (2003). Sources of writing self-efficacy beliefs of elementary, middle, and high school students. Research in the Teaching of English, 42(1), 104-120.

Pajares, F. \& Miller, M. D. (1994). Role of self-efficacy and self-concept beliefs in mathematical problem solving: A path analysis. Journal of Educational Psychology, 86(2), 193-203.http://dx.doi.org/10.1037/0022-0663.86.2.193

Papert, S. (1987). Computer criticism vs. technocentric thinking. Educational Researcher, 16(1), 22-30.

Parnell, A. (2018). Data analytics for student success. In Gagliardi, J. S., Parnell, A., \& Carpenter-Hubin (Eds.), The analytics revolution in higher education: Big data, organizational learning, and student success (43-54). Sterling, VA: Stylus Publishing.

Perry, L. C. \& Morgan, A. K. (1993). Sex-role development in young children: Relationships to behavioral and attitudinal measures of parental gender schemas. Paper presented at biennial meeting of Society for Research in Child Development. New Orleans, LA.

Petre, M. \& Price, B. (2004). Using robotics to motivate 'back-door' learning. Education and Information Technologies, 9(2), 147-158.

Pinto, G., Bigozzi, L., Vittori, G., \& Vezzani, C. (2018). The relationship between conceptions of learning and academic outcomes in middle school students according to gender differences. Learning, Culture, and Social Interaction, 2018(16), 45-54. https://doi.org/10.1016/j.lcsi.2017.11.001

Rich, P. J., Jones, B. L., Belikov, O., Yoshikawa, E., \& Perkins, M. (2017). Computing and engineering in elementary school: The effect of a year-long training on elementary 
teacher self-efficacy and beliefs about teaching computing and engineering. International Journal of Computer Science Education in Schools, 1(1). DOI: 10.21585/ijcses.v1i1.6

Riedo, F., Freire, M., Fink, J., Ruiz, G., Fassa, F., \& Mondada, F. (2013). Upgrade your robot competition: Make a festival! Institute of Electrical and Electronics Engineers Robotics and Automation Magazine, September, 12-14. DOI: 10.1109/MRA.2013.2272203

Ringrose, J. (2007). Successful girls? Complicating post-feminist, neoliberal discourses of educational achievement and gender equality. Gender and Education, 19(4), 471-489.

Schunk, D. H. \& DiBendetto, M. K. (2016). Self-efficacy theory in education. In K. R. Wentzel \& D. B. Miele (Eds.), Handbook of motivation at school (34-54). London, UK: Routledge. https://doi.org/10.4324/9781315773384.ch3

Seidman, I. (2013). Interviewing as qualitative research (4th ed.). New York, NY: Teachers College Press.

Shober, A. F. (2016). Individuality or community? Bringing assessment and accountability to K16 education. In Loss, C. P. \& McGuinn, P. J. (Eds.) (p. 67-86). The convergence of $K$ 12 And higher education: Policies and programs in a changing era. Cambridge, MA: Harvard Education Press.

Sniderman, D. (2014). Grooming future engineers: All girls robotics team thrives. IEEE Women in Engineering Magazine, December, 48-50.

Spoloar, N. \& Benitti, F. (2017). Robotics applications grounded in learning theories on tertiary education: A systematic review. Computers \& Education, 112, 97-107.

Starr, C. R. \& Zurbriggen, E. L. (2016). Sandra Bem's gender schema theory after 34 years: A review of its reach and impact. Sex Roles, March. https://doi.org/10.1007/s11199-016$\underline{0591-4}$ 
Sullivan, A. \& Bers, M. U. (2016). Girls, boys, and bots: Gender differences in young children's performance on robotics and programming tasks. Journal of Information Technology Education: Innovations in Practice, 15, 145-165.

Toh, L. P. E., Causo, A., Tzuo, P.-W., Chen, I. M., \& Yeo,S. H. (2016). A review on the use of robots in education and young children. Journal of Educational Technology \& Society, 19(2), 148-163.

Usher, E. L. \& Pajares, F. (2006). Inviting confidence in school: Invitations as a critical source of the academic self-efficacy beliefs of entering middle school students. Journal of Invitational Theory and Practice, 12, 7-16

Usher, E. L. \& Pajares, F. (2008). Sources of self-efficacy in school: Critical review of the literature and future directions. Review of Educational Research, 78(4), 751-796.

Vantiegham, W. \& Van Houtte, M. (2015). Are girls more resilient to gender conformity pressure? The association between gender conformity pressure and academic selfefficacy. Sex Roles, 73, 1-15.

Vantiegham, W. \& Van Houtte, M. (2018). Differences in study motivation within and between genders: An examination by gender typicality among early adolescents. Youth \& Society, 50(3), 377-404.

Vantiegham, W., Vermeersch, H., \& Van Houtte, M. (2014). Transcending the gender dichotomy in educational gender gap research: The association between gender identity and academic self-efficacy. Contemporary Educational Psychology, 39, 369378.

Veltman, M., Davidson, V., \& Deyell, B. (2012). Advances in engineering education: Richer connections to robotics through project personalization. Paper presented at American 
Society for Engineering Education Summer 2012. Ontario, Canada.

Vongkulluksn, V. W., Matewos, A. M., Sinatra, G. M., \& Marsh, J. A. (2018). Motivational factors in makerspaces: A mixed methods study of elementary students' situational interest, self-efficacy, and achievement emotions. International Journal of STEM Education, 5(43). https://doi.org/10.1186/s40594-018-0129-0

Williams, K., Igel, I., Poveda, R., Kapila, V., \& Iskander, M. (2012). Enriching K-12 science education using LEGOs. Paper presented at Summer 2012 American Science for Engineering Education Conference. San Antonio, TX.

Williams, D. C., Ma, Y., Prejean, L., Ford, M. J., \& Lai, G. (2007). Acquisition of physics content knowledge and scientific inquiry skills in a robotics summer camp. Journal of Research on Technology in Education, 40(2), 201-216.

Witherspoon, E. B., Schunn, C. D., Higashi, R. M., \& Baehr, E. C. (2016). Gender, interest, and prior experience shape opportunities to learn programming in robotics competitions. International Journal of STEM Education, 3. https://doi.org/10.1186/s40594-016-0052

Woodington, W. (2010). The cognitive foundations of formal equality: Incorporating gender schema theory to eliminate sex discrimination towards women in the legal profession. Law Psychology Review, 34(1), 135-152.

Xu, D. \& Li, Q. (2018). Gender achievement gaps among Chinese middle school students and the role of teachers' gender. Economics of Education Review, 2018(67). 82-93. https://doi.org/10.1016/j.econedurev.2018.10.002

Yuen, T. T., Boecking, M., Tiger, E. P., Gomez, A., Guillen, A., Arreguin, A., \& Stone, J. (2014). Group tasks, activities, dynamics, and interactions in collaborative robotics 
projects with elementary and middle school children. Journal of STEM Education, $15(1), 39-45$.

Zeldin, A. L. \& Pajares, F. (2000). Against all odds: Self-efficacy beliefs of women in mathematical, scientific, and technological careers. American Educational Research Journal, 37(1), 215-246. 


\section{Appendix A}

\section{IRB Acceptance Letter}

Institutional Review Board

University of Missour-Colambla

FWA Numbur: 00002876

IRB Fegibutration Numbers: 00000731, 00009014
432 Mefiernolds Hall

Columbia, MO 65211

$573-882-3181$

ifLoumissonatiedu

March 09, 2020

Principal Investigator: Carvy Dowis (MCD-Studetat)

Department: Educarional Leadership-EDD

Your IHB Application to project entitled A Multiple Case Stody of Female Students' Academic SelfEfficacy while Participaring in a Middle School Robotics Program was reviewed and approwed by the MU Institurional Revisw Board according to the terms and coesditions described below:

\begin{tabular}{|c|c|}
\hline IPB Project Number & 2017602 \\
\hline IRB Review Number & 254430 \\
\hline Initial Applicarion Approval Date & March 09, 2020 \\
\hline IRB Expiration Date & March 09, 2021 \\
\hline Level of Review & Exempt \\
\hline Project Stanus & Active - Eximpt \\
\hline Evempt Casogaries (Revised Common Rule) & $45 \mathrm{CFH} 46.104 \mathrm{~d}(1)$ \\
\hline Besk Level & Minimal Besk. \\
\hline
\end{tabular}

The principal imestigator (PI) is responsible for all aspects and coedact of this stady. The PI must comply with the following conditions of the approval:

1. No subjects may be imolved in any stody procedare prior to the IRB approval date or after the expiration date.

2. All changes mast be IHB approved prior to impletwentarion utiliaing the Exempt Amendment Form.

3. The Annual Exempt Form must be submitted to the IRB for review and approwal at least 30 days peiot to the peoject expiration date to heop the study active of to elowe it.

4. Maimain all research recoeds for a period of seven years from the project completion date.

If you are offering subject payments and would tike more information about research participant payments, please click here to view the MU Basinesed Policy and Procedure: brted.

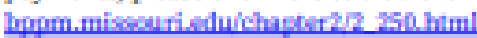

If you hare any questions of concerns, please comact the MU IRB Offsee at $573-862-3181$ of email to muresearchirbimissouri.edu.

Thank you,

MU Institurional Fevisew Board 


\section{Appendix B}

Observation Form

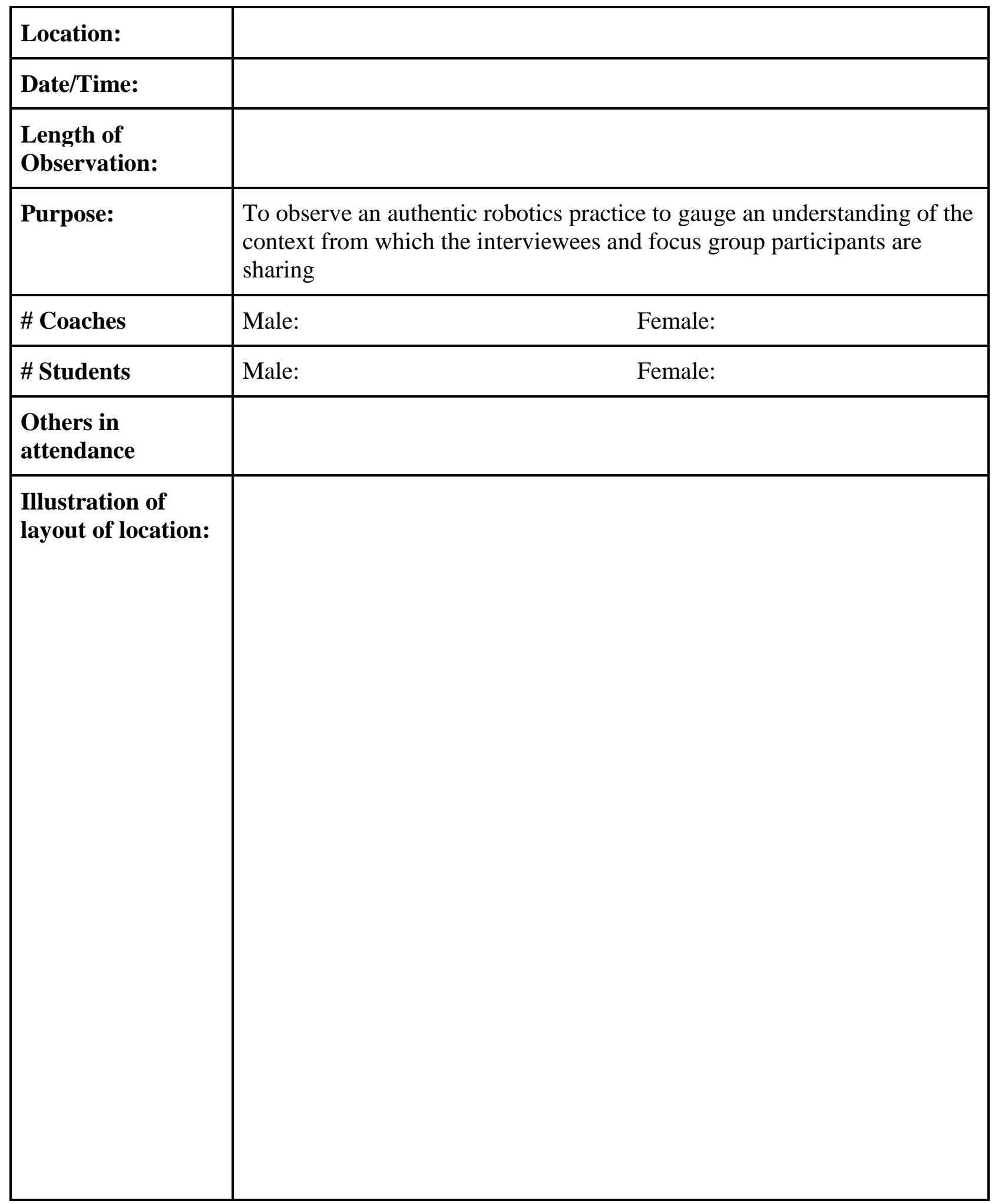




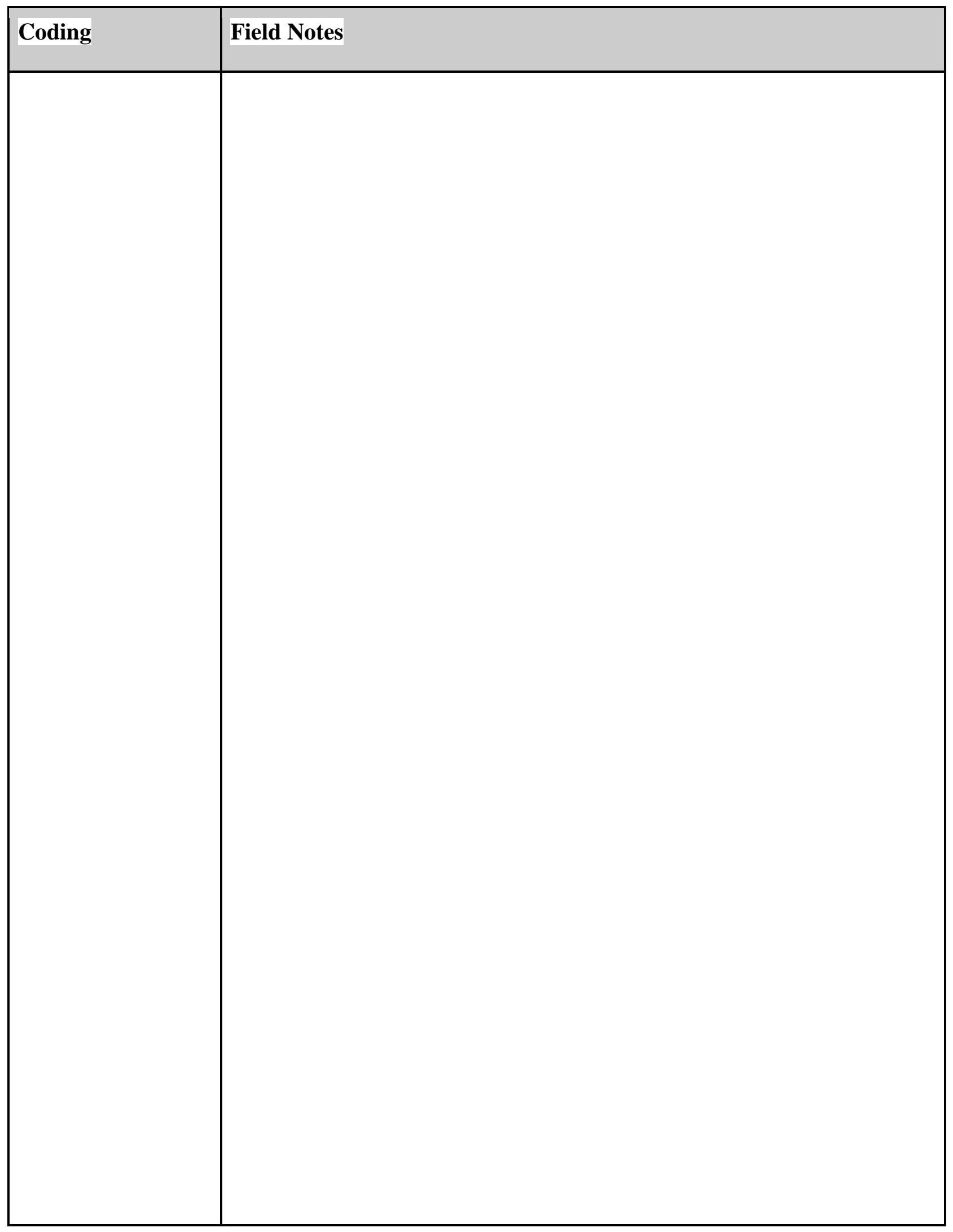




\section{Appendix C}

\section{Coaches Focus Group Protocol}

\section{Date/Time:}

\section{Location:}

\section{Questions:}

Research Questions Addressed:

\section{Introduction: 10 minutes}

[Researcher]: Hello. Thank you for taking the time to meet with me to discuss your robotics program. I sincerely appreciate your time. Do you mind if I record this focus group using Voice Recorder on my phone?

My name is Carey Davis, and I will serve as the moderator for today's focus group. The purpose of this focus group is to gain information regarding your perspective on the impact participating in a robotics program has on students, especially female students.

Please remember, there are no right or wrong answers but rather differing points of view. Feel free to share your point of view even if it differs from what others have said. If you would like to follow-up on something that someone has said, you want to agree, disagree or give an example, please feel free to do that. This is meant to be a conversation among yourselves, so don't feel like you have to respond to me all of the time. I am here to ask questions, listen and make sure everyone has a chance to share. I am interested in hearing from each of you. Please speak up and remember only one person should talk at a time.

Our session will last about an hour, and we will not be taking a formal break. Feel free to leave for any reason if you need to. While the nature of a focus group makes it impossible to provide complete anonymity, the evaluator will maintain your confidentiality during future reporting. No names will be included in any reports. Let us begin by going around the room and finding out more about each other.

1. Please tell me your name and how long you have been an educator and a robotics coach.

2. Please describe your roles within and outside the robotics program.

3. What made you decide to coach robotics?

Learn about participants

Learn about participants

Learn about participants 


\begin{tabular}{|c|c|}
\hline \multicolumn{2}{|l|}{ Key Questions: 30 minutes } \\
\hline 4. Describe a typical robotics practice. & Q3 \\
\hline 5. Describe the robotics competition experience. & Q3 \\
\hline $\begin{array}{l}\text { 6. How do you feel participating in a robotics program impacts the } \\
\text { students? }\end{array}$ & Q1, Q3 \\
\hline $\begin{array}{l}\text { 7. Why do you think students choose to participate in a robotics } \\
\text { program? }\end{array}$ & $\mathbf{Q 2}$ \\
\hline 8. How do you engage new students in the robotics program? & Q2, Q3 \\
\hline $\begin{array}{l}\text { 9. What academic impacts have you observed in students who } \\
\text { participate in robotics? }\end{array}$ & Q1, Q3 \\
\hline $\begin{array}{l}\text { 10. Approximately what percentage of your past and present robotics } \\
\text { students would you say have been male and what percentage have been } \\
\text { female? }\end{array}$ & $\begin{array}{l}\text { Introduce possible } \\
\text { gender differences }\end{array}$ \\
\hline $\begin{array}{l}\text { 11. What similarities and differences do you notice about how male and } \\
\text { female students participate in robotics? }\end{array}$ & Q1, Q2, Q3 \\
\hline $\begin{array}{l}\text { 12. What steps do you take when students and teams are struggling to } \\
\text { achieve team goals and how do these steps compare when a male is } \\
\text { struggling and when a female is struggling? }\end{array}$ & Q1 \\
\hline $\begin{array}{l}\text { 13. What other similarities and differences do you notice when } \\
\text { comparing male and female students in the robotics program? }\end{array}$ & Q1, Q2, Q3 \\
\hline $\begin{array}{l}\text { 14. What career fields do you foresee your robotics students joining in } \\
\text { the future? }\end{array}$ & Q4 \\
\hline $\begin{array}{l}\text { 15. What do future career discussions look like with your robotics } \\
\text { students? }\end{array}$ & Q4 \\
\hline $\begin{array}{l}\text { 16. What similarities and differences do you notice in career discussions } \\
\text { involving male students and those involving female students? }\end{array}$ & Q1, Q2, Q3, Q4 \\
\hline \multicolumn{2}{|l|}{ Ending Questions: 5 minutes } \\
\hline $\begin{array}{l}\text { As we close, what else would you like me to know about your } \\
\text { experiences coaching robotics or any of the topics we discussed today? }\end{array}$ & Q1, Q2, Q3, Q4 \\
\hline Closing: 1 minute & \\
\hline
\end{tabular}


Those are all the questions I have for you at this time. Thank you so much for participating in my study. I appreciate your time! 


\section{Appendix D}

\section{Student Interview Protocol}

\begin{tabular}{|l|l|}
\hline Participant: & \\
\hline Position: & \\
\hline Date/Time: & \\
\hline
\end{tabular}

\section{Questions:}

Research Questions

Addressed:

\section{Introduction: 2 minutes}

[Researcher]: Good (morning, afternoon, evening). Thank you for coming to meet with me today. My name is Carey Davis. Do you mind if I record this interview using Voice Recorder on my phone?

I am a doctoral student in the University of Missouri's Cooperative EdD program working with the University of Central Missouri. The purpose of this study is to find out more about the experiences of middle school girls who participate in robotics programs. In order to do this, I will be asking you some questions. If at any time, you would like to expand on an idea to talk more about it or go back to previous discussion that you have thought of more related information, feel free. If you would like to take a break, just let me know. My goal is to make you as comfortable as possible and just have a conversation about robotics. Do you have any questions for me at this point?

\section{Opening Questions: 3 minutes}

1. How long have you or did you participate in a FIRST LEGO League robotics program?

2. What has been your role(s) on your robotics teams?

Learn about participant

Learn about participant

\section{Key Questions: 20-25 minutes}

3. What made you decide to join a robotics program?

4. Describe a typical robotics practice you have experienced.

5. Describe a robotics competition in which you have participated.

6. Tell me about your experiences with your robotics teams. 


\begin{tabular}{|c|c|}
\hline $\begin{array}{l}\text { 7. How do your actual robotics experiences compare with what you } \\
\text { thought robotics would be like? }\end{array}$ & Q3 \\
\hline $\begin{array}{l}\text { 8. Describe what you feel are the best and the worst parts of participating } \\
\text { in a robotics program. }\end{array}$ & Q1, Q2, Q3 \\
\hline $\begin{array}{l}\text { 9. How do you think robotics has affected your feelings and performance } \\
\text { about school in general? }\end{array}$ & Q1, Q3 \\
\hline $\begin{array}{l}\text { 10. How have your feelings about school and your academic abilities } \\
\text { changed over time while participating in a robotics program? }\end{array}$ & Q1, Q3 \\
\hline $\begin{array}{l}\text { 11. After participating in a robotics program, what skills do you feel you } \\
\text { have learned and how will these affect you beyond robotics? }\end{array}$ & Q1, Q3, Q4 \\
\hline $\begin{array}{l}\text { 12. What kind of job do you see yourself doing when you are an adult? } \\
\text { How has robotics affected that decision? }\end{array}$ & Q3, Q4 \\
\hline 13. How would you describe your overall experience in robotics? & Q1, Q3 \\
\hline \multicolumn{2}{|l|}{ Ending Questions: 3 minutes } \\
\hline $\begin{array}{l}\text { 14. (If student is still in a robotics program) Do you see yourself } \\
\text { continuing to participate in robotics in the future and how has your } \\
\text { experience with robotics affected that decision? }\end{array}$ & Q2, Q3 \\
\hline $\begin{array}{l}\text { 15. As we close, what else would you like me to know about your } \\
\text { experiences in robotics? }\end{array}$ & $\mathbf{Q 1}, \mathbf{Q} 2, \mathbf{Q 3}, \mathbf{Q 4}$ \\
\hline \multicolumn{2}{|l|}{ Closing: 1 minute } \\
\hline \multicolumn{2}{|c|}{$\begin{array}{l}\text { Those are all the questions I have for you at this time. Thank you so much for participating in my } \\
\text { study. I appreciate your time! }\end{array}$} \\
\hline
\end{tabular}




\title{
Appendix E
}

\section{Child Assent to Participate in A Research Study}

\author{
INVESTIGATOR'S NAME: CAREY A. DAVIS \\ PROJECT IRB \#: 2017602
}

\section{Study Title: A Multiple Case Study of Female Middle School Students'

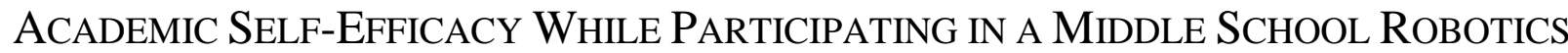 PROGRAM}

We want to tell you about something we are doing called a research study. Research studies help us learn new things and test new ideas. We collect lots of information about something to find out more about it.

We are doing this study to find out more about what it's like to be in a robotics program because we want to know about your feelings about robotics and how it affects you in other parts of school.

We are asking you if you would like to be in this study because you have been part of a robotics program at school at least 2 years.

About 12 kids in Missouri will be in this study, and 2 kids from your school.

This letter tells you about our study. We want you to ask us any questions you have. Here are some things you need to know about being in a research study:

- You get to decide if you want to be in the study.

- You can say "No" or you can say "Yes". Whatever you decide is OK.

- No one will be upset with you if you don't want to be in the study.

- If you say "Yes" first, you can say "No" later if you change your mind.

- If you want to be in the study, your parent or guardian have to give us their permission for you to join.

- We will take good care of you no matter what you decide.

\section{WHAT WILL HAPPEN IF I AM IN THE STUDY?}

We will ask you to do these things:

- Answer some questions

You will come to an agreed upon location and we will ask you some questions about robotics and school.

If you don't want to answer any of the questions, that's OK, you don't have to.

This part will take about 30 minutes to one hour. We will do this one time. 


\section{Will Anything In This Study Hurt Me?}

Some of the questions we ask you might be hard to answer or make you feel uncomfortable. It's OK to tell us if you don't want to answer any questions.

\section{Do I Have To Be In The STUdY?}

No, you don't! Research is something you do only if you want to. Nothing bad will happen if you don't want to be in the study. Just tell us what you want to do.

And remember, you can change your mind later if you want to stop being in the study.

\section{Will You Keep My Stuff Private?}

We will do our best to keep your information private. But we do need to share your information with some people.

We might write about this study later or talk about it at meetings, but we will not mention your name or other private things. We will just talk or write about what we learned from all the results put together.

\section{What If I Want To Ask Questions About The Study?}

You can ask us questions about the study any time you think of them. You can ask now or later. You can ask when you come for a visit or you can call us at this phone number (417)-766-4044.

If you want to talk privately to someone about what is happening in the study, you can call 888280-5002, or you can send an email to MUResearchRPA@ missouri.edu.

\section{ASSENT OF ChILD}

If you decide that you want to be in the study, and your parent or guardian says it's OK, we will give you a copy of this letter to keep. That way, you can look at it again later if you want to.

$\underline{\text { Read this and then write your name on the first line: }}$

Writing my name on this page means:

- That I read this letter, or someone read it to me.

- I want to be in the study.

- I know what will happen to me in the study.

- I know I can stop being in the study if I want to. 


\section{Child's signature (written by child only) Date}

\section{If verbal assent only is being obtained:}

Person obtaining assent: Initial here if child cannot sign, to document that the child received this information and gave assent verbally: 
Appendix F

\title{
Parental Consent Form For A Child to Participate IN A RESEARCH STUDY
}

\author{
Name(s) Of ReSearcher(s): Carey A. Davis, Dr. Barbara N. Martin \\ PROJECT IRB \#: 2017602 \\ Study Title: A Multiple Case Study of Female Students' Academic \\ Self-efFicacy While Participating in Middle School Robotics \\ PROGRAM
}

This research study is about female middle school students participating in a school-based robotics program. We are doing this study to gain qualitative information regarding their experiences and how participation in a robotics program affects academic self-efficacy and career aspirations.

We ask your permission for your child to take part in this research study because, as a student who is participating or has participated in a robotics program in the past, they can give a firsthand account of their experiences in the program and its effects. This consent form tells you why we are doing the study, and what will happen if your child joins the study.

Please take as much time as you need to read this consent form. You can discuss it with your family, friends, or anyone you choose. If there is anything you do not understand, please ask us to explain. Then you can decide if you want your child to take part in the study or not.

Research studies help us to answer questions that may improve our understanding of human behavior, attitudes, beliefs, and interactions. Taking part in a research study is voluntary. You are free to say yes or no. We will only include your child in this study if you give us your permission first by signing this consent form.

\section{Why Is This Study BeING Done?}

The purpose of this research is to collect qualitative data on the experiences of female middle school students participating in a school-based robotics program in order to get a clearer picture of the effects the students' experiences have on their academic self-efficacy and career aspirations. As there is currently a global shortage of workers in STEM fields and females are underrepresented in these careers, a better understanding is needed of the reasons why females do not persist in STEM into their careers.

\section{HOW MANY CHILDREN WILL BE IN THIS STUDY?}

About 12 children will take part in this study, 2 female students from each site will be interviewed.

\section{WHAT WILL HAPPEN IF MY CHILD TAKES PART IN THIS STUDY?}

If you agree, your will come to a previously determined agreed-upon location and do the following: 
- Participate in an interview with the researcher lasting no longer than 1 hour with parent supervision

- Answer questions related to his or her experiences while participating in robotics and its effects

- Agree to an audio recording of the interview

\section{HOW LONG WILL MY CHILD BE IN THE STUDY?}

Your child will be in the study for a total of 1 hour over 1 day.

\section{CAN MY CHILD STOP BEING IN THE STUDY?}

Yes, your child can stop being in the study at any time without giving a reason. Just tell the researcher or study staff right away if your child wants to stop taking part.

Also, the researcher may decide to take your child off this study at any time, even if you and your child want to stay in the study. The researcher will tell you the reason why your child needs to stop being in the study. These reasons may be:

- It is determined the child does not meet the criteria for participation in the study.

\section{ARE THERE ANY BENEFITS TO TAKING PART IN THIS STUDY?}

There might be no direct benefit to your child from taking part in this study. However, the information we learn from your child during this study may help us better understand how to make robotics and other STEM programs more effective in developing students who will continue to participate in STEM through their career choices.

\section{ARE THERE ANY RISKS TO MY CHILD FROM BEING IN THIS STUDY?}

The only foreseeable risk in this study is a feeling of discomfort due to speaking to an unknown about their personal feelings about robotics and their experiences.

\section{WHAT OTHER CHOICES DOES MY CHILD HAVE IF THEY DON'T TAKE PART?}

There are no other participation options planned at this time.

\section{WILL INFORMATION ABOUT MY CHILD BE KEPT PRIVATE?}

The information we collect about your child will be stored in the researcher's electronic/computer files and on a secure Google server. No files will be printed. Computer files are protected with a password and the computer is with the researcher at all times.

We will give your child's records a code number and they will not contain your child's name or other information that could identify your child. The code number that connects your child's name to your child's information will be kept in digital form only on a secure Google server. Information that may identify your child may not be given to anyone who is not working on this study without your written consent, or if required by law.

We will do our best to make sure that your child's personal information from this study is kept private, but we cannot guarantee total privacy. We may give out your child's personal 
information if the law requires it. If we publish the results of this study or present them at scientific meetings, we will not use your child's name or other personal information.

We will keep the information we collect from your child for this study to use in future research or to share with other investigators to use in future studies without asking for your consent again. Information that could identify your child will be removed from your child's research information so no one will know that it belongs to your child.

You must give us permission to use the audio recordings we take of your child during the study.

You will be able to listen to them and look at the transcripts before you give your permission for us

to use them.

\section{WILL I OR MY CHILD BE PAID FOR TAKING PART IN THIS STUDY?}

You and your child will not be paid for taking part in this study.

\section{WHAT ARE MY CHILD'S RIGHTS AS A STUDY PARTICIPANT?}

Taking part in this study is voluntary. If you and child do decide to take part, you both have the right to change your mind and drop out of the study at any time. Whatever your and your child's decision, there will be no penalty to either of you in any way.

We will tell you about any new information discovered during this study that might affect your child's health, welfare, or change your mind about them taking part.

\section{WHO CAN I CALL IF I HAVE QUESTIONS, CONCERNS, OR COMPLAINTS?}

If you have more questions about this study at any time, you can call Carey Davis at 417-7664044 or email at careyadavis@ yahoo.com. You can also contact the dissertation advisor for this study, Dr. Barbara Martin at 816-830-3904 or email bmartin@ucmo.edu.

You may contact the University of Missouri Institutional Review Board (IRB if you:

- Have any questions about your child's rights as a study participant;

- Want to report any problems or complaints; or

- Feel under any pressure to have your take part or stay in this study.

- The IRB is a group of people who review research studies to make sure the rights of participants are protected. Their phone number is 573-882-3181.

If you want to talk privately about your child's rights or any issues related to their participation in this study, you can contact University of Missouri Research Participant Advocacy by calling 888-280-5002 (a free call), or emailing MUResearchRPA@ missouri.edu.

We will give you a copy of this consent form. Please keep it where you can find it easily. It will help you to remember what we discussed today. 


\section{Signature of Parent/Guardian ANd Minor SubJect}

\section{Consent to Participate in Research}

By signing my name below, I confirm the following:

- I have $\mathrm{read} / \mathrm{had}$ read to me this entire consent form.

- All of my questions were answered to my satisfaction.

- The study's purpose, procedures/activities, potential risks and possible benefits were explained to me.

- I voluntarily agree to allow my child to take part in this research study. I have been told that my child/I can stop taking part at any time.

\section{Parent Signature Date}

\begin{tabular}{|l|l|l|}
\hline & \multicolumn{2}{|l|}{} \\
\hline Signature of Witness (if applicable)* & Date & \\
&
\end{tabular}


Appendix G

\title{
CONSENT Form to PARTicipate in A RESEARCh Study
}

\author{
Name(s) Of ReSearcher(s): Carey A. Davis, Dr. Barbara N. Martin \\ PROJECT IRB \#: 2017602 \\ Study Title: A Multiple Case Study of Female Students' Academic \\ Self-efFicaCy While Participating in A Middle School Robotics \\ PROGRAM
}

This research study is about female middle school students participating in a school-based robotics program. We are doing this study to gain qualitative information regarding their experiences and how participation in a robotics program affects academic self-efficacy and career aspirations.

We invite you to take part in this research study because, as a coach, you are familiar with the students being interviewed and the robotics program in which they are participating. This consent form tells you why we are doing the study, and what will happen if you join the study.

Please take as much time as you need to read this consent form. You can discuss it with your family, friends, or anyone you choose. If there is anything you do not understand, please ask us to explain. Then you can decide if you want to take part in the study or not.

Research studies help us to answer questions that may improve our understanding of human behavior, attitudes, beliefs, and interactions. Taking part in a research study is voluntary. You are free to say yes or no. We will only include you in this study if you give us your permission first by signing this consent form.

\section{Why Is ThIS STUDY BeING Done?}

The purpose of this research is to collect qualitative data on the experiences of female middle school students participating in a school-based robotics program in order to get a clearer picture of the effects the students' experiences have on their academic self-efficacy and career aspirations. As there is currently a global shortage of workers in STEM fields and females are underrepresented in these careers, a better understanding is needed of the reasons why females do not persist in STEM into their careers.

\section{How Many People Will Be In This Study?}

About 30-40 people will take part in this study. There will be 12 students interviewed and around 20-30 coaches will participate. At each site, 2 students will be interviewed and a focus group of 2-5 coaches will be conducted.

\section{What Will Happen If I Take Part In This Study?}

If you agree, you will come to a previously determined agreed-upon location and do the following: 
- Participate in a focus group lasting no longer than 1 hour

- Answer questions related to your experiences coaching robotics

- Answer questions related to male and female student experiences in robotics

- Agree to an audio recording of the focus group

\section{How LoNG WiLl I Be In The STUdy?}

You will be in the study for a total of 1 hours over 1 day.

\section{Can I Stop Being In The STUdy?}

Yes, you can stop being in the study at any time without giving a reason. Just tell the researcher or study staff right away if you wish to stop taking part.

Also, the researcher may decide to take you off this study at any time, even if you want to stay in the study. The researcher will tell you the reason why you need to stop being in the study. These reasons may be:

- Participant does not meet the research criteria

- Participant's behavior creates an uncomfortable or unprofessional climate within the focus group

- Participant's position is determined to greatly affect the responses of participants who are subordinate to participant

\section{Are There Any Benefits To Taking Part In This Study?}

There might be no direct benefit to you from taking part in this study. However, the information we learn from you during this study may help us better understand how to make robotics and other STEM programs more effective in developing students who will continue to participate in STEM through their career choices.

\section{Are There Any Risks From Being In This Study?}

Since the focus group will be conducted with other robotics coaches in your district or school, it will not be possible to keep your responses confidential. This may lead to some professional discomfort. Also, since many of the questions focus on the differences you observe between male and female students' participation in your robotics program, there may be some feelings that your work is being criticized. I assure you, this is not the case. The study is for informationgathering purposes only so that we can learn to better help students.

\section{What Other Choices Do I Have If I Don't TAKe Part?}

There are no other participation options planned at this time.

\section{Will Information About Me Be KePt Private?}

The information we collect about you will be stored in the researcher's electronic/computer files and on a secure Google server. No files will be printed. Computer files are protected with a password and the computer is with the researcher at all times.

We will give your records a code number and they will not contain your name or other information that could identify you. The code number that connects your name to your 
information will be kept in digital form only on a secure Google server. Information that may identify you may not be given to anyone who is not working on this study without your written consent, or if required by law.

We will do our best to make sure that your personal information from this study is kept private, but we cannot guarantee total privacy. We may give out your personal information if the law requires it. If we publish the results of this study or present them at scientific meetings, we will not use your name or other personal information.

We will keep the information we collect from you for this study to use in future research or to share with other investigators to use in future studies without asking for your consent again. Information that could identify you will be removed from your research information so no one will know that it belongs to you.

You must give us permission to use the audio recordings we take of you during the study. You will

be able to listen to them and look at the transcripts before you give your permission for us to use

them.

\section{Will I Be Paid For Taking Part In This Study?}

You will not be paid for taking part in this study.

\section{What Are My Rights as a Study Participant?}

Taking part in this study is voluntary. If you do decide to take part, you have the right to change your mind and drop out of the study at any time. Whatever your decision, there will be no penalty to you in any way.

We will tell you about any new information discovered during this study that might affect your health, welfare, or change your mind about taking part.

\section{Who Can I Call If I Have Questions, Concerns, Or Complaints?}

If you have more questions about this study at any time, you can call Carey Davis at 417-7664044 or email at careyadavis@ yahoo.com. You can also contact the dissertation advisor for this study, Dr. Barbara Martin at 816-830-3904 or email bmartin@ucmo.edu.

You may contact the University of Missouri Institutional Review Board (IRB if you:

- Have any questions about your rights as a study participant;

- Want to report any problems or complaints; or

- Feel under any pressure to take part or stay in this study.

- The IRB is a group of people who review research studies to make sure the rights of participants are protected. Their phone number is 573- 882-3181.

If you want to talk privately about your rights or any issues related to your participation in this study, you can contact University of Missouri Research Participant Advocacy by calling 888280-5002 (a free call), or emailing MUResearchRPA@ missouri.edu. 
We will give you a copy of this consent form. Please keep it where you can find it easily. It will help you to remember what we discussed today.

\section{Signature OF PARTiCiPANT}

\section{Consent to Participate in Research}

By signing my name below, I confirm the following:

- I have read/had read to me this entire consent form.

- All of my questions were answered to my satisfaction.

- The study's purpose, procedures/activities, potential risks and possible benefits were explained to me.

- I voluntarily agree to take part in this research study. I have been told that I can stop at any time.

\section{Subject's Signature Date}

\section{Signature of Witness (if applicable)*}




\section{Appendix H}

\section{Gatekeeper Permission}

Dear Dr./Mr./Ms. <name>,

I would like to request permission to invite applicable students and educators in your district to participate in a research study entitled: A Multiple Case Study of Female Students' Academic Self-Efficacy While Participating in a Middle School Robotics Program conducted by Carey A. Davis. I am examining the qualitative relationship between female middle school students' academic self-efficacy and participation in STEM subjects as it relates to progression into STEM careers. Interviews, focus groups, and observations will be coded to determine how participation in a FIRST LEGO League robotics program contributes to the academic self-efficacy of female students. The information gathered should be beneficial as attempts are made to provide successful paths from school to career in occupational fields that will continue to be in high demand in the future. This study is part of my dissertation research for a doctoral degree in Educational Leadership and Policy Analysis from the University of Missouri-Columbia.

For this study, a FIRST LEGO League practice will be observed, a focus group of FIRST LEGO League coaches will be conducted, and two female middle school students who have participated in FIRST LEGO League will be asked to complete a qualitative interview. I am seeking your permission as the head administrator of this school program to contact the educators and students involved in these roles to participate in this study. Copies of the interview and focus group protocols, observation form, and informed consent form are attached for your review.

Participation in the study is voluntary. The participants may withdraw from participation at any time without penalty, including in the middle of or after completion of the interview. Participants' answers will remain confidential, anonymous, and separate from any identifying information. The researcher will not list names of participants in the dissertation or any future publications of this study.

Please do not hesitate to contact me with any questions or concerns about participation either by phone at (417) 766-4044 or by electronic mail careyadavis@yahoo.com. In addition, you are also welcome to contact the dissertation advisor for this research study, Dr. Barbara Martin, who can be reached at 660-543-8823 or by email at bmartin@ucmo.edu.

If you choose to allow me to contact educators and students regarding participation in this study, please complete the attached permission form. A copy of this letter and your written consent should be retained by you for future reference. Thank you for your time and consideration.

Sincerely,

Carey A. Davis, Doctoral Candidate 


\section{Gatekeeper Permission for Administrator and Educator Participation}

$\mathrm{I}$, grant permission for students and

educators within the school district to be contacted to participate in the study A Multiple Case Study of Female Students' Academic SelfEfficacy While Participating in a Middle School Robotics Program conducted by Carey A. Davis, doctoral candidate at the University of Missouri.

By signing this permission form, I understand that the following safeguards are in place to protect faculty choosing to participate:

- All participation is voluntary, and may be withdrawn at any point before culmination of the study.

- All responses will be used for dissertation research and for potential future journal publications.

- All identities will be kept confidential in all phases of the research.

- An interview or focus group will occur with each administrator, instructional coach, and teacher either in-person or via videoconference, lasting approximately one hour in length.

- One observation of a FIRST LEGO League robotics practice will be conducted.

Please keep the consent letter and a copy of the signed consent form for your records. If you choose to grant permission for students and educators in your school district to participate in this study, please complete this Administrative Permission for Program Participation Form, please return it to Carey A. Davis as soon as possible.

I have read the material above, and any questions that I have posed have been answered to my satisfaction. I grant permission for administrators and educators in my program to be contacted and invited to participate in this study.

Signed: Date:

Title/Position:

School District:

Please return to: Carey A. Davis, 510 Willowdale Ct., Nixa, MO 65714

Cell Phone: 417-766-4044 Email: careyadavis@yahoo.com 


\title{
Appendix I
}

\section{SOCIAL/BEHAVIORAL/EDUCATIONAL RESEARCH PROTOCOL UNIVERSITY OF MISSOURI}

\author{
Project Title: A Multiple Case Study of Female Middle School Students' Academic Self-Efficacy \\ While Participating in a Middle School Robotics Program \\ IRB Number: 2017602 \\ Version Number: 1 \\ Version Date: 02-03-2020 \\ Principal Investigator: Carey A. Davis
}

\section{Research Objectives/Background}

This purpose of this study is to more closely examine the experiences of female middle school students participating in school-based robotics programs in order to gain a deeper understanding of the relationship between their gender beliefs and academic self-efficacy as it relates to STEM subjects, ultimately leading to their decisions to remain in STEM fields or pursue other career paths. The researcher will strive to gain insight into the personal and social factors impacting middle school females and limiting the number of females choosing to remain in STEM fields from early secondary education to career. The primary research question guiding this study is: How does participating in school-based robotics programs affect the learning and academic selfefficacy of female students? The secondary research questions are: Why do female students choose to participate in a robotics program? How do female students' perceptions of STEM fields change over time after participating in a robotics program? How does participation in a robotics program affect female students' career aspirations?

The data collected through this study will be qualitative in nature, providing an understanding of STEM participation from the perspective of female middle school students. This is unique in that no other studies were found that captured these experiences in the participants' own words. Additionally, with significant research pointing to the importance of adolescence as a pivotal time in life when critical social and personal skills are developing (John, Stoebenau, Ritter, Edmeades, \& Balvin, 2017), it is necessary for society to understand the specific experiences of middle school females who have shown an interest in STEM fields early in their educational career and later may or may not choose to continue participating. As evidence reveals a global shortage of post-secondary STEM students and workers, this study will make important contributions in both scholarship and practice. This study will make three important contributions to the field of study as determined by the researcher. First, this study will provide important understanding of the personal and social factors that are impacting middle school females who are currently participating in STEM subjects. This knowledge is imperative due to the fact that data show some will choose to remain in STEM and others will choose to pursue other career paths. Second, this study will allow comparisons to be made to future studies to determine at what point the desire to continue participating in STEM subjects is either dampened or encouraged, leading to these females either choosing to remove themselves from continuing their education in STEM subjects or furthering their resolve to remain a member of this group. Third, this study will allow a better understanding of what areas require further qualitative and 
quantitative research in order to solve the global shortage of individuals entering STEM careers at a time when there is an ever-growing need for individuals in these careers.

\section{Recruitment Process}

There will not be outside recruitment. Access to students and coaches will be provided through gatekeepers including superintendents, principals, and coaches. These individuals will make connections and allow access only to the individuals who meet the criteria previously mentioned.

\section{Consent Process}

Participants and the parents of minor participants will be sent the consent form via paper or electronic prior to the focus group or interview. Any and all questions from the participants or parents of minor participants will be answered to their satisfaction before beginning the focus group or interview. In the case of the student consent form, easy-to-understand language was deliberately used, and technical jargon was avoided. Written consent of participants and parents of minor participants will be obtained at the start of the focus group or interview.

\section{Inclusion/Exclusion Criteria}

The sites included in this study will meet the following criteria:

1. Public middle school with an established robotics program

2. Robotics program competes in official FIRST LEGO League tournaments

3. School teams have been registered and active in FIRST LEGO League tournaments for at least three years

4. District, coaches, and participants are open and willing to allow researcher to conduct the study

Of these, two of these will be from a community classified as rural, two from a suburban community, and two from an urban community.

The focus groups will consist of individuals who are currently coaching or have coached a FIRST LEGO League team in the past.

The interviews will be conducted with female middle school students who have participated in a FIRST LEGO League team for at least two years.

Sites and individuals who do not meet the above criteria will not be considered for this study. Each site will be limited to only the number of participants previously discussed.

\section{Number of Subjects}

No more than 40 individuals will participate in this study. This will include 12 students participating through interviews and 12-25 coaches participating through focus groups.

\section{Study Procedures/Study Design}

The qualitative data collection tools used for this study will be observations, interviews, and focus groups. Observations will be conducted wherein the researcher observes a robotics practice or meeting and takes field notes on the observation form regarding the behaviors and interactions of the participants. The researcher expects to gather significant data and the bulk of 
the answers to the research questions through interviews with female participants within the robotics programs. The interviews will allow the researcher to gain an understanding of the experiences of the students and the meaning they have constructed from those experiences. Since the students are minors and the locations will be spread out over the state of Missouri, the researcher anticipates interviewing each student one time, with the potential for follow-up questions via digital means or through adult gatekeepers.

In addition to observations and interviews, the researcher will conduct focus groups made up of coaches who work with the female students being interviewed for this study. Within the focus group, the coaches will be able to freely discuss their robotics program and their opinions regarding the effects the program has specifically on the female students and their interactions.

Due to having the resources for one formal interview per participant and one focus group per site, the semi-structured interview format discussed by Merriam and Tisdell (2016) will be used. This format requires the researcher to have a predetermined list of questions or interview protocol for the interviewee to answer, but allows the researcher to ask follow up questions based off of the interviewee's responses in order to gain clarification or more information in regard to the research questions. Interviewees and focus group participants will be committed to no more of one hour of time outside of a routine activity.

\section{Potential Risks}

Some potential risks that the researcher has foreseen are breach of confidentiality, psychological and social effects attributable to bringing attention to social factors participants may not have previously considered. Describe any reasonably foreseeable risks or discomforts to the subjects and the steps to minimize risks.

Any problems, deviations, or unforeseen risks will be reported to the IRB within five days of the researcher becoming aware of said event.

\section{Anticipated Benefits}

This study will most likely have no direct benefits for participants aside from a feeling of pride for participating in a much-needed career field.

This study will benefit the community and society by adding to the body of research in the field of education and STEM education. Potentially, the findings of this study could result in changes to educational programs that are more welcoming and encouraging to female students participating in STEM and continuing their participation into STEM careers. This continued participation will help alleviate the global shortage of STEM workers.

\section{Compensation}

No compensation will be offered for participating in this study.

\section{Data Safety Monitoring Plan}

With minimal sensitive data being collected, data will be stored on a school district-protected Google server and on the primary researcher's home computer, which is protected with AVG 
virus protection. If there is a security breach, participants will be notified within 24 hours. Only the primary researcher and advisor will have access to the data.

\section{Multiple Sites}

1. There is not a lead site in this study as it is a multiple case study. Each site will provide two student interviewees, a focus group, and a practice to observe.

2. Most school districts require prior IRB approval before issuing official school district approval. Verbal approval is in place at most sites. Official written approval will be obtained before gathering any data for the study outside of normal operations.

3. The school districts will rely on the MU IRB to approve and oversee the study.

4. Data from each site will be stored on a school district-protected Google server and on the primary researcher's home computer, which is protected with AVG virus protection.

\section{References}

Please see reference list uploaded to IRB application. 


\section{VITA}

Carey Davis is from Odessa, Missouri, but currently calls Nixa, Missouri home. She is the daughter of Clinton Barnes of Blue Springs, Missouri and Carole Dowell of Odessa, Missouri. She graduated from Odessa High School in 1997, and earned a bachelor's degree in elementary education in 2003 from what was then Southwest Missouri State University. She went on to earn a master's degree in educational leadership and policy analysis from the University of Missouri in 2010 and a specialist degree in educational leadership from Missouri State University in 2016. In 2020, she earned a doctorate in educational leadership and policy analysis from the University of Missouri.

Carey's career in education spans eighteen years in the elementary education classroom, teaching first, second, and third grades, both in person and virtually with changes brought about by the COVID-19 pandemic. She taught for two years in the rural district of Chadwick, Missouri teaching second grade, before moving to Nixa. During her tenure in Nixa, Carey has held a number of leadership positions, including committee memberships and chairs and served on a number of advisory committees. Currently, she holds the leadership positions of Nixa Teachers Association President and Building Operations Manager.

Carey also manages the district's FIRST robotics teams, serving nearly 200 students in four different buildings and is the head coach for three FIRST LEGO League teams, although the current season has been put on hold due to COVID-19. She is passionate about fighting gender bias, providing STEM opportunities to students from college to career, especially female students, and supporting teachers through a pandemic. In the future, Carey plans to continue working as an educational leader in whatever capacity that manifests. 